Portland State University

PDXScholar

1991

\title{
Solvent and Substituent Effects on the Redox Potentials of Several Substituted Tetraphenylporphyrins
}

Robert Arthur Ransdell

Portland State University

Follow this and additional works at: https://pdxscholar.library.pdx.edu/open_access_etds Let us know how access to this document benefits you.

\section{Recommended Citation}

Ransdell, Robert Arthur, "Solvent and Substituent Effects on the Redox Potentials of Several Substituted Tetraphenylporphyrins" (1991). Dissertations and Theses. Paper 1230.

https://doi.org/10.15760/etd.1229

This Dissertation is brought to you for free and open access. It has been accepted for inclusion in Dissertations and Theses by an authorized administrator of PDXScholar. Please contact us if we can make this document more accessible: pdxscholar@pdx.edu. 


\title{
SOLVENT AND SUBSTITUENT EFFECTS ON THE REDOX POTENTIALS OF SEVERAL SUBSTITUTED TETRAPHENYLPORPHYRINS
}

\author{
by \\ ROBERT ARTHUR RANSDELL
}
A dissertation submitted in partial fulfillment of the requirements for the degree of

\author{
DOCTOR OF PHILOSOPHY \\ in \\ ENVIRONMENTAL SCIENCES AND RESOURCES: \\ CHEMISTRY
}

\author{
Portland State University \\ 1991
}


TO THE OFFICE OF GRADUATE STUDIES:

The members of the Committee approve the dissertation of Robert Arthur Ransdell presented March 4, 1991.

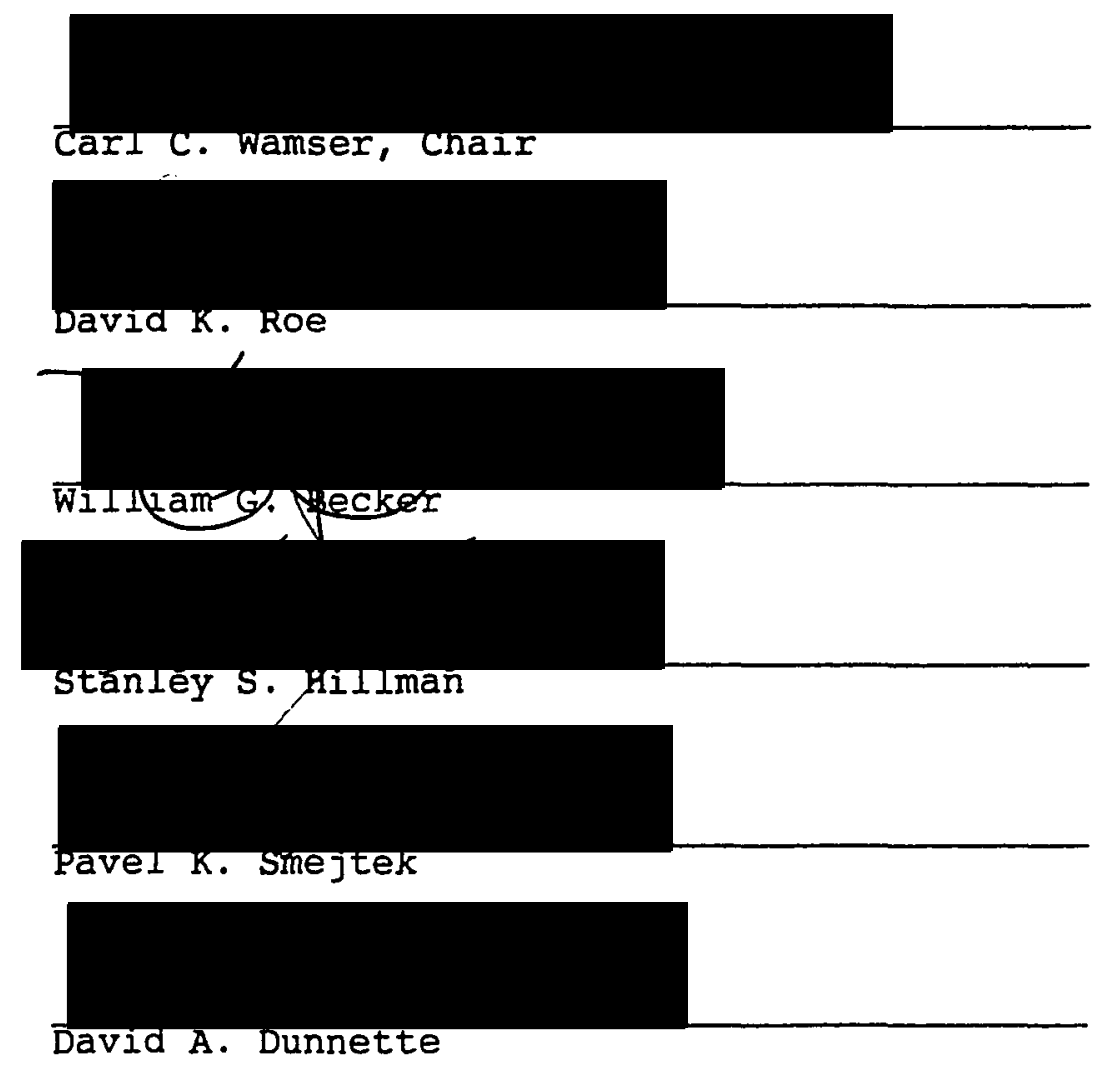

\section{APPROVED:}

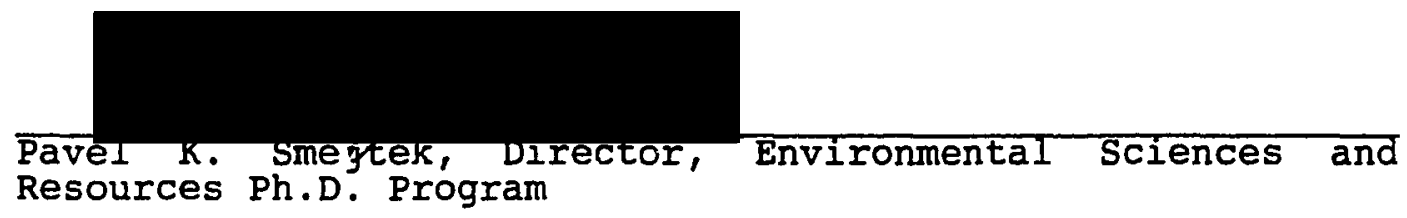
Resources Ph.D. Program

C. William Savery, Interim Vicecłoovost for Graduate Studies and Research 
AN ABSTRACT OF THE DISSERTATION OF Robert Arthur Ransdell for the Doctor of Philosophy in Environmental Sciences and Resources: Chemistry presented March 4, 1991.

Title: Solvent and Substituent Effects on the Redox Potentials of Several substituted Tetraphenylporphyrins.

APPROVED BY THE MEMBERS OF THE DISSERTATION COMMITTEE:

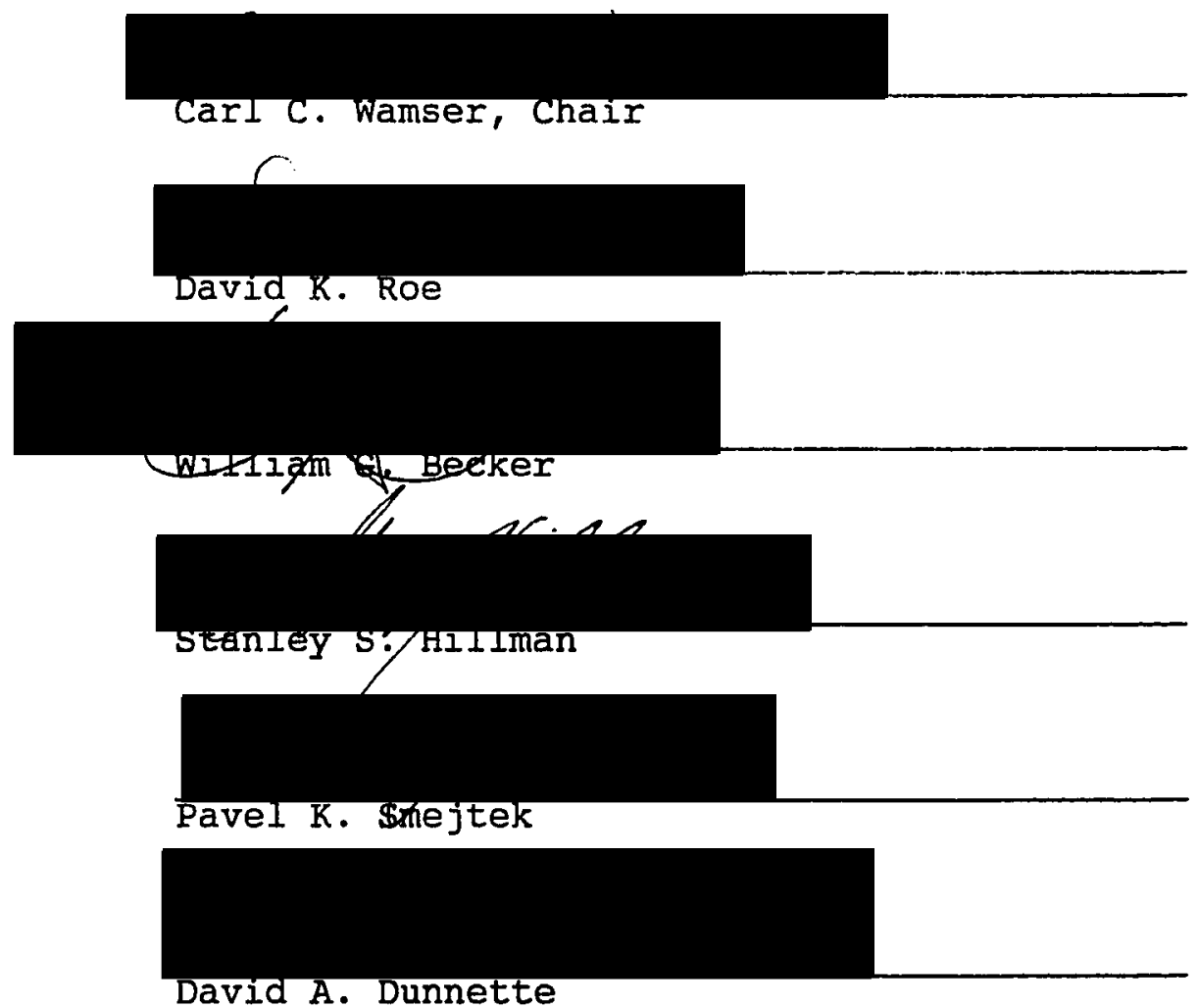

Tetraphenylporphyrins can be used to absorb visible light and pass on their excitation energy to electron transfer agents. The purpose of this research has been to investigate our ability to understand and control the energetics of 
porphyrin derivatives in order to use their electron transfer ability to harness the energy of sunlight.

Shifts in the redox (reduction and oxidation) potentials of tetraphenylporphyrins result from variations in the substituents attached at the para-position of the phenyl rings of tetraphenylporphyrins, as well as variations in the state of ionization of those substituents, and the solvent in which the reactions are carried out.

To measure the effect these variations, results from cyclic voltammetric experiments were plotted versus literature values of Hammett substituent constants to confirm the validity of linear free energy relationships as a model of substituent effects. Solvent effects on reduction potentials were correlated using experimentally determined values of the empirical solvent parameter $E_{T}$.

Some specific conclusions are summarized.

1. The usefulness of linear free energy relationships in correlating variations in redox potentials with changes in substituent was confirmed with two exceptions. Two of the porphyrins were shown to undergo a different electrochemical oxidation mechanism than the remaining porphyrins, and another porphyrin was shown to be more difficult to reduce than predicted on the basis of its substituent constant.

2. Solvent effects, here investigated as the effect of added water on the reduction potential of tetraminophenylporphyrin in DMSO, were demonstrated to correlate with the Dimroth-Reichardt solvent parameter, $E_{T}$, determined experimentally for each water-DMSO $\mathrm{mix}$. 
3. Variations in the state of ionization of ionizable substituents such as carboxylic acid, amine, and hydroxy substituents were shown to affect porphyrin electrochemistry mostly through the protonation of bulk, solution-phase porphyrin by added proton donor. An additional effect of added proton donor was noted in an alteration in the mechanism of reduction to include some of a different mechanism wherein reduced porphyrin is protonated in a chemical equilibrium and then further reduced electrochemically. 


\section{ACKNOWLEDGEMENTS}

Synthesis of some of the porphyrins was performed by Dr. R. Bard, Dr. V. Senthilathipan, T. Rice, and R. Bottner. The assistance and ideas of Dr. D.K. Roe of Portland State University are gratefully acknowledged, as is the loan of equipment by him and by Dr. W.G. Becker of Portland State University. Special thanks are due to my advisor, Dr. Carl Wamser for his unfailing support. 
TABLE OF CONTENMS

PAGE

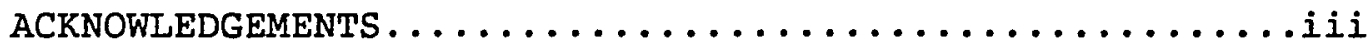

LIST OF TABLES.........................

LIST OF FIGURES ........................ vi

CHAPTER

I LINEAR FREE ENERGY CORRELATIONS OF THE REDOX BEHAVIOR OF TETRAPHENYLPORPHYRINS

Introduction...................

Materials and Methods.............17

Results and Discussion............22

II SOLVENT EFFECTS ON THE REDUCTION OF TETRA-( $\mathrm{P}-A M I N O P H E N Y L)$ PORPFYRIN

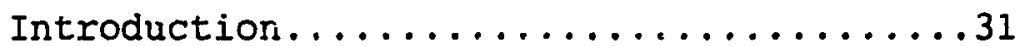

Materials and Methods..............53

Results and Discussion..............54

III IONIZATION EFFECTS ON THE REDOX BEHAVIOR OF SUBSTITUTED TETRAPHENYLPORPHYRINS

Introduction. ..................64

Materials and Methods..............72

Results and Discussion.............74

IV CONCLUSIONS

Correlations of the Redox Potentials

of Tetraphenylporphyrins.........95

Solvent Effects on TAPP Reduction......998

Ionization Effects on the Redox Behavior of Tetraphenylporphyrins.........100

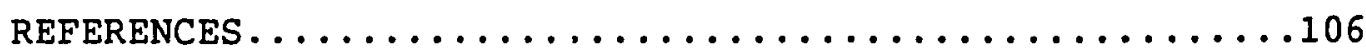




\section{LIST OF TABIES}

TABLE

PAGE

I Hammett Plot Data for Substituted Tetra-

$$
\text { phenylporphyrins in DMSO...........26 }
$$

II Solvent Effects on Reichardt's Dye.........40

III Measured Peak Wavelengths and Calculated

$E_{T}$ Values for Reichardt's Dye in

Aqueous-DMso Mixes..................57

IV Oxidation Potential of SCE (VS. FC/FC ${ }^{+}$) in

Various Aqueous-DMso Mixes..........60

$\checkmark$ Reduction Potentials of TAPP in Aqueous-

DMSO Mixes vs. SCE and vs. FC/FC ${ }^{+} \ldots \ldots \ldots 62$

VI Spectroscopic Data for TAPP in Neutral and

Acidified DMso................93 


\section{IIST OF FIGURES}

FIGURE

PAGE

1. Photochemical Splitting of Water............

2. Tetraphenylporphyrin structure............2

3. Comparison of Hydrolysis Rates of Esters With Ionization Constants of Acids For mand p-Benzoic Acid Derivatives.........

4. Vectorial Electron Transport.............10

5. Electrochemical Apparatus...............19

6. Idealized Voltammetric Scan............21

7. Voltammogram of TAPP in DMSO with $0.10 \mathrm{M}$ Tetra(n-butyl)ammonium Perchlorate (TBAP).23

8. Voltammogram of TCPP in DMSO with $0.10 \mathrm{M}$ TBAP..24

9. Voltammogram of TPP in DMSO with $0.10 \mathrm{M}$ TBAP...25

10. Hammett Plot of Tetraphenylporphyrins.......27

11. Structure of Reichardt's Dye in Ground and

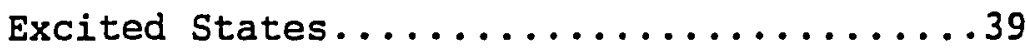

12. Solvent Effect on Electronic Transition

Energy .....................42

13. Plot of Various Solvent Parameters vs. $E_{\frac{1}{2}}$ of Reduction of ZnTPP in Various Solvents....50

14. Visible Spectra of Reichardt's Dye in AqueousDMSO Mixes..................... 55

15. Photograph of Solutions of Reichardt's Dye in $0 \%$ to $50 \%$ water in DMSO..........56 
16. Experimental Data for Reichardt's Dye

in Aqueous-DMso Mixes..............58

17. Plot of TAPP Reduction Potentials (V VS. SCE)

vs. Solvent $\mathrm{E}_{\mathrm{T}}$ Values...............59

18. Plot of TAPP Reduction Potentials ( $V$ vs.

FC/FC ${ }^{+}$) vs. Solvent $\mathrm{E}_{\mathrm{T}}$ Values........61

19. Resonance Structures of an Amino Group on an

Aromatic Ring.................64

20. Voltammetry of TPP in Benzonitrile.........72

21. Reduction of Hydrogen Ion in DMSO.........75

22. Effect of Acid on TCPP Voltammetry........76

23. Effect of Acid on TCPP Voltammetry in

Basic DMSO......................

24. Effect of Acid on TPP Voltammetry.........80

25. Comparison of Voltammetry of Neutral and

Acidified TPp.....................

26. Effect of Acid on CuTpp Voltammetry........82

27. Effect of Acetic Acid on TAPP Voltammetry.....85

28. Effect of Trifluoroacetic Acid on TAPP

voltammetry.................... 87

29. Scan Rate Study of the Voltammetry of

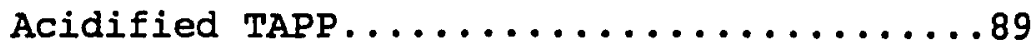

30. Effect of Acid on CuTAPP Voltammetry........90

31. Large Potential Scale View of the Effect of

Acid on CuTAPp Voltammetry...........91

32. Changes in the visible spectrum of TAPP

with Added Acid.................92

33. Oxidation of Aminophenyl Moiety Showing

Resonance Stabilization............97 


\section{CHAPTER I}

\section{IINEAR FREE ENERGY CORRELATIONS OF THE REDOX BEHAVIOR OF TETRAPHEINYLPORPHYRINS}

\section{INTRODUCTION}

\section{Background}

Artificial photosynthesis is one of several approaches to solar energy conversion and storage schemes. In this approach, organized assemblies such as liposomes, vesicles, and thin film membranes are used to generate and separate charged species. These species then go on to yield useful chemical products. For example, a photogenerated electron-hole pair can be used to drive the photochemical splitting of water into hydrogen gas and oxygen gas. This is illustrated in Figure 1, where $S$ is an absorbing chromophore, $A$ is an electron acceptor, and $D$ is an electron donor.

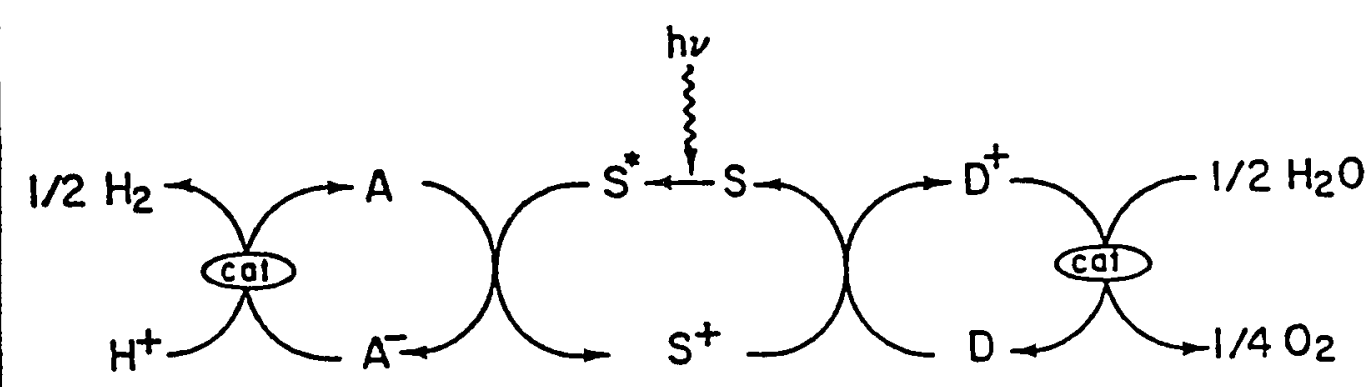

Fiqure 1. Photochemical Splitting of water.

Thin-film polymer membranes made from reactive tetraphenylporphyrins have been used in fabricating artificial photo- 
synthesis devices. ${ }^{1}$ one way to investigate the ability of these membranes to support the transport of photogenerated charged species is to look at the electrochemical properties of the reactive tetraphenylporphyrin monomers. A structure of tetraphenylporphyrin and a list of abbreviations used is shown in Figure 2 .

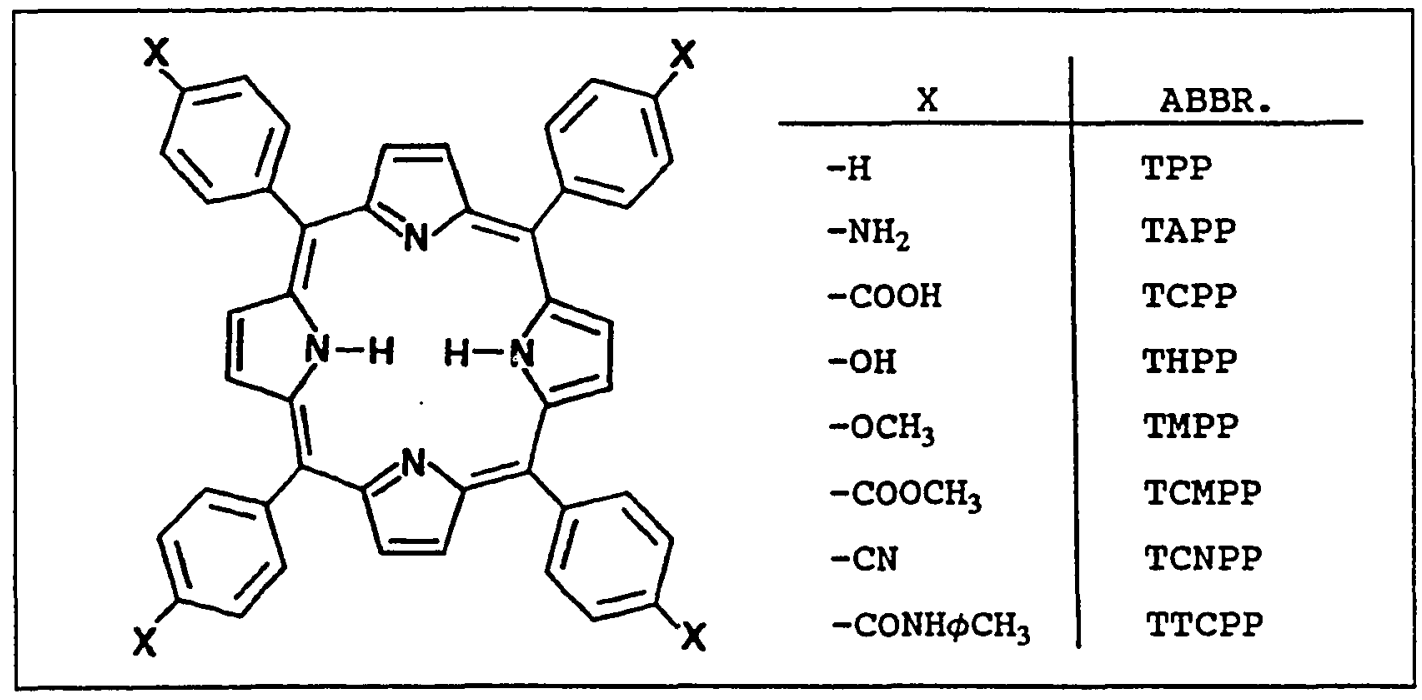

Figure 2. Tetraphenylporphyrin Structure.

This research has as its overall objective the measurement of the oxidation and reduction potentials, of various substituted tetraphenylporphyrins in order to correlate the effects of substituents and solvents on redox properties. The investigation will include the porphyrins used in thin-film membrane fabrication in various states of ionization and in mixed solvents.

This project will attempt to demonstrate, using the results presented in Chapter $I$, that the data obtained from measuring the redox potentials of various substituted tetraphenylporphyrins can be correlated using a linear free energy 
relationship (LFER). The research will also attempt to demonstrate in Chapter II that the effects of varying the composition of the solvent will result in changes in porphyrin reduction potentials that can be correlated to one or more solvent parameters. Finally, in Chapter III, the research will attempt to demonstrate that linear free energy relationships can be extended to correlate the effect of unsymmetrically substituted tetraphenylporphyrins, specifically, various ionization states of ionizable tetraphenylporphyrins.

The problem being investigated here is addressed by using electrochemical techniques to obtain thermodynamic data. Changes in the nature of the substituents on a parent molecule should result in predictable changes in the thermodynamics of reactions undergone by that molecule. In this case, the thermodynamics of the oxidation and reduction of substituted tetraphenylporphyrins is reflected in the electrochemical potential at which those reactions take place. It is those electrochemical potentials which should change predictably with the nature of the substituents on the tetraphenylporphyrins .

Linear Free Energy Relationships

In the late 1930's, Louis Hammett at Columbia University and others, ${ }^{2}$ published a series of articles describing empirical relationships they had discovered between two series of rate or equilibrium constants for benzene side chain reactions.

In his 1940 book, Physical Organic Chemistry, Hammett ${ }^{3}$ used as an example the relationship between the equilibrium 
constant $k_{i}$ of ionization of substituted benzoic acids, and the rate $k_{h}$ of hydrolysis of similarly substituted ethyl benzoate esters.

If one plots $\log \mathrm{K}_{\mathrm{i}} / \mathrm{K}_{\mathrm{i}}$ ' for a $\mathrm{m}$ - or p-substituted benzoic acid $\left(K_{i}\right.$ ' is the value of $K_{i}$ for the unsubstituted benzoic acid) vs. $\log k_{h}$ for the ethyl benzoate derivative with the identical substitution pattern (see Figure 3), the resultant straight line can be written as:

$$
\log k_{h}=\rho \cdot \log K_{i} / K_{i}^{\prime}+A
$$

where $\rho$ is the slope of the plot and $A$ is the Y-intercept, which is equal to $\log k_{h^{\prime}}$. As before, $k_{h}$ ' is the value of $k_{h}$ for the unsubstituted ethyl benzoate. This notation is used instead of that of Hammett, who used $k_{i}{ }^{\circ}$ and $k_{h}{ }^{\circ}$ in their place, in order to avoid confusion when correlating $\mathrm{E}^{\circ}$ values. Hammett then proposed choosing one system as the reference $k$ or $k$, and recommended using $k_{i}$ for substituted benzoic acids since at the time those constants were readily available and easily measured with good precision. A general relationship between a given rate or equilibrium constant $k$ and the reference system $K_{i}$ can be described using the equation below:

$$
\log k=\rho \cdot\left(\log K_{i} / K_{i}^{\prime}\right)+\log k^{\prime}
$$

Hammett then went on to define $\sigma_{(x)}$, the substituent constant for substituent $X$, as below: 


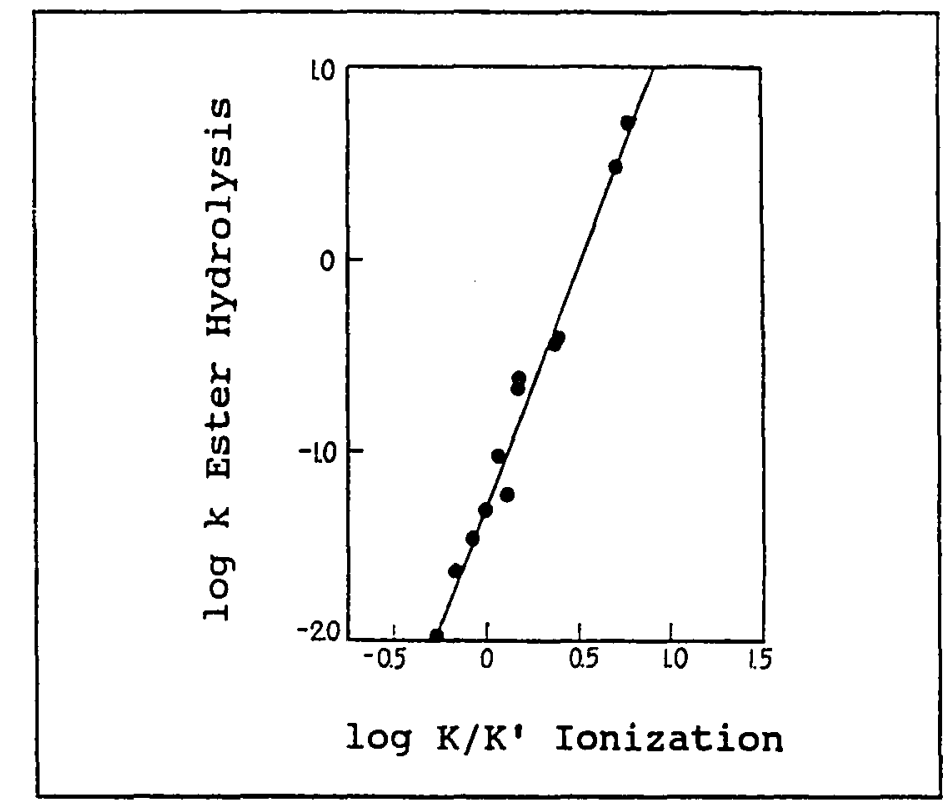

Figure 3. Comparison of hydrolysis rates of esters with ionization constants of acids for $\mathrm{m}$ - and $\mathrm{p}-$ benzoic acid derivatives. ${ }^{3}$

$$
\sigma_{(x)}=\log K_{i(x)} / K_{i}^{\prime}
$$

Substituting equation [3] into equation [2] relating the generic $k$ to $k_{i}$ for benzoic acids yields the following equation:

$$
\begin{aligned}
& \log k-\log k^{\prime}=\sigma \cdot p \\
& \text { or, } \quad \log \left(k / k^{\prime}\right)=\sigma \bullet \rho
\end{aligned}
$$

Equation [5] is the most generally used form of the Hammett equation.

The substituent constant $\sigma$ is by definition determined only by the nature of the substituent, and is independent of the reaction being investigated. The slope or reaction constant $\rho$ is by the nature of such correlations a constant 
for all substituents, and depends only on the reaction or reaction series. Electron-donating substituents have $\sigma<0.00$ and electron-withdrawing substituents have $\sigma>0.00$. The hydrogen substituent has $\sigma$ defined as zero. Reactions facilitated by electron-withdrawing substituents have $\rho>0.00$ and those facilitated by electron-donating substituents have $\rho<0.00$.

In Hammett's own words: ${ }^{4}$

Given the existence of a quantitative correlation, the fact that it is linear in the logarithms can be no mere accident; for the linear relationship between the logarithms of the constants is equivalent to a relationship between the quantities $-\mathrm{RT}$ in $k$, which are the free energies of reaction or of activation.

Thus these relationships have come to be known as linear free energy relationships. These relationships have allowed researchers to assign substituent constants to a large number of substituents. "Primary" substituent constants are those that were determined directly from measurements of $k_{i}$ 's of substituted benzoic acids. Most common substituents have been determined in this manner.

Free energies of activation or of reaction can be affected by substituents through other means than just electron-donating or electron-withdrawing effects ("polar" effects). Substituents can also participate through resonance stabilization of positive or negative charges, or through steric effects. 5 In such cases, the substituent constants determined by Hammett do not yield linear correlations. Instead, new types of substituent constants have been developed for almost every case in which the standard Hammett constants do not work well. This has led to a profusion of 
substituent constants of which only some are applicabie in any given system. Several compilations of substituent constants are available which attempt to make sense of this confusion. ${ }^{6}$ For this research, an examination of the probable mechanism of reaction of porphyrin oxidation or reduction leads one to conclude that the original Hammett sigma constants are the most appropriate. Oxidation and reduction of tetraphenylporphyrins has been shown to involve only electrons of the 18-electron aromatic porphyrin ring. ${ }^{7}$ Substituents on the phenyl group of tetraphenylporphyrins cannot participate significantly in the reaction in a resonance fashion since the phenyl ring is not coplanar with the porphyrin. 8 steric considerations involving the substituents are not important, since they will not affect electron density in the macrocyclic ring portion of the porphyrin.

When one attempts to use Hammett $\sigma$ values to correlate the effect of substitution on redox reactions, the generic $k$ used in equation [5] is replaced by the equilibrium constant $\mathrm{K}$ of the electrochemical reaction:

$$
\log \left(K / K^{\prime}\right)=\sigma \cdot \rho
$$

From the definition of an equilibrium constant, we know that $\Delta G^{\circ}=-R T \cdot I n K=-n F E^{\circ}$. From this it follows that:

$$
\ln \mathrm{K}=(\mathrm{nF} / \mathrm{RT}) \cdot \mathrm{E}^{\circ}
$$

or converting to base 10 ,

$$
\log K=(n F / 2.303 R T) \cdot E^{\circ}
$$


Expressing equation [8] in the form of equation [4] yields the following equation:

$$
(\mathrm{nF} / 2.303 \mathrm{RT}) \cdot \mathrm{E}^{\circ}-(\mathrm{nF} / 2.303 \mathrm{RT}) \cdot \mathrm{E}^{\circ} \cdot=\sigma \cdot \rho
$$

where $E^{\circ}$, is $E^{\circ}$ for unsubstituted tetraphenylporphyrin. Rearranging gives

$$
\begin{array}{ll} 
& (\mathrm{nF} / 2.303 \mathrm{RT}) \bullet\left(\mathrm{E}^{\circ}-\mathrm{E}^{\circ}\right)=\sigma \bullet \rho \\
\text { or, } \quad & \left.\mathrm{E}^{\circ}-\mathrm{E}^{\circ}\right)=(2.303 \mathrm{RT} / \mathrm{nF}) \bullet \sigma \bullet \rho
\end{array}
$$

If one then defines $\rho^{\prime}=(2.303 \mathrm{RT} / \mathrm{nF}) \cdot \rho$ and $\Delta \mathrm{E}^{\circ}=$ $E^{\circ}-E^{\circ}$, equation [11] can be simplified to the form below:

$$
\Delta E^{\circ}=\sigma \cdot \rho^{\prime}
$$

For those reactions where the substrate has more than one substituent group, $\sigma$ can be replaced by $\Sigma \sigma$, which is the sum of the $\sigma$ values for all participating substituent groups. Equation [12] can then be written as:

$$
\Delta \mathrm{E}^{\circ}=\Sigma \sigma \cdot \rho^{\prime}
$$

Equation [13] or a form of it is used in this thesis to correlate the effect of substituent constants on the electrochemical reduction and oxidation potentials of tetraphenylporphyrins in DMSO solution.

Tetraphenylporphyrins generally have four substituents symmetrically placed around the central ring system of the 
porphyrin: at the ortho-, meta-, or para- positions on the phenyl rings. Because of this $4 \cdot \sigma$ is used in correlating substituent effects on tetraphenylporphyrin reactions.

Some researchers have investigated the effects of unsymmetrically-placed substituents on tetraphenylporphyrin reactivity, ${ }^{9}$ and found that the effect of the different substituents is additive, as one would expect. Other researchers have looked at the dependence of such linear free energy correlations on the solvent in which they are performed. They have found that to a first approximation, changes in $E^{\circ}$ for a given compound can be correlated with solvent polarity (as measured by solvent dielectric constant), but that other solvent parameters such as Gutmann acceptor number or the Dimroth-Reichardt $E_{T}$ parameter yield better correlations. 10

Model Porphryins For Thin-Film Membranes

The assembly of molecular components into photochemical molecular devices is the goal of a new field of research. ${ }^{11}$ Many useful applications are possible, such as photochemical synthesis, photochromism, and photodecomposition. Applications such as these may not require an organized assembly (also called a supramolecular assembly) in order to function. More complex functions such as vectorial electron transport, molecular switching ability, or migration of electronic energy, however, cannot be performed by isolated molecules. These functions require an appropriate assembly of molecular components. 
Artificial photosynthesis, or the conversion of light energy into chemical energy, utilizes one of the more complex functions mentioned above: vectorial electron transport (see Figure 4). Several researchers have investigated electron transfer in model systems consisting of linked donor-sensitizer-acceptor molecules. 12 The result of this research has

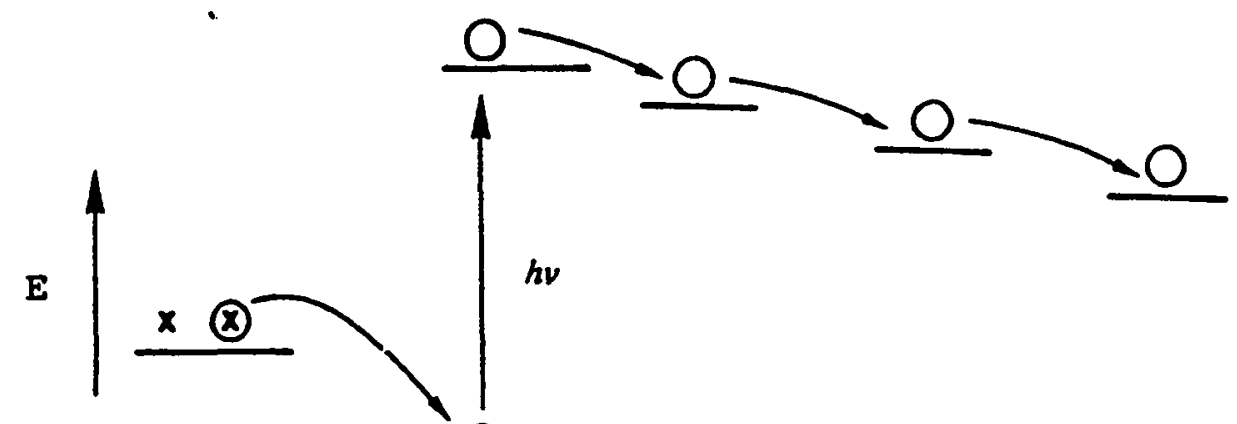

(ג) $x$

Donor Sensitizer Acceptors

Figure 4. Vectorial Electron Transport.

been to show that it is possible to get charge separation across varying lengths of intervening saturated hydrocarbon connectors. The rate constant for electron transport is shown to depend exponentially on the distance separating the sensitizer and acceptor. 13

The next level of complexity involves electron transfer in heterogenous media. This work includes monolayer-solution interfaces as well as lipid bilayers and vesicles. Such studies, including those of Grätzel,14 have shown that electron transport can occur across interfaces loaded with the appropriate arrangement of donors, sensitizers, and acceptors. 
Other researchers have investigated the transfer of electrons between donors and sensitizers in a polymer environment. 15

Vectorial electron transport is enhanced in the presence of an electric field. Semiconductor interfaces, whether with another semiconductor, a metal, or an electrolyte solution, have a gradient of electric potential which assists electron transport by separating electrons and holes. ${ }^{16}$ Another way in which this effect has been demonstrated is by the application of an external bias potential to a photoelectrochemical cell. 17

The artificial photosynthesis project supported by this work is designed to fabricate a device in which porphyrin molecules are assembled into a polymeric film. Such films are postulated to have a gradient of redox potentials which will assist in the separation of photogenerated charge. This phenomenon is a predicted result of the technique used to form the films: interfacial polymerization.

In interfacial polymerization, the two monomers that react to form the polymer are dissolved separately in immiscible solvents. When the solvents are brought into contact, the monomers can react only at the interface between the two phases. The porphyrin molecules used are relatively large, and therefore their reaction is self-limiting. Once sufficient polymer has formed, it constitutes a barrier to the diffusion of more monomer to the reactive interfacial region, and the reaction stops. Because films formed in this manner are often too thin to be handled, the polymerization is often 
carried out on a substrate for support. Such films are called "thin-film composite" membranes. 18

Interfacially polymerized porphyrin membranes are predicted to be chemically asymmetric, and it is this asymmetry which would give rise to the gradient of redox potentials. For example, the acid chloride of tetra(4-carboxyphenyl)porphyrin, TCCPP, dissolved in chloroform, can be reacted with an aqueous solution of tetra(4-aminophenyl)porphyrin, TAPP. The resultant polymer film is postulated to show this chemical asymmetry in which each of the two monomers exhibits a gradient of concentration across the membrane. 1

Since tetraphenylporphyrins have four reactive moieties, when substituted tetraphenylporphyrins are used as the monomers, heavy crosslinking is expected in the resultant polymer. Interior porphyrins will have variable numbers of linkages, causing them to differ in terms of substituent nature from the original monomers. It is expected that such asymmetry will give rise to an electrochemical gradient across the membrane which could be used to drive electron transport. ${ }^{1}$

In order for the electrochemical potential gradient to be favorable for efficient electron transport across the membrane, the potentials of the porphyrins (in both excited and ground states) on one side of the membrane must be sufficiently different from those of the porphyrins on the other side to drive electrons in one direction and holes in the other. There also should be no trap or barrier sites in the interior of the membrane. One way to help predict the success of the membrane as an electron-transport device is to choose appropriate monomeric tetraphenylporphyrins as model compounds to 
mimic the electrochemical potentials anticipated for porphyrins incorporated in the polymeric film.

The film asymmetry arises primarily because the unreacted surface sites on one side of the membrane are carboxylate groups and those on the other side are amines, due to the two substituted tetraphenylporphyrins commonly used in these experiments. Interior porphyrins are amides that originated as either carboxylates or amines, and have a few unreacted groups in addition to their amide linkages.

\section{Electrochemical Reactivity of Porphyrins}

As of this writing, there is a large body of literature dealing with the chemistry of naturally-occurring and synthetic porphryins. A significant percentage of this work involves investigations into the electrochemical reactivity of porphyrins. A summary of this work will be necessary before discussion of the research described in this thesis.

Potentiometric studies were the focus of early research into porphyrin electrochemistry; this work is summarized in the reviews of Falk $^{19}$ and Clark. ${ }^{20}$ Potentiometry was used to indicate the "midpoint" potential of various redox reactions of porphyrins in order to give a thermodynamic basis for the structure-reactivity correlations that formed the rationale for these early experiments. The measurements were usually performed in aqueous solutions at a mercury electrode.

This presentation will focus on the reactions of what are termed "free-base" porphyrins - those that have no central metal to which the porphyrin is complexed. Much of the complexity of porphyrin electrochemistry can be avoided by 
eliminating discussion of the reactivity of the metal ion and any associated axial ligands. Many if not most of the freebase porphyrins are not water-soluble and hence are investigated in non-aqueous solvents.

In non-aqueous media, free base tetraphenylporphyrins, octaethylporphyrins, etioporphyrins, and protoporphyrin dimethyl esters are all reduced in 2 one-electron steps to the $\pi$-radical anion and then to the dianion.21-24 Similarly, oxidation of free-base porphyrins yields first a $\pi$-radical cation and then the dication. 25-28 The site of oxidation or reduction and the identity of the final products were established through the use of electron spin resonance spectroscopy

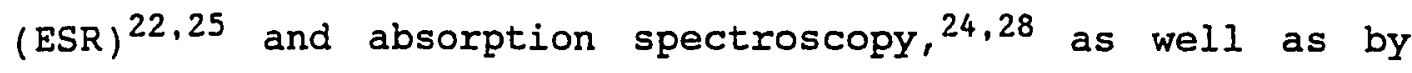
noting certain regularities in electrochemical behavior. 21,23 Further reductions are possible but are irreversible and involve disproportionation and simultaneous uptake of protons from solution. $24 \mathrm{~b}, 29$

Clack and Hush ${ }^{23}$ were the first to notice the constancy of the potential difference between the reduction steps of metalloporphyrins. Because this difference $(0.42 \pm 0.05 \mathrm{~V})$ was independent of the central metal ion, it was postulated that reactions of the porphyrin $\pi$-ring system were involved. This was later confirmed for other complexes by Felton and Linschitz 22 and by Fuhrhop, Kadish and Davis. 21

Felton and Linschitz were also among the first to make use of ESR spectroscopy to investigate the products of the reductions of porphyrin complexes. Their results showed that addition of electrons in the first two reductions was into 
orbitals belonging to the porphyrin ring, except in the case of certain metalloporphyrins which undergo metal-centered reactions. Wolberg and Manassen 25 later confirmed these results and extended them to allow discrimination between ring- and metal-centered oxidations of porphyrins.

Stanienda and $\mathrm{Biebl}^{28}$ were among the first to investigate oxidation reactions of metalloporphyrins. Their experiments in butyronitrile allowed correlation of oxidation potentials with spectral data in further confirmation that the oxidation of porphyrins involved $\pi$-ring orbitals and not orbitals arising from the complexed metal.

Fuhrhop, Kadish and Davis compared oxidations and reductions of metalloporphyrins and discovered another constancy in their redox potentials: the difference between the potential of the first reduction to form a radical anion and that of first oxidation to form a radical cation was found to be a constant $2.25 \pm 0.15 \mathrm{~V}$. This value is in good agreement with the theoretically calculated difference of 2.18 $\mathrm{eV}$ between the HOMO and LUMO (Highest occupied Molecular Orbital, and Lowest Unoccupied Molecular orbital, respectively) of most metalloporphyrins. This information, together with the constant difference of $0.42 \pm 0.05 \mathrm{~V}$ between the first and second reductions (or ca. $0.3 \mathrm{~V}$ between 1 st and 2nd oxidations), further allows one to distinguish between metalcentered and $\pi$-ring-centered reactions.

The effect of electron-donating or -withdrawing substituents on the electrochemical reactivity of porphyrins have been discussed in detail by Kadish ${ }^{30}$ and Gross. 31 Studies by Kadish included mostly phenyl-substituted tetraphenylporphy- 
rins, while those of Gross centered on porphyrins with $\mathrm{CN}$ and Br substituents attached directly to the porphyrin ring.

Contradictory to the results obtained by Kadish for parasubstituted tetraphenylporphyrins, Gross and colleagues discovered from plots of $E_{\frac{1}{2}}$ vs. various values of $\sigma$ (the modified substituent constants $\sigma^{+}$and $\sigma^{-}$, as well as $\sigma$ ) that oxidation involved abstraction of electrons from the lone pair of electrons associated with the pyrrolic nitrogens, whereas reduction of $\beta$-pyrrole substituted tetraphenylporphrins added electrons to the conjugated $\pi$ system with which the $\beta$ substituents were in direct resonance interaction. $31 \mathrm{~b}$

The work of Kadish's group demonstrated that for all para-substituted tetraphenylporphyrins (with the exception of certain metalloporphyrins whose metal ion undergoes a change of oxidation state), plots of $E_{\frac{1}{2}}$ vs. $\sigma$ (as opposed to $\sigma^{+}$or $\sigma^{-}$) were linear, indicating a uniformity of electron-transfer mechanism. Oxidations and reductions gave similar values of $p$, indicating that the charge on the reaction product has no significant effect on the magnitude of the substituent effect. Also, the constancy of $p$ over a wide range of metal ions was further evidence that the electron transfer involves orbitals of the $\pi$-ring rather than of the metal. $30 \mathrm{c}$

As it relates to the goals of this research, the work of Kadish's group shows that correlations of electrochemical reduction and oxidation potentials using Hammett substituent constants are a valid model with which to begin investigations into the effect of substituent on electrochemical properties of tetraphenylporphyrins. 


\section{MATERIALS AND METHODS}

\section{Materials}

Tetra (4-carboxyphenyl) porphyrin (TCPP) was purchased from Porphyrin Products (Logan, UT) and used as received. Tetra(4aminophenyl)porphyrin (TAPP) was purchased from Midcentury Chemicals (Posen, IL) and used as received. Tetra(4-methoxyphenyl)porphyrin (TMPP) was purchased from Aldrich and used as received. Tetra(4-hydroxyphenyl)porphyrin (THPP) was prepared from TMPP by demethylation with pyridinium chloride. ${ }^{32}$ Tetraphenylporphyrin (TPP) was obtained from Mid-Century Chemicals and was treated with $D^{33}$ (dichlorodicyano-pbenzoquinone) to oxidize any chlorins present back to porphyrins. Tetra(4-carboxymethylphenyl)porphyrin (TCMPP) was prepared from p-carboxymethylbenzaldehyde and pyrrole according to the method of Adler. ${ }^{34}$ The toluamide derivative of TCPP (tetra(4-[N-(4'-methylphenyl)-carboxamido]phenyl)porphyrin, TTCPP) was prepared first by preparing the acid chloride of TCPP (TCCPP) from TCPP by refluxing with thionyl chloride. P-Toluidine dissolved in pyridine was added to the reaction mixture, and the product was isolated after washing with aqueous acid and base. Tetra(4-cyanophenyl)porphyrin was prepared from p-cyanobenzaldehyde and pyrrole according to the method of Adler. ${ }^{34}$

Identity of porphyrins synthesized at Portland State was confirmed by NMR spectroscopy, using a Varian model EM-390 operating at $90 \mathrm{MHz}$. The purity of tetra(4-carboxyphenyl)porphyrin (TCPP) was checked by high performance liquid chromatography. Using a reverse-phase C-18 column with 80:20 
$T H F: \mathrm{H}_{2} \mathrm{O}$ as the mobile phase, TCPP received from Strem Chemical eluted as two peaks. This material was rejected in favor of TCPP obtained from Porphyrin Products, which eluted as only one peak.

Dimethyl sulfoxide (DMSO) was obtained from Aldrich (spectroscopic grade) and used as received. Tetra(n-butyl)ammonium perchlorate was obtained from Southwestern Analytical Chemicals (electrometric grade) and was recrystallized twice from 3:1 methanol:water before use and dried in a $60{ }^{\circ} \mathrm{C}$ vacuum oven for $24 \mathrm{hr}$.

\section{Methods}

Measurements of electrochemical reduction and oxidation potentials were accomplished with linear sweep voltammetric experiments using a standard three-electrode set-up. In most cases the working electrode was glassy carbon, the counter electrode was platinum wire, and the reference electrode was saturated calomel (SCE), connected to the non-aqueous solutions via a custom-built salt bridge equipped with Vycor frit junctions.

The function generator and potentiostat were models built at the University of Texas and provided for these experiments by Dr. W.G. Becker of Portland State University. Voltammograms were recorded on either a Hewlett-Packard 7004B or Coulter Electronics Model $4 \mathrm{X}-\mathrm{Y}$ recorder. A block diagram of the apparatus is included in Figure 5.

Cleaned, oven-dried 4-dram vials were used as electrochemical cells. Vials were cleaned by rinsing in alcoholic $\mathrm{KOH}$ and soaking overnight in concentrated nitric acid. After 
rinsing in deionized water, the vials were dried in a laboratory oven at $120 \mathrm{C}$.

The glassy carbon working electrode was cleaned by polishing with $0.05 \mu \mathrm{m}$ alumina (Buehler, Ltd.). The alumina was rinsed from the electrode with deionized water and the electrode sonicated for at least 5 minutes to remove all

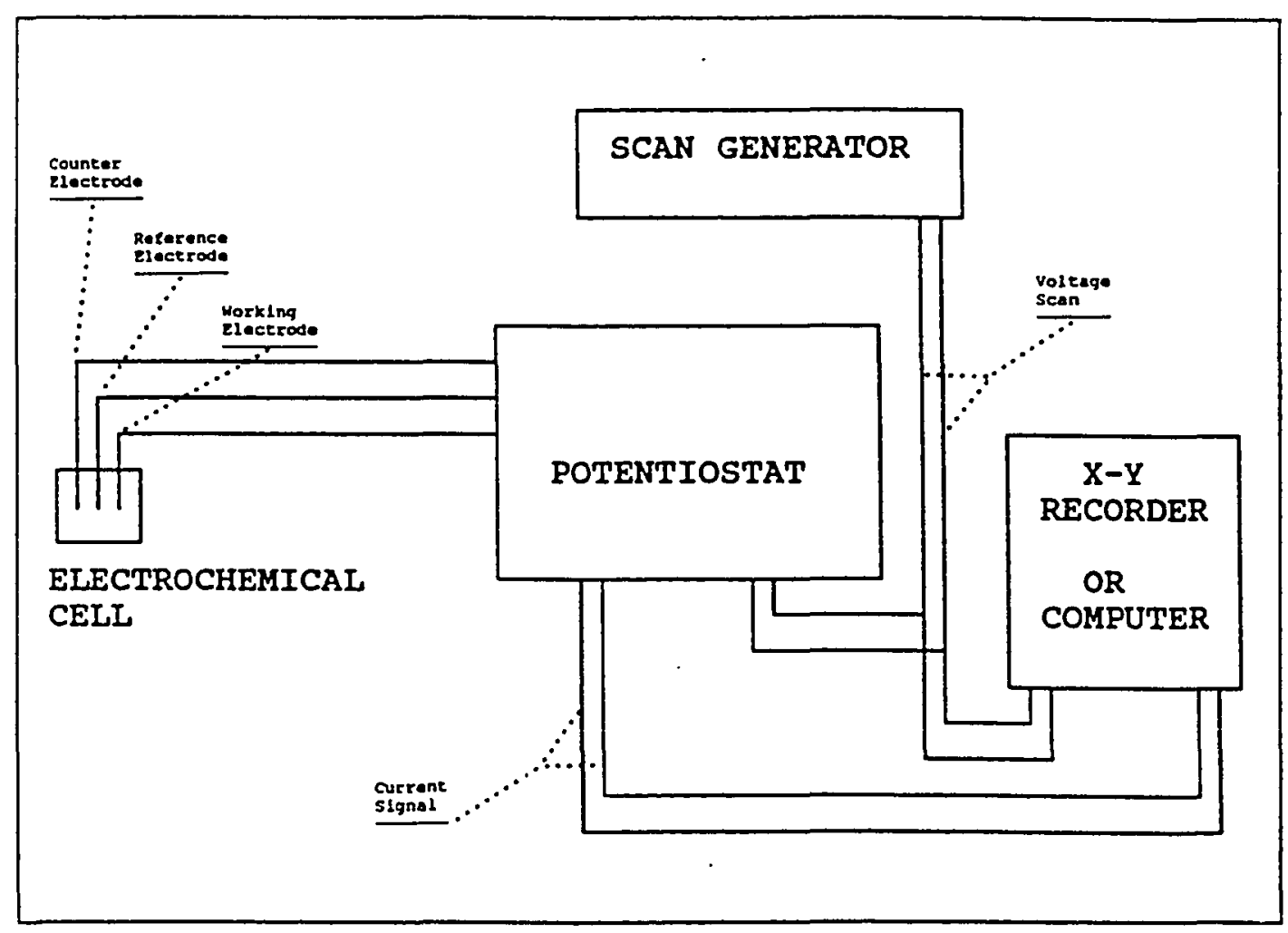

Figure 5. Electrochemical Apparatus.

traces of polishing compound. After sonication, the electrode was rinsed again with deionized water, and then with the solvent of interest.

The platinum counter electrode was cleaned by passing through a Bunsen burner flame until red-hot, and then dipping in concentrated nitric acid. The acid was rinsed off with 
deionized water, and then with the solvent of interest. The saturated calomel reference electrode was reconditioned before use by refilling the electrode chamber with saturated $\mathrm{KCl}$, and by replacing the salt bridge solution with fresh electrolyte solution in the solvent of interest.

Electrochemical solutions were purged of oxygen with ordinary tank nitrogen which had been passed through a commercial oxygen-removing cylinder ("Oxiclear", Labclear, Inc.), or through a gas-washing train consisting of two consecutive gas-washing bottles filled with a saturated solution of sodium dithionite with added methyl viologen chloride (as an indicator of oxygen-free conditions). 35

Experiments on symmetrically substituted tetraphenylporphyrins were performed as follows. Supporting electrolyte (tetra(n-butyl)ammonium perchlorate, TBAP) was weighed into clean electrode vessels and diluted to $0.10 \mathrm{M}$ with fresh DMSO. Purging with a nitrogen stream was begun, and the electrodes cleaned as above. After purging was complete (15-20 min), a blank voltammogram was recorded. Dried, solid porphyrin was then added, and sample voltammograms recorded.

After all sample voltammograms had been recorded, the solution was removed, and a UV-VIS spectrum recorded on a Shimadzu UV260 cusing $0.1 \mathrm{~cm}$ cuvettes, with $0.10 \mathrm{M}$ TBAP in DMSO in the reference cell. The spectrum allowed calculation of approximate porphyrin concentration by measuring the absorption of the soret band (porphyrin $\pi, \pi^{*}$ transition) and assuming an absorptivity for the soret band of $5 * 10^{5} \mathrm{M}^{-1} \mathrm{~cm}^{-1}$. This absorptivity is, to one significant figure, a constant for all neutral porphyrins. 
Voltammetric peak potentials were noted for the reactions of interest, and corrected to $E_{\frac{1}{2}}$ by taking the average of the forward and reverse peak potentials (see Figure 6 for a representation of the potentials of interest on an idealized voltammetric scan). However, in some cases in these experiments, the background currents dwarf any Faradaic currents, and reverse peak potentials cannot be reliably determined. In these cases, $E_{\frac{1}{2}}$ values are calculated by subtracting $28 \mathrm{mV}$ (the difference between $E_{p}$ and $E_{\frac{1}{2}}$ in an ideal voltammogram) from the forward peak potential.

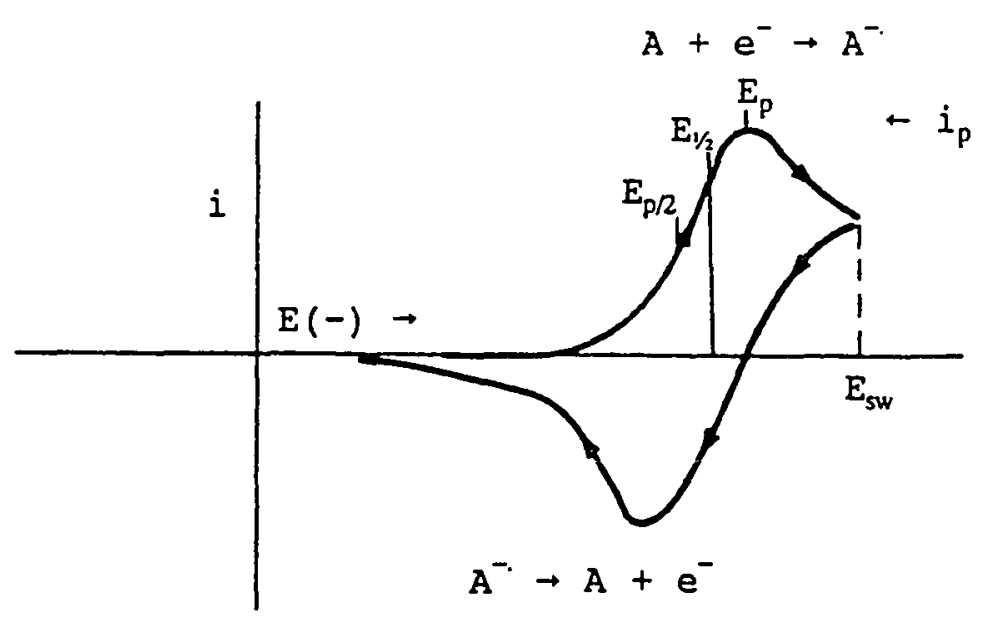

Figure 6. Idealized voltammetric scan. $E_{p}$ is the peak potential, $E_{\frac{1}{2}}$ is the polarographic half-wave potential, $E_{s w}$ is the switching potential, and $i_{p}$ is the peak current.

The precision of estimation of peak potentials is roughly $15 \mathrm{mV}$. This is distinct from the reported errors of tabulated values of $E_{\frac{1}{2}}$ (e.g. Table I), which are the sample standard deviations of multiple measurements. 
The reversibility of the electrochemical reaction being studied can in many cases be estimated by observing the potential difference between the forward and reverse peaks of a voltammogram (provided that the switching potential is at least $90 / n \mathrm{mV}$ past the forward peak potential, where $n$ is the number of electrons transferred). In this case, a perfectly reversible oxidation/reduction couple has a peak separation of approximately $59 / \mathrm{n} \mathrm{mV}$ at $25^{\circ}$.

Adsorption of porphyrins onto the electrode surface might be expected when using a carbon working electrode. Adsorbed material would be reduced or oxidized in waves with distinctive peak shapes. Since no peaks with the characteristic peak shape of adsorbed material were observed, it is concluded that the possibility of porphyrin adsorption can be discounted.

\section{RESULTS AND DISCUSSION}

Cyclic voltammetry of substituted tetraphenylporphyrins in dimethyl sulfoxide (DMSO) shows two reversible (by the criteria of cyclic voltammetry) reductions and one quasireversible oxidation at the glassy carbon working electrode. A second oxidation can be observed in other solvent systems, but the anodic potential limit of this system will not permit observation of this reaction, due to solvent oxidation.

A sample voltammogram of TAPP is shown in Figure 7. The potential range accessible at the glassy carbon electrode in the solvent/electrolyte system of DMSO with $0.10 \mathrm{M}$ tetra(nbutyl)ammonium perchlorate (TBAP) is from roughly $+1.10 \mathrm{~V}$ on the anodic end to -2.70 on the cathodic end. 


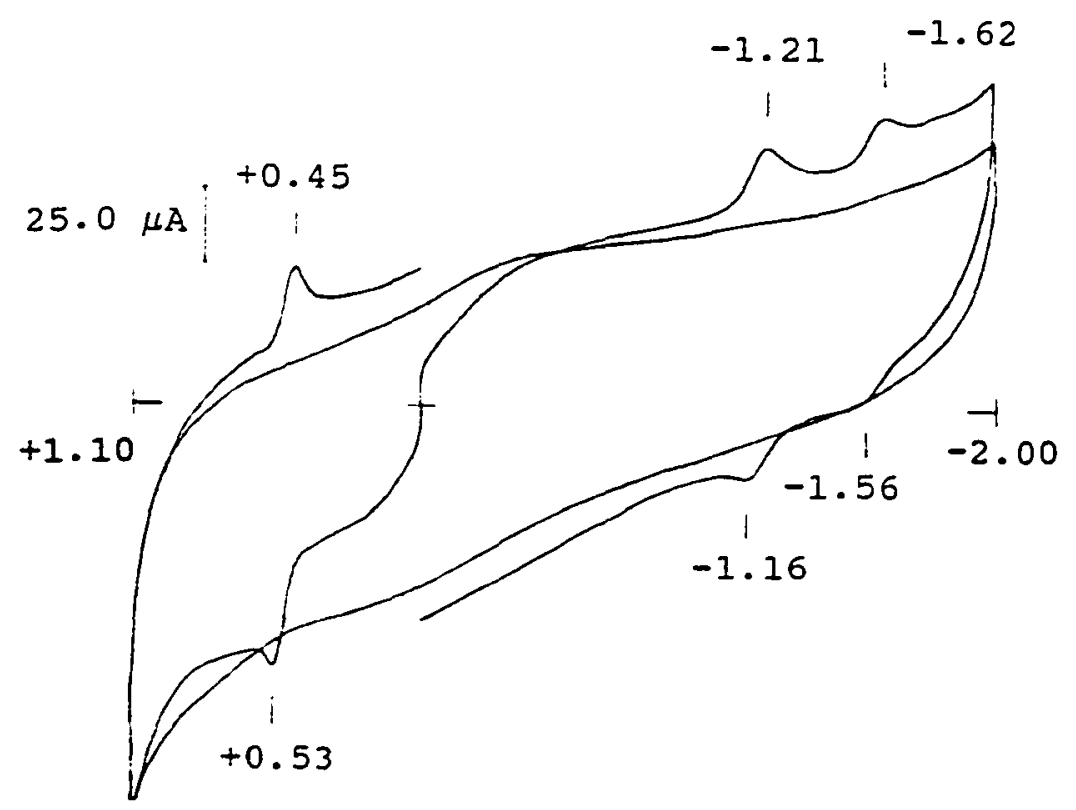

Eigure 7. Voltammogram of TAPP in DMSO with $0.10 \mathrm{M}$ tetra(n-butyl)ammonium perchlorate (TBAP). Cathodic (reduction) and anodic (oxidation) scans both use $0.00 \mathrm{~V}$ as the initial potential. Also shown is a blank scan ( $0.1 \mathrm{M}$ TBAP in DMSO) recorded at the same scale.

An exception to the general trend of reversible reductions is TCPP, the tetra(p-carboxyphenyl)porphyrin, whose first and second reductions are largely irreversible in DMSO and DMF. This is shown in Figure 8. For several of the porphyrins, low solubility limits observation of the return oxidation of radical anion or dianion, making estimation of reversibility difficult.

The parent tetraphenylporphyrin, TPP, also exibits low solubility in DMSO. Despite this fact, both reductions and the first oxidation can be observed. The first reduction is nearly reversible, with a $\Delta \mathrm{E}$ of $80 \mathrm{mV}$. This is shown in Figure 9 . 


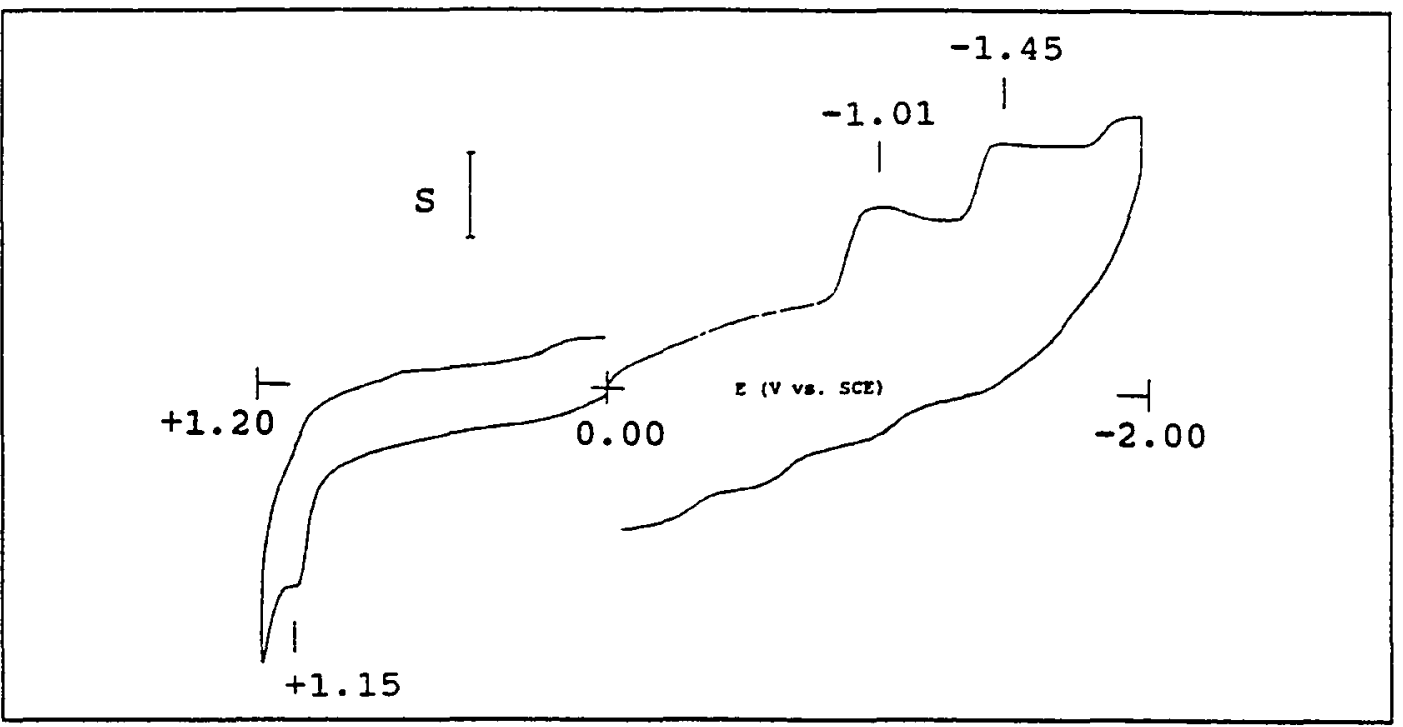

Figure 8. Voltammogram of TCPP in DMSO with $0.10 \mathrm{M}$ TBAP. Scale $S$ is $50 \mu A$ for the cathodic scan, 100 $\mu \mathrm{A}$ for the anodic.

A plot of the values of $E_{\frac{1}{2}}$ obtained for each porphyrin versus four times the Hammett $\sigma$ values for the substituents on each of those porphyrins is shown in Figure 10. All three reactions possible in DMSO are shown, and $4 \sigma$ is used because there are four of each substituent on a given porphyrin. For each reaction, the least squares best fit line is also shown, with two exceptions. The line representing the first oxidation reaction excludes two points from the least squares analysis for reasons discussed below, and that representing the first reduction reaction excludes the starred values which are included for comparison only. Values of $E_{\frac{1}{2}}$ and $\sigma$ used in plotting Figure 10 are shown in Table $I$.

There are features of two of these plots that had not before been observed. First, in the correlation between the $E_{\frac{1}{2}}$ values of the first reduction reaction and $4 \sigma$, the order of 


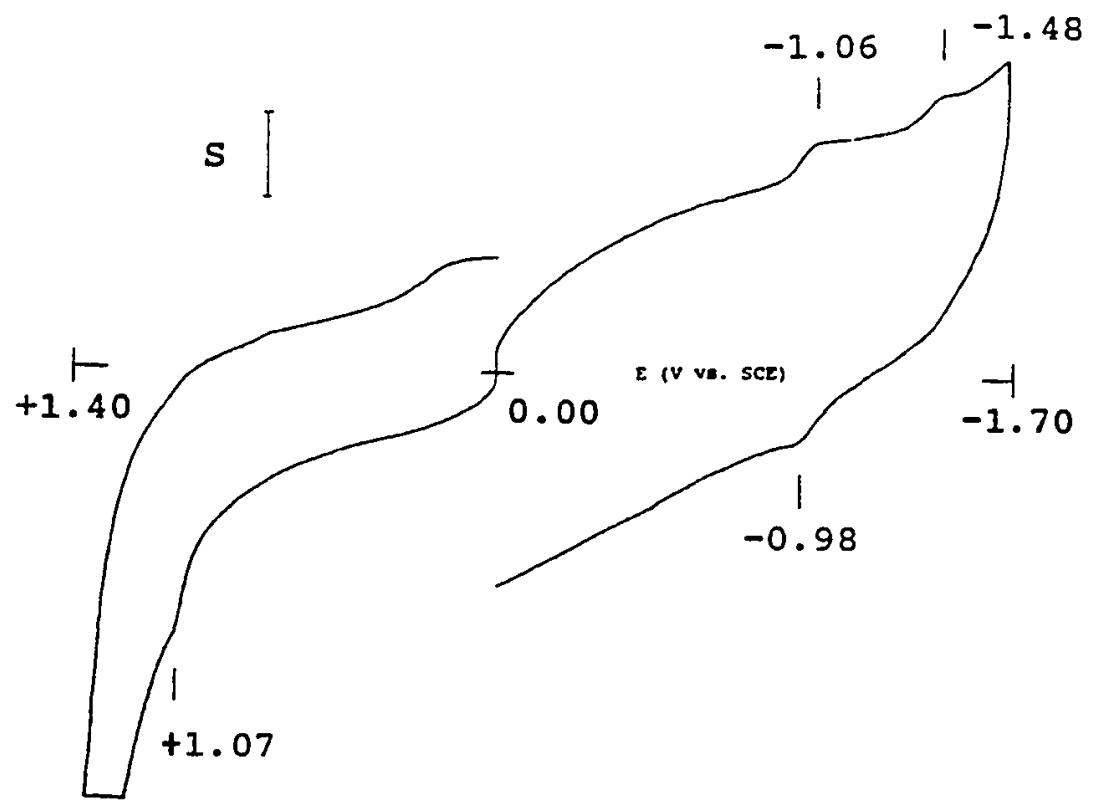

Figure 9. Voltammogram of TPP in DMSO with $0.10 \mathrm{M}$ TBAP. Scale $S$ is $25 \mu \mathrm{A}$ for the cathodic scan and $50 \mu \mathrm{A}$ for the anodic scan.

reduction of TCPP and TTCPP, the toluamide derivative of TCPP, is reversed.

Hammett $\sigma$ constants (a measure of electron-donating ability) lead one to predict that TCPP should be easier to reduce than its toluamide, since the carboxylic acid substituent is slightly more electron-withdrawing than the derivative substituent. The fact that the above is not true in this system has implications for the ability of polyporphyrin thin-film membranes to transport electrons.

The starred values shown on Figure 10 are obtained from the research reported in Chapter III. These values have been measured under conditions of either added acid (- $\mathrm{COOH}^{*}$ ) or base $\left(-\mathrm{COO}^{-*}\right)$ relative to that represented by the label -COOH. 
TABLE I

HAMMETT PLOT DATA FOR SUBSTITUTED TETRAPHENYLPORPHYRINS IN DMSO

\begin{tabular}{|c|c|c|c|c|c|}
\hline \multirow{2}{*}{ ABBR. } & \multirow{2}{*}{ SUBST } & \multirow{2}{*}{$\sigma$} & \multicolumn{3}{|c|}{$E_{x}, V$ vs SCE (trials, std. dev.) } \\
\hline & & & 1st Red. & 2nd Red. & 1st Ox. \\
\hline TAPP & $-\mathrm{NH}_{2}$ & -0.66 & $\begin{array}{c}-1.18 \\
(8,0.01)\end{array}$ & $\begin{array}{c}-1.59 \\
(5,0.004)\end{array}$ & $\begin{array}{c}+0.48 \\
(5,0.004)\end{array}$ \\
\hline THPP & $-\mathrm{OH}$ & -0.38 & $\begin{array}{c}-1.12 \\
(4,0.01)\end{array}$ & $\begin{array}{c}-1.47 \\
(3,0.01)\end{array}$ & $\begin{array}{c}+0.75 \\
(4,0.01)\end{array}$ \\
\hline TMPP & $-\mathrm{OCH}_{3}$ & -0.28 & $\begin{array}{c}-1.08 \\
(2,0.01)\end{array}$ & $\begin{array}{c}-1.46 \\
(2,0.01)\end{array}$ & $\begin{array}{c}+0.94 \\
(2,0.01)\end{array}$ \\
\hline TPP & $-\mathrm{H}$ & 0.00 & $\begin{array}{c}-1.03 \\
(5,0.01)\end{array}$ & $\begin{array}{c}-1.44 \\
(5,0.01)\end{array}$ & $\begin{array}{c}+1.04 \\
(2,0.00)\end{array}$ \\
\hline TTCPP & - CONHR & +0.38 & $\begin{array}{c}-0.98 \\
(1, \mathrm{NA})\end{array}$ & $\mathrm{NA}$ & $\begin{array}{c}+1.16 \\
(1, \mathrm{NA})\end{array}$ \\
\hline TCPP & $-\mathrm{COOH}$ & +0.44 & $\begin{array}{c}-1.00 \\
(5,0.02)\end{array}$ & $\begin{array}{c}-1.44 \\
(3,0.02)\end{array}$ & $\begin{array}{c}+1.12 \\
(1, \mathrm{NA})\end{array}$ \\
\hline TCMPP & -COOMe & +0.47 & $\begin{array}{c}-0.92 \\
(3,0.00)\end{array}$ & $\begin{array}{c}-1.33 \\
(3,0.01)\end{array}$ & $\begin{array}{c}+1.14 \\
(1, \mathrm{NA})\end{array}$ \\
\hline TCNPP & $-\mathrm{CN}$ & +0.70 & $\begin{array}{c}-0.87 \\
(1, \mathrm{NA})\end{array}$ & $\begin{array}{c}-1.26 \\
(1, \mathrm{NA})\end{array}$ & $\begin{array}{c}+1.18 \\
(1, N A)\end{array}$ \\
\hline TCPP -4 & $-\mathrm{COO}^{-}$ & -0.05 & $\begin{array}{l}-0.87^{\star} \\
(1, \mathrm{NA})\end{array}$ & NA & NA \\
\hline TCPP & $-\mathrm{COOH}$ & +0.44 & $\begin{array}{l}-1.01^{\star} \\
(1, N A) \\
\end{array}$ & NA & NA \\
\hline Regr & slope & $\left.0^{\prime}\right)$ & 0.051 & 0.047 & 0.063 \\
\hline
\end{tabular}

* Starred values are measured under conditions which vary the ionization state of the substituent (see Chapter III Results and Discussion). 


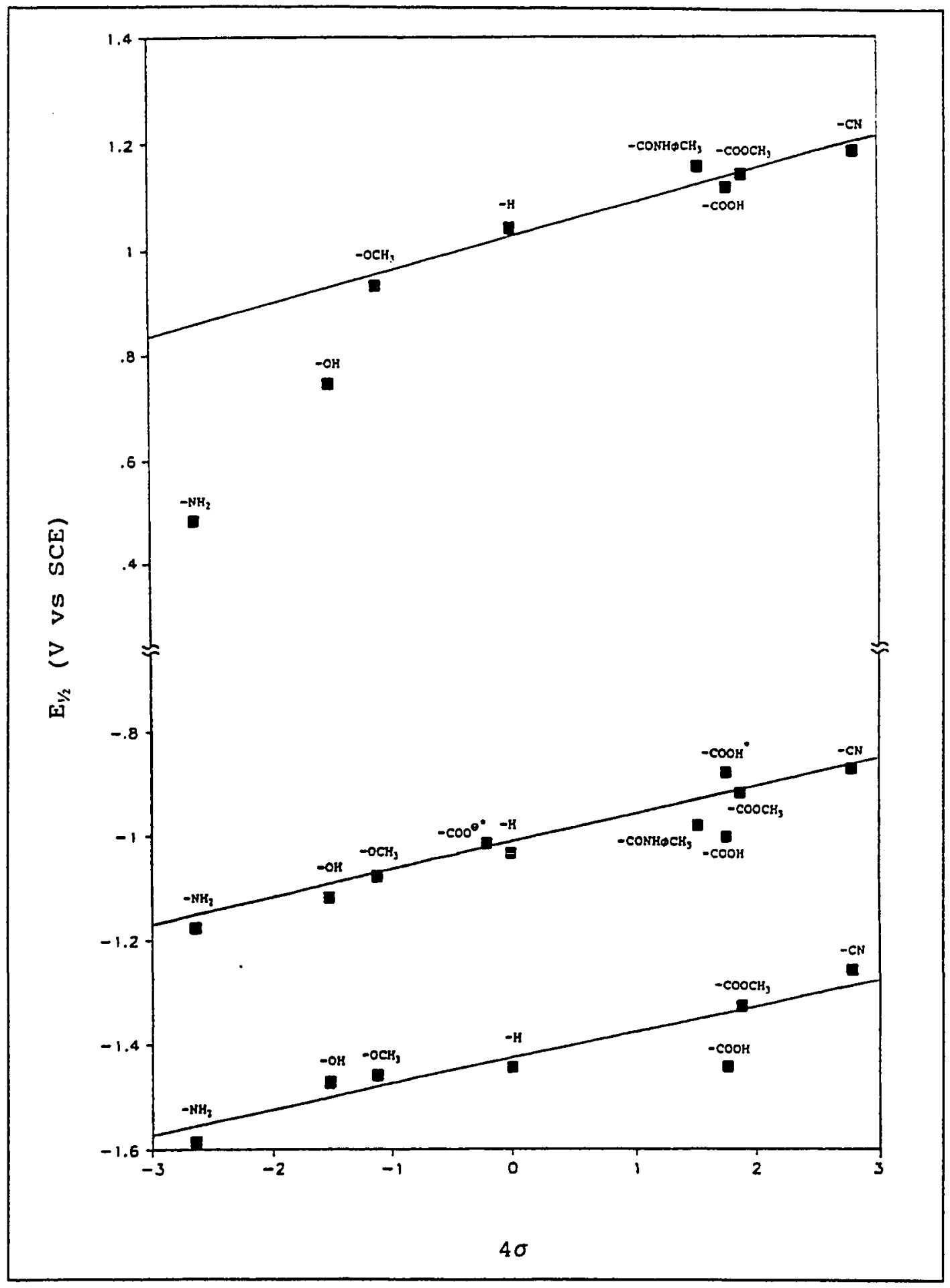

Fiqure 10. Hammett plot of tetraphenylporphyrins. Starred values are corrected for the effects of ionization (see discussion). 
The value obtained under conditions of added acid served to reestablish the predicted order of reduction of TCPP and TTCPP, and that obtained using DMSO with added base exaggerates the previously mentioned disparity in the order of reduction of TCPP and TTCPP. From this it can be concluded that the original value of reduction of TCPP shows some effect of partially ionized carboxylic acid substituents.

Another feature previously unobserved is the deviation from a linear correlation of the values of $E_{\frac{1}{2}}$ for the oxidation of TAPP and THPP, the amino-and hydroxy- substituted tetraphenylporphyrins. For the reasons indicated below, these two points are not included in the linear regression of the plot of oxidation data.

First, when the points representing the $E_{\frac{1}{2}}$ of oxidation for TAPP and THPP are excluded from the linear regression, the resulting slope (or reaction constant, $\rho$ ) of the best-fit straight line is roughly the same as for the other two reactions studied $(0.063$ versus 0.051 for the 1 st reduction and 0.047 for the second reduction). When these points are included, the resultant slope does not agree well with that of the other two reactions $(0.118)$.

The above values are to be compared with that obtained by Kadish ${ }^{30 d}(\rho=0.053)$ for the first reduction of para-substituted tetraphenylporphyrins in DMSO. As stated in the Introduction to this chapter, Kadish has demonstrated that both oxidations and reductions of tetraphenylporphyrins yield similar values of $\rho$, which he attributes to a similarity in the mechanism of oxidation or reduction. ${ }^{7}$ The implication of 
this finding for this research is that when the reaction constants of two reactions differ significantly, the reactions may undergo different mechanisms.

A second reason can be found in the early observation by Fuhrhop, Kadish, and Davis ${ }^{21}$ that the difference in potential between the first and second oxidation waves for porphyrins was consistent $(\approx 0.3 \mathrm{~V})$. Applying this observation to the anodic scans of TAPP (shown in Figure 7) or of THPP, means that additionally the second oxidation wave of both compounds should fall within the accessible potential range in DMSO. That no such wave is observed suggests that the wave which does appear is not due to the first oxidation of the $\pi$ electron system of the porphyrin macrocycle.

The above observations can be accounted for if one considers what other electrode reactions can occur in that potential range. Murray and coworkers have shown that both the tetra (p-aminophenyl) - and tetra (p-hydroxyphenyl)porphyrins can undergo anodic electropolymerization. ${ }^{36}$ This oxidation does not remove electrons from the macrocyclic porphyrin $\pi$ system, but from the substituted electron-rich phenyl ring instead.

Since it appears that oxidation of TAPP and THPP occur by different reaction mechanisms than the rest of the porphyrins investigated, it is not surprising that their oxidation potentials do not correlate well with potentials for the oxidation of other substituted tetraphenylporphyrins, and therefore those two points are not used in the regression analysis of first oxidations. 
The actual slope $(\rho)$ of the line drawn through the points for TAPP, THPP, and TMPP is 0.29 . Hertl reports on substituent effects on the electrooxidation of substituted 4aminobiphenyls.37 This reaction, electrooxidation of parasubsituted phenyl rings, is used as an analog for the proposed mechanism of oxidation for TAPP and THPP.

The $\rho$ values which they report for the correlation of oxidation potentials with standard Hammett constants must be modified to $\rho$ ' values for comparison with the values reported here. When this is done, the equivalent $\rho$ value for their correlation is 0.24 . The agreement between their results and that reported above is additional evidence that the reaction mechanism for the electrooxidation of TAPP and THPP involves oxidation of the substituted phenyl ring. 
CHAPTER II

\section{SOLVENT EFFECTS ON THE REDUCTION} OF TETRA (P-AMINOPHENYL) PORPHYRIN

\section{INTRODUCTION}

\section{Background}

The standard oxidation or reduction potential of an electroactive species in solution depends on the nature of the solvent system. 38 (By "system" is meant solvent, electrolyte and any other solute present.) Such solvent effects arise from interactions between the soluble oxidized and/or reduced species and the molecules of the solvent.

For purposes of this thesis, it is of interest to determine the effect of added water on the reduction potentials of porphyrins in DMSO. Since any working photosynthetic membrane is intended to function in water, prediction of the aqueous performance of such a membrane would be useful. If a quantitative correlation is found to be valid, it could be used to to estimate (knowing the redox behavior in DMSO) the behavior of model porphyrins in water, in which they are not soluble.

This estimate would only be as valid as the process of extrapolation, which entails many uncertainties. The measurements described in this Chapter cover aqueous-DMSO mixes up to $50 \% \mathrm{v} / \mathrm{v}$ water or roughly 80 mole 8 . This leaves room for considerable error in the remaining region; for example, strong specific interactions between porphyrins and water 
molecules may show an effect only at higher water concentrations, causing one to underestimate the potential necessary to reduce a porphyrin in water.

A summary of the treatment of solvent effects on reactions in general, and specifically on electrochemical reactions is presented below.

Early conceptual treatments of solvent effects on organic reactions used purely electrostatic considerations. Usually the solvent was considered to be a non-structured continuum, and attempts to understand solvent effects were couched in terms of the "polarity" of the solvent. The concept of solvent polarity was qualititatively easily grasped, but difficult to precisely define. Usually some macroscopic property of the solvent such as refractive index, dipole moment, or dielectric constant was used, with dielectric constant being the most common of these.

The solvent dielectric constant, $\epsilon$, is usually measured by evaluating the effect of solvent between two plates on the field that can be built up between the plates. Since the distance between the plates is many times molecular dimensions, the measured value of $\epsilon$ reflects the average arrangement of the solvent between the plates. Such a property of the bulk liquid is sufficient for approximate correlations, but does not allow for specific interactions between solute and solvent such as hydrogen bonding or differences in solvation of cations and anions.

Another very influential conceptual treatment of solventsolute interactions considers solvent effects on rates or equilibria as due primarily to coordination between electron 
pair acceptor (EPA) solutes and electron pair donor (EPD) solvents. The majority of common organic solvents are better electron pair donors (Lewis bases) than acceptors (Lewis acids).$^{39}$ Nevertheless, the opposite type of interaction (EPD solutes with EPA solvents) is also possible, and will be later shown to be the more important in the reduction of porphyrins.

Such conceptual descriptions of solvent/solute interactions do not readily lend themselves to theoretical treatments due to their complexity. As Reichardt ${ }^{39}$ says,

The interaction between species in solvents (and in solutions) is on the one hand too big for it to be treated by the laws of the kinetic theory of gases; on the other hand it is too small for it to be treated by the laws of solid state physics. ... Thus, neither of the two possible models - gas and crystal model - can be applied to solutions without limitation. ... Due to the complexity of the interactions, the structure of liquids - in contrast to that of gases and solids - is the least-known of all aggregation states.

No theory as yet can incorporate all of the different possible intermolecular forces that constitute solvent/solute interactions. Among the possible types of interactions are iondipole, dipole-dipole and dipole-induced dipole forces, hydrogen bonding, and van der Waals (also called dispersion or instantaneous dipole/induced dipole) forces.

\section{Empirical Solvent Parameters}

In the absence of theoretical models for the structure and properties of liquids, attempts have been made to introduce empirical solvent parameters based on solvent-dependent reference processes. Implicit in these attempts is the idea that the chosen reference process is a suitable model for a large class of solvent-sensitive processes. In this way, the 
effects of all possible solvent/solute interactions are summed up in the response of the model system, giving a more comprehensive measure of solvent polarity than any single physical constant.

From the point of view of maximum solvent sensitivity the ideal model process would be one that converted an ion pair into a neutral species or the reverse. ${ }^{40}$ Such processes encompass a range of interactions from the maximum possible (ion pair/solvent interactions) to the minimum (neutral species/solvent interactions).

Many solvent parameters have been used in correlating the effect of solvent on various reactions. These include the solvent dielectric constant, as well as empirical coefficients such as the Gutmann acceptor number (ACN) and donor number (DN), Winstein's $Y$ values, Kosower's $Z$ values, and the Dimroth-Reichardt $E_{T}$ parameter. ${ }^{39}$

All of the many empirical solvent parameters currently found in the literature can be classified into three types based on the experimental information used to obtain them. These classes are: 1) parameters obtained from solvent effects on equilibrium constants, 2) those obtained from solvent effects on reaction rate constants, and 3 ) those obtained from the energetics of solvent-dependent electronic transitions (or nuclear transitions, in the case of solvent effects on NMR spectra).

The first attempt to delineate an empirical measure of solvent polarity was by K.H. Meyer in 1914.41 The relationship he describes is of the first class noted above, and used 
the equilibrium constant for keto-enol tautomerization for ethyl acetoacetate as the solvent-dependent parameter.

One of the principal empirical solvent polarity parameters, the Gutmann donor number (DN), also belongs to the first class of solvent parameters. ${ }^{42}$ Introduced in 1966, the Gutmann donor number is based on the idea that many chemical reactions are subject to solvent influence primarily through the interaction of electron pair donating (EPD) solvents and electron pair accepting (EPA) solutes.

The solvent's ability to donate electron pairs was assessed by calorimetry; the heat of formation of Lewis acidLewis base adducts formed from the solvent of interest and $\mathrm{SbCl}_{5}$ in dilute 1,2-dichloroethane solutions was determined. The solvent DN was then defined as:

$$
\mathrm{DN}=-\Delta \mathrm{H}_{\mathrm{D}-\mathrm{SbCl5}} \quad(\text { in } \mathrm{kcal} / \mathrm{mole})
$$

The values thus measured range from a low of 0.00 for 1,2-dichloroethane (defined as the standard solvent for measurement) to a high of 38.8 for hexamethylphosphoramide. However, these values are measured for solvent molecules at high dilution; the electron donating ability of a solvent increases in the pure solvent. ${ }^{43}$ Measured DN values have been shown to correlate well with energy of the HOMO of the solvent, as well as with the solvent's gas-phase proton affinity. ${ }^{44}$

Other solvent polarity parameters determined from equilibrium measurements include several scales of Lewis base 
activity: that of Gal and Maria, ${ }^{45}$ and also that of Kelly ${ }^{46}$ are of note. Hansch and Leo's octanol-water partition coefficient, 47 which is widely used in toxicology and environmental science, can also be considered to be derived from equilibrium measurements.

Of those empirical solvent polarity parameters determined from kinetic measurements, only that of winstein ${ }^{48}$ is of general interest. The reference process used by winstein is the solvolysis of t-butyl chloride in 80:20 ethanol:water. The rates of solvolysis in other solvents are compared to this standard to obtain the Winstein $Y$ value as shown in Equation [15].

$$
\mathrm{Y}=\ln \mathrm{k}_{\mathrm{x}}-\ln \mathrm{k}_{\mathrm{o}}
$$

where $k_{x}$ is the rate of solvolysis in solvent $x_{\text {, and }} k_{0}$ is the standard rate in 80:20 ethanol:water.

$Y$ values provide a measure of the "ionizing" ability of a solvent. The solvolysis of t-butyl chloride is almost purely a $S_{N} 1$ process, and is thus able to correlate well the effect of solvent on other $S_{N} I$ reactions. Correlations using $Y$ values are not as good if the solvent nucleophilicity can assist the reaction, however, and many modified forms of Winstein's original correlation incorporating extra parameters have been proposed in the literature to correct for other contributions of the solvent. ${ }^{48 \mathrm{~b}, 49}$

The most widely used measures of empirical solvent polarity belong to the third class of parameters, having been 
determined from changes in spectroscopic properties with solvent. 50 While UV/Vis spectra have been the most common source for these solvent-sensitive properties, the effect of solvent has also been investigated using IR, fluorescence, ESR, and NMR spectroscopy. 51

Absorption bands can change in position, shape and intensity with a change in polarity of solvent. 52 Brooker ${ }^{53}$ was the first to suggest, in 1951, that solvent-dependent spectral shifts should be used to develop empirical solvent parameters. The first such use of spectral shifts was by Kosower ${ }^{54}$ in 1958, who proposed using as a reference process the solvent-sensitive charge-transfer (CT) band in the visible spectrum of 1-ethyl-4-methoxycarbonylpyridinium iodide.

The wavelength of maximum absorption of this dye exibits a hypsochromic (blue) shift of $109 \mathrm{~nm}$ in changing the solvent from cis-1,2-dichloroethene to methanol. Such a hypsochromic shift with increasing solvent polarity is usually termed negative solvatochromism. Kosower used this shift to define a new scale of solvent polarity which he called the z-scale. The value of $Z$ for each solvent tested was defined as the molar energy of transition, $E_{T}$, for the long-wavelength $C T$ band for 1-ethyl-4-methoxycarbonylpyridinium iodide.

$$
\begin{aligned}
Z & =E_{T}(\text { in } \mathrm{kcal} / \mathrm{mole}) \\
& =\left(2.859 * 10^{-3}\right) \cdot V\left(\text { in } \mathrm{cm}^{-1}\right)
\end{aligned}
$$

Kosower's 2-scale has some practical disadvantages which limit its usefulness. First, in highly polar solvents, the 
$\left(n-\pi^{*}\right)$ charge-transfer band is shifted so far to the blue that it cannot be observed under the much stronger $\left(\pi-\pi^{*}\right)$ transition of the pyridine ring. Also, the dye is not soluble in many nonpolar solvents. The second disadvantage can be overcome by the use of secondary pyridinium iodide dyes with greater solubility whose shifts can be correlated with the primary dye.

Many other spectroscopically-obtained empirical solvent polarity parameters have been proposed in the literature, including a measure of the accepting ability of a solvent, the Gutmann acceptor number, $\mathrm{ACN}, 55$ which was determined by the ${ }^{31}$ P-NMR chemical shift values of triethylphosphine oxide relative to the adduct $\mathrm{Et}_{3} \mathrm{PO}-\mathrm{SbCl}_{5}$. For purposes of this thesis, however, the most important of those remaining is that defined by Dimroth and Reichardt. 56

Dimroth and Reichardt proposed in 1963 the use of a new scale, $\mathrm{E}_{\mathrm{T}}(30)$, (after dye \#30 in reference 56a) that is very similar to Kosower's $\mathrm{Z}$ value in that it is defined as the transition energy (in kcal/mole) for the solvent-dependent CT band of a dye. In this case, the dye is a pyridinium-Nphenoxide betaine dye whose structure is shown in Figure 11.

Reichardt's dye has the advantage that its long-wavelength CT band is shifted to the red relative to the pyridinium iodide dye used to determine $\mathrm{z}$ values. This yields an unusually large range for the solvatochromic behavior; in changing from diphenyl ether to water the position of the CT band shifts hypsochromically by $357 \mathrm{~nm}$. Because this range allows for a very sensitive characterization of the solvent 
<smiles>CC(C)CC(C)C</smiles>

Figure 11. Structure of Reichardt's dye in ground polarity, values of $\mathrm{E}_{\mathrm{T}}(30)$ have been determined for more than 270 pure solvents and many binary solvent mixtures, making the $E_{T}(30)$ scale currently the most comprehensive empirical solvent parameter available. 57 Table II shows the response of Reichardt's dye in selected solvents as reported in the Iiterature. ${ }^{39}$

One disadvantage of the $E_{\mathrm{T}}(30)$ scale is that Reichardt's dye is only sparingly soluble in water, and completely insoluble in nonpolar solvents. This has been overcome by the use of a penta(t-butyl) derivative as a secondary standard, owing to the excellent correlation between the response of the two dyes.57a A second disadvantage is that values of $E_{\mathrm{T}}(30)$ cannot be determined in acidic solvents, since in such solvents the phenolic oxygen is protonated, and the CT band completely disappears. ${ }^{39}$ 
TABLE II

SOLVENT EFFECTS ON REICHARDT'S DYE ${ }^{39}$

\begin{tabular}{|l|c|c|c|c|c|}
\hline Solvent: & $\mathrm{H}_{2} \mathrm{O}$ & EtOH & DMSO & $\mathrm{CHCl}_{3}$ & $\mathrm{Ph}_{2} \mathrm{O}$ \\
\hline$\lambda_{\max } \mathrm{nm}:$ & 453 & 550 & 635 & 730 & 810 \\
\hline $\mathrm{E}_{\mathrm{T}}(30), \mathrm{kcal} / \mathrm{mole}:$ & 63.1 & 51.9 & 45.0 & 39.1 & 35.3 \\
\hline
\end{tabular}

As will be discussed later, solvent-induced shifts in the reduction potentials of porphyrins can be correlated using $\mathrm{E}_{\mathrm{T}}(30)$ values. ${ }^{7}$ In light of the intended use of this reference system in correlations of porphyrin redox potentials, it will be necessary to consider the specific interactions that are responsible for the solvent sensitivity of Reichardt's dye.

The negative solvatochromism of both Kosower's dye and Reichardt's dye can be explained in terms of changes in the dipole moment of the dye occurring during excitation. If the ground state of the dye is more dipolar (has a larger dipole moment) than the excited state, then the ground state will be stabilized relative to the excited state in polar solvents (see Figure 12). This means that the energy required for the transition will be larger for such dyes in polar solvents, relative to that in nonpolar solvents.

since more energy is required for the transition in polar solvents relative to nonpolar solvents, the wavelength of maximum absorption for that band will be at shorter wavelengths when the dye is in polar solvents. This is what we 
have termed negative solvatochromism. (Conversely, if the excited state dipole moment of the dye, $\mu_{e}$, were larger than the ground state dipole moment, $\mu_{g}$, then the dye would exibit positive solvatochromism.)

The above discussion assumes that the electronic transition represented by the absorption of a photon follows the Franck-Condon principle. This principle states that, during the course of a transition between potential energy surfaces (such as absorption or fluorescence), the nuclear geometry of a molecule cannot undergo significant change in position or momentum. In other words, to a first approximation the absorption of a photon by a molecule can be modelled by means of its effect on only the electronic distribution in that molecule.

As Figure 12 indicates, the shift in peak wavelength of Reichardt's dye with increasing solvent polarity is brought about by stabilization of the zwitterionic ground state relative to the less polar excited state. This effect is observed despite the stabilization (relative to an absolute frame of reference) of the excited state by polar solvents.

In addition to the generalized polarity effects, the localized negative charge on the phenoxy oxygen allows the dye to have specific interactions with Lewis acids and hydrogen bond donors. The pyridinium nitrogen's positive charge is sterically shielded and therefore is less apt to have specific interactions with Lewis bases. 39

This means that in addition to all of the non-specific dye/solvent interactions that affect the wavelength of absorption of Reichardt's dye, shifts in the peak wavelength 
(a)

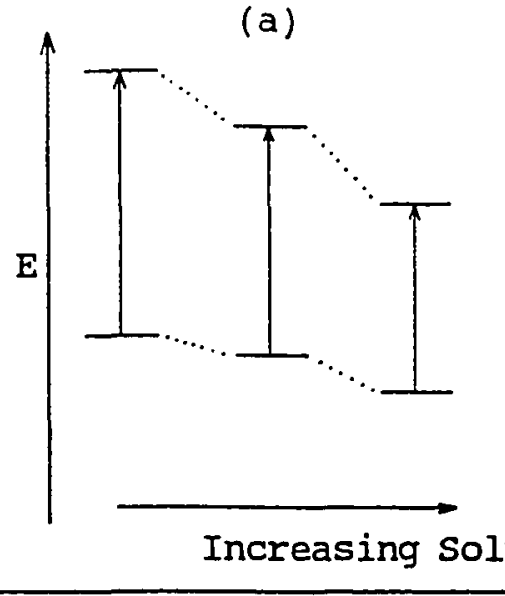

(b)

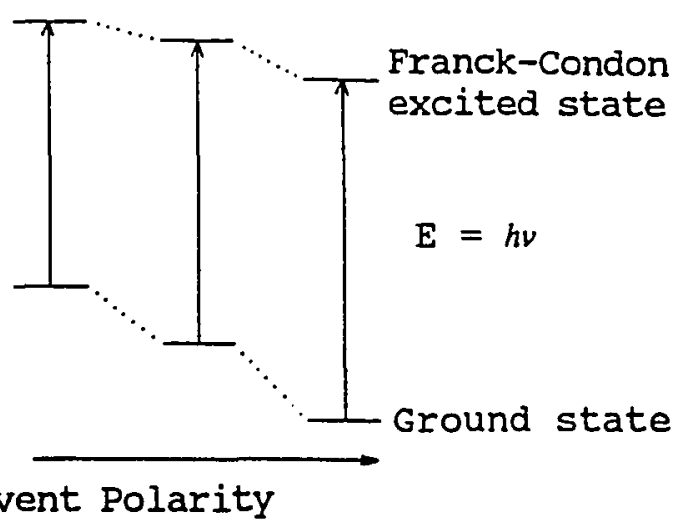

Fiqure 12. Solvent effect on electronic transition energy. Case (a): $\mu_{\mathrm{g}}<\mu_{\mathrm{e}}$, and case (b): $\mu_{\mathrm{g}}>\mu_{\mathrm{e}} \cdot 3 \mathrm{~g}$

of Reichardt's dye can also reflect the Lewis acidity of the solvents in which it is used. Reichardt's dye and tetraphenylporphyrins are both large molecules with extensive $\pi-$ electron clouds. This may be enough of a similarity in terms of electron-donating ability to ensure that the model process (electronic excitation of the dye) provides an appropriate measure of both specific and non-specific solvent interactions with porphyrins.

It has also been shown that in some binary solvent mixes Reichardt's dye is preferentially solvated by one of the two components, 58 usually the more polar one. In these cases, the value of $\mathrm{E}_{\mathrm{T}}(30)$ measured reflects the microenvironment of the dye, leading to unexpectedly high values. Krygowski has shown that this is not the case for mixtures of DMSO and water. ${ }^{59}$

$\mathrm{E}_{\mathrm{T}}(30)$ values have also been shown to depend on temperature, pressure, and ionic strength. $56 \mathrm{~b}, 57 \mathrm{~b}, 60$ The effect of salts on peak wavelength is largest for cations with high 
charge density, so we expect that variations in the concentration of cations such as tetraalkylammonium ions should have a minimal effect due to their low charge density.

Solvent Effects In Electrochemistry

Empirical solvent parameters have been used to correlate solvent effects on various chemical reactions, including electrochemical reactions. Of the many investigations into solvent effects on electrochemistry, most can be classified into one of two types: solvent effects on equilibria, as measured by shifts in the formal potential, $E^{\circ}$, of the reaction, and solvent effects on the kinetics of reaction, as measured by changes in the rate of heterogeneous electron transfer.

An example of the latter is the work by cotton and Heald $d^{61}$ on oxidations of bacteriochlorophyll a in dichloromethane and methanol. The heterogeneous rate of electron transfer in methanol was approximately ten times larger than that in dichloromethane. This is as predicted using Marcus theory. ${ }^{62}$ Most bimolecular electron-transfer reactions can be treated within the framework of Marcus theory, which considers the solvent to be a dielectric continuum. As such, it is not surprising that changes in electron transfer rate are correlated in Marcus theory using solvent dielectric constant as a solvent parameter.

Cotton and Heald attribute their observed changes in electrochemical electron-transfer rate to a difference in solvent reorganization energy between the two cases. Gibbs free energy of solvent reorganization is that which arises 
from the rearrangement of solvent molecules as the nuclei of the reactant complex shift to form product. In Marcus theory it is only this energy term that is solvent-dependent.

Changes in the formal potential of oxidation or reduction of a species with solvent reflect more than just alterations in the free energy of solvent reorganization. Specific interactions between the oxidized or reduced species and the solvent can and do alter the thermodynamic driving force and thus the equilibrium constant of electrochemical reactions, which are considered to be solvent-independent in Marcus theory treatment.

Despite the added complexities, the following discussion will cite many studies of both porphyrins and other species that are investigations into the effect of solvent on the formal (or half-wave) potentials of electroactive species. As might be expected, empirical parameters are used to correlate the shifts in redox potentials with solvent.

Solvent effects are usually discussed in terms of the solvent's electron donor/acceptor abilities in these studies and frequently correlated with Gutmann donor or acceptor numbers. This is due to the fact that electrochemical oxidation or reduction always involves the formation or destruction of charged species. In those cases where the solvent can be expected to preferentially stabilize a cation due to its electron-donating ability (or conversely, stabilize an anion with electron-accepting ability), donor/acceptor interactions can be used to predict the direction of observed shifts in redox potential. 
An example of such treatment of electrochemical data is presented in the work of Gritzner. ${ }^{63}$ His investigation of the polarographic and cyclic voltammetric reductions of metal cations to their corresponding metal amalgams showed a good correlation between the redox potentials of the cations and the donor number of the solvent. In this work, only the oxidized species is in solution and subject to solvent interactions; the reduced species is the mercury amalgam. In this case the solvent can only act as a donor with respect to the positively-charged electroactive species in solution (the metal cation), so it is not surprising that solvent-dependent shifts in reduction potential can be correlated with solvent donor number.

In keeping with conventional wisdom, the observed trend in reduction potential in Gritzner's work showed that solvents that are the better donors (i.e., have higher donor numbers) result in more stable oxidized species in solution, and therefore, more difficult reductions (i.e., more negative reduction potentials or a cathodic shift in potential).

\section{Solvent Effects on Porphyrin Electrochemistry}

Electrochemistry of porphyrins belongs to a different class of reactions that includes most organic species. In oxidation or reduction of organics (usually in organic solvents due to solubility considerations), a radical cation or radical anion is formed from a neutral species.

One can deduce, following the rationale discussed above, that solvent-dependent shifts in the oxidation potential of organic species could be correlated using solvent donor 
number, but that the trend in potential would be opposite to that demonstrated by Gritzner for metal cations. Because solvent-solute interactions would be stronger for the oxidized species (the radical cation) than for the neutral reduced species, solvent donor number would be the appropriate correlation parameter.

The oxidation reaction would be expected to be made easier with better donor solvents since the oxidized species would be stabilized relative to the neutral species, so the trend in potential would be towards more positive potentials with increasing solvent donor number. This is opposite in direction from the trend exibited by the reduction of metal cations, in which increasing solvent donor number yielded more negative potentials.

By the same logic, shifts in reduction potential should be correlated not by donor number of the solvent, but by solvent acceptor properties, since reductions of neutral organics involves the formation of a radical anion. The solvent can act as a donor or acceptor towards the neutral species, but the reduced species (the radical anion) would be expected to show the most significant interactions with acceptor solvents. Reductions of neutral organic species should be made easier with better acceptor solvents, and therefore reduction potentials should tend towards more positive potentials with increasing solvent acceptor number.

The literature has many hundreds of examples of porphyrin electrooxidation or reduction in non-aqueous solvents. More often than not, the porphyrins under investigation are complexed to a central metal; the porphyrin acts as a -2 
ligand. In some cases, the mechanism of oxidation or reduction has been worked out in some detail, but few researchers report results in more than one solvent.

A notable exception to this rule is the work of the Kadish group, as well as a few others. Beginning in the mid1970's, this group published papers investigating the effect of solvent on the electrochemistry of both free-base and metalloporphyrins.10,30f,64 Much of this work is collected in Kadish's 1986 article "The Electrochemistry of Metalloporphyrins in Nonaqueous Media", however, the solvent-dependence information is scattered throughout the 170 page review and is difficult to synthesize into a whole. ${ }^{7}$

The coordination chemistry of the central metal ion in metalloporphyrins presents another difficulty of investigating their solvent dependence. In addition to the porphyrin ligand, the complexed metal ion usually has one or more other ligands complexed as well (often referred to as the metal's counterion), and their number and configuration vary with the metal oxidation state and the solvent coordinating ability (another name for solvent electron-donating ability).

The "iron metals" ( $\mathrm{Mn}, \mathrm{Fe}, \mathrm{Co}$, and $\mathrm{Ni}$ ) have been studied most comprehensively of all metalloporphyrins and are representative of solvent effects on the electroreduction or oxidation of most metalloporphyrins. The metal-centered reductions of tetraphenylporphinato complexes of the above metals show similar solvent dependencies which, in turn, are dependent on the number and kind of counterion as well.

When the counterion is $\mathrm{Cl}^{-}, \mathrm{Br}^{-}, \mathrm{F}^{-}$, or $\mathrm{N}_{3}^{-}$, the metal $($ III ) $\rightarrow$ (II) reductions for $\mathrm{Fe}$ - or Co-tetraphenylporphyrins 
show a linear correlation with solvent donor number: with increasing solvent donor number, the reduction becomes easier and the reduction potential shifts to more positive potentials. ${ }^{7}$ This suggests that better donor solvents stabilize the +2 oxidation state over the +3 state.

Such results are difficult to predict in advance. In fact, when the counterion of $\mathrm{Fe}$ or $\mathrm{Co}$ is $\mathrm{ClO}_{4}^{-}$, the opposite trend is observed. In this case, reduction potentials for the (III) - (II) reaction become more negative (more difficult) with an increase in solvent donor number, implying that better donor solvents stabilize the +3 state relative to the +2 state. ${ }^{7}$

Some of the metal-centered electroreactions of metalloporphyrins show little or no solvent dependence, such as the Fe(II) - (I) reduction, ${ }^{7}$ and others show other types of linear correlations, such as the Mn(III) - (II) reduction potentials, which correlate well with solvent dielectric constant.?

Early work on the solvent dependence of the porphyrin $\pi-$ ring system electroreactions is less complete. In 1976 , Kadish published a paper giving substituent effects on the redox reactions of free-base porphyrins in several solvents. 30d From these data a qualitative solvent effect could be seen in that the slope (or reaction constant) of the $E^{\circ}$ vs $4 \sigma$ plots (Hammett plots) varied systematically with the polarity of solvent.

In dichloromethane, a solvent of low dielectric constant $(E=9)$, Hammett plots of the observed electroreactions yielded larger slopes than in DMF or DMSO $(E=37$ and 46 , 
respectively). For example, the reaction constant for the 1st reduction of the porphyrin $\pi$-ring system varied from 0.073 in dichloromethane to 0.053 in DMSO. From this it follows that the effect of changing substituents on the redox potentials of substituted tetraphenylporphyrins is greatest in low dielectric solvents. The sensitivity of the ring oxidation was not significantly different from that of the reductions observed.

Not until 1987 was a paper published that comprehensively treated the effect of solvent on the electroreactions of the porphyrin $\pi$-ring system.10 In this case, the porphyrins investigated were various metallo-tetraphenylporphyrins, and their reductions to the radical anion were treated in up to 13 different nonaqueous solvents (see Figure 13).

The solvents chosen represent a wide range of electrondonating and -accepting abilities and were chosen to avoid possible correlations between solvent dielectric constant and electron acceptor properties. In addition, the measurements of reduction potentials were made with reference to an internal reference redox couple whose potential is considered to be solvent-independent. This latter detail is needed to eliminate the effect of solvent-dependent reference electrode junction potentials on the measured reduction potentials.

In this study, reduction potentials for each metalloporphyrin (referenced to the potential of the ferrocene/ferrocenium redox couple) were correlated with a number of solvent parameters: the solvent dielectric constant (see Figure 13d), the solvatochromic Taft parameters $\beta$ and $\pi^{*}$ (Figures $13 a$ and 13b), the Gutmann donor number (Figure 13c) and acceptor number (Figure 13e), and the Dimroth-Reichardt parameter $\mathrm{E}_{\mathrm{T}}$ 
(Figure 13f). The example used in Figure 13 is that of the reduction of $\mathrm{ZnTPP}$ to form the radical anion.

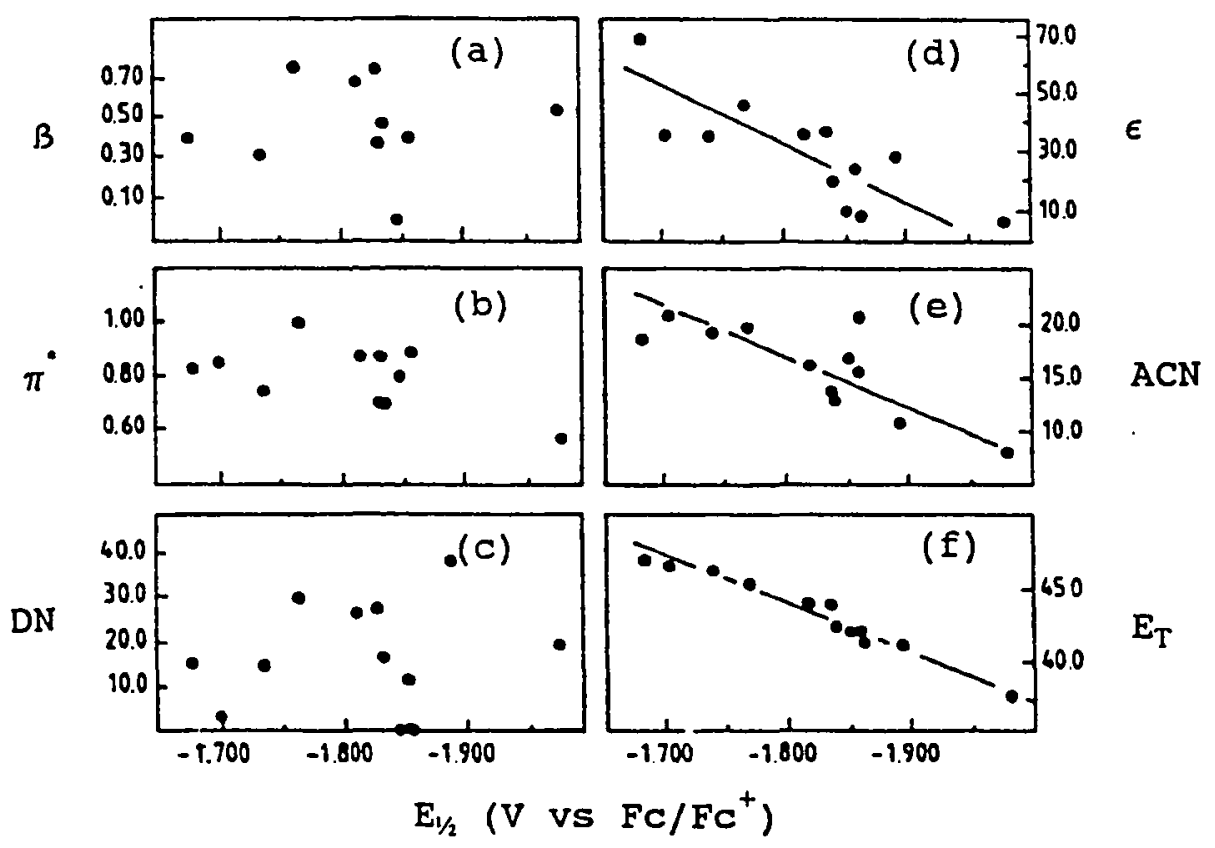

Figure 13. Plot of various solvent parameters vso $E_{\frac{3}{z_{2}}}$ of reduction of $\mathrm{ZnTPP}$ in various solvents. 10 Eâch graph point represents the literature value of the appropriate solvent parameter for a given solvent vs. the reduction potential of ZnTPP determined in that solvent.

As is clear from the above plots, no correlation was observed between $E_{\frac{1}{2}}$ and the solvent donor number, or between $E_{\frac{1}{2}}$ and the Taft parameters $\beta$ and $\pi^{*}$. When solvent dielectric constant was used a positive correlation resulted, but there was considerable scatter in the data.

The best correlations obtained by Kadish in this study were those that reflected the acceptor or Lewis acidity properties of the solvent: the Gutmann acceptor number and the Dimroth-Reichardt $E_{T}$ parameter. ( $E_{T}$ was originally a 
solvent polarity parameter, but as mentioned above has inadvertently found use as a measure of Lewis acidity.)

Kadish's results can be interpreted in the same terms as were used earlier in explaining the solvent effects on electrochemistry of metal cations: the soluble species that can exibit solvent interactions are the neutral metalloporphyrin and its corresponding radical anion. Solvents can act as both electron donors and acceptors when interacting with the neutral reactant, but predominantly act as electron acceptors with respect to the negatively-charged radical anion product.

Solvent interactions with charged species would be expected to dominate in such a case, leading to greater stabilization of the reaction product than the reactant in acceptor solvents. Better acceptor solvents would be expected to better stabilize the radical anion which gives rise to the trend of easier reductions (less negative reduction potentials) with increasing solvent acceptor number.

The solvents used in Kadish's research show a correlation between their Gutmann acceptor number and $E_{T}$ values which has no physical meaning but implies that either of the two parameters could be used to correlate solvent-induced shifts in porphyrin reduction potentials. The Dimroth-Reichardt $E_{T}$ parameter yielded the better correlation when judging from the regression coefficients $\left(r=0.97\right.$ for the plot of $E_{\frac{1}{2}}$ vs $E_{T}, r$ $=0.82$ for $\mathrm{ACN}$ ), and use of $\mathrm{E}_{\mathrm{T}}$ is recommended by Kadish on this basis and on the basis of principal vector analysis as well. Kadish lists as one possible explanation for this result the speculation that the dye used in measuring $E_{T}$ 
values (Reichardt's dye \#30) more accurately reflects the solvent acceptor properties with respect to the negatively charged tetraphenylporphyrin complexes than does the indicator compound used in determining the Gutmann acceptor number, triethylphosphine oxide.

In the experiments described in this thesis, it is proposed that a series of measurements of reduction potentials be made in mixes of DMSO and water in order to extrapolate from the electrochemical reactivity of porphyrins of interest in DMSO to their expected reactivity in water, in which they are not soluble. Of the two solvents, water is the more polar and is the better electron acceptor. DMSO with added water should thus be a better acceptor than is pure DMSO.

The literature data presented above lead one to predict that addition of water to DMSO solutions of porphyrins should make reduction of those porphyrins easier: better acceptor solvents stabilize the negatively-charged products of electroreductions relative to the neutral reactants. Increasing concentrations of water in DMSO yield values of the DimrothReichardt $E_{\mathrm{T}}$ parameter that are larger than that of pure DMSO $\left(E_{T}=45.0\right.$ for pure DMSO, $E_{T}=63.1$ for water $)$. If $E_{T}$ is used as a measure of solvent polarity, a plot of $E_{\frac{1}{2}}$ vs. $E_{T}$ is predicted to exibit a positive correlation - increasing $E_{T}$ values (indicating better solvent acceptor properties) will result in less negative reduction potentials (or easier reductions). 


\section{MATERIALS AND METHODS}

\section{Materials}

Tetra(4-aminophenyl)porphyrin (TAPP) was obtained from Midcentury Chemical (Posen, IL) and used as received. Reichardt's dye \#30 (2,6-diphenyl-4-(2,4,6-triphenyl-1pyridinio)phenoxide) was obtained from Aldrich Chemical Co. (Milwaukee, WI) and was used as recieved. DMSO was Aldrich spectroscopic grade and was used as received. Tetraethylammonium perchlorate was obtained from Southwestern Analytical Chemicals and dried at $60^{\circ} \mathrm{C}$ and $1-2$ torr for $24 \mathrm{hr}$. The water used in making DMSO/water mixes was purified using a Millipore "Milli-Q" system.

\section{Methods}

Solutions of DMSO with added water were prepared by pipetting the required volume of water into a volumetric flask and diluting with DMSO. The wavelength of maximum absorption of Reichardt's dye \#30 was measured in each DMSO/water mix by weighing dye (and electrolyte, in some cases) into a volumetric flask and diluting with the appropriate solvent mix. Then the UV/VIS spectrum of each solution was recorded with DMSO as the reference (with added electrolyte if necessary).

Spectrophotometric peak positions were measured with a wavelength accuracy of $1 \mathrm{~nm}$. Wavelength accuracy was determined from the spectrum of a standard holmium oxide filter relative to published values.

Measurements of the reduction potential of TAPP in each of the solvent mixes were obtained using the experimental protocol described in Chapter I (with the exception of the 
electrolyte used, which was changed to TEAP (tetraethylammonium perchlorate) from the tetra(n-butyl) ammonium salt.

\section{RESULTS AND DISCUSSION}

\section{Response of Reichardt's Dye In Aqueous-DMSO Mixes}

The solvent-dependent absorption spectrum of Reichardt's dye was investigated in mixes of DMSO and water from pure DMSO to $50 \%$ water in DMSO. (All values of composition in this section are volume/volume unless otherwise stated.) The wavelength of maximum absorption of the long-wavelength charge-transfer band shifted from $631 \mathrm{~nm}$ in pure DMSO to 512 $\mathrm{nm}$ in 508 DMSO: $\mathrm{H}_{2} \mathrm{O}$. Shown in Figure 14 is a set of sample spectra of Reichardt's dye normalized to equivalent peak absorbance values.

A photograph of one set of solutions, representing Reichardt's dye in solvent mixtures between $0 \%$ and 508 water, is shown in Figure 15. Variations in color intensity are a result of slight differences in dye concentration.

The response of Reichardt's dye was measured in aqueousDMSO mixes both with and without added electrolyte $(0.10 \mathrm{M}$ tetraethylammonium perchlorate (TEAP)). Raising the ionic strength by adding electrolyte might be expected to increase the effective polarity of the solutions, leading to a hypsochromic (blue) shift in the dye wavelength in any given aqueous-DMSO $\mathrm{mix}$. However, no significant difference was observed in the dye absorption wavelengths in the presence of added electrolyte. This lends support to the idea put forth by Kadish ${ }^{10}$ that large, bulky tetraalkylammonium cations 


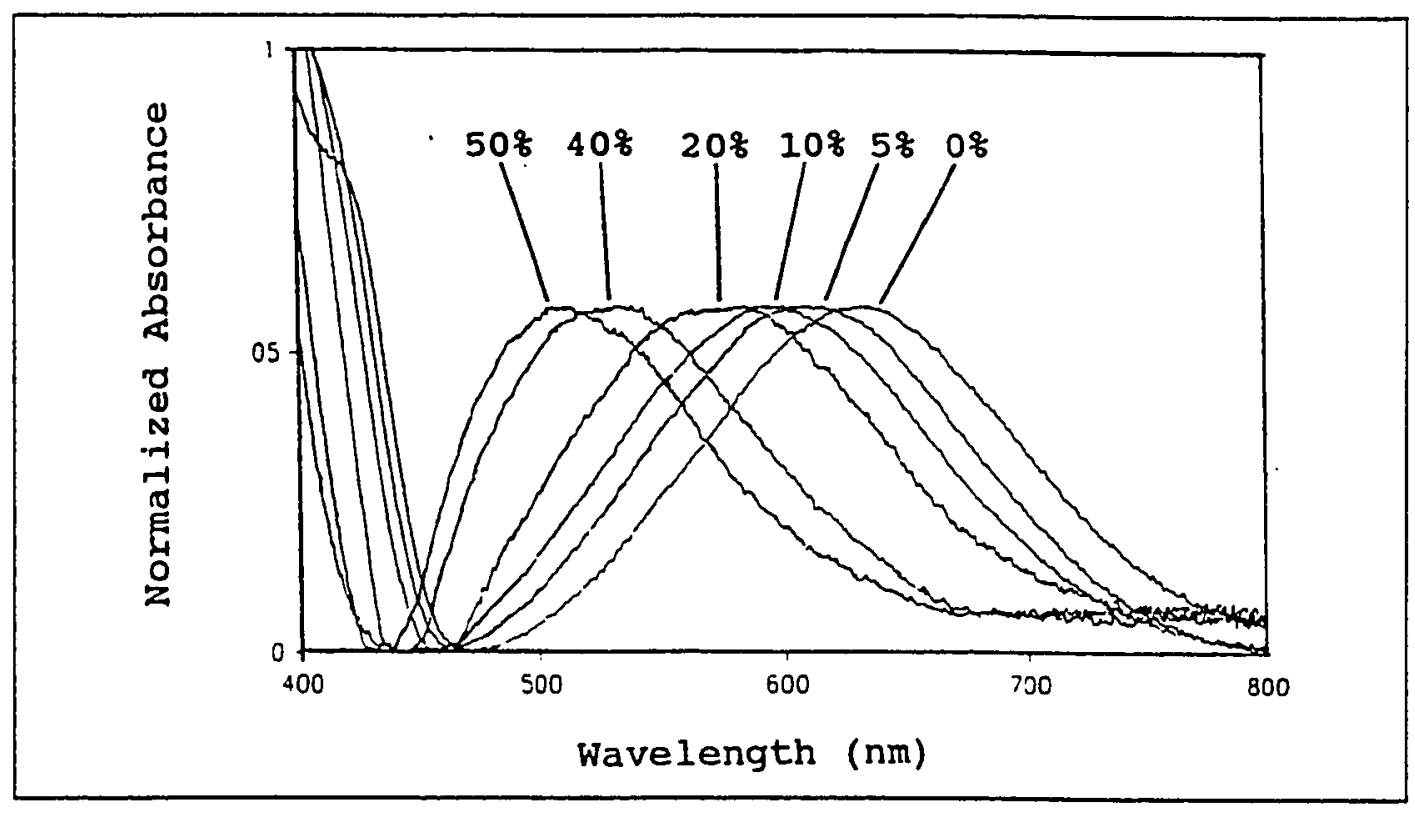

Figure 14. Visible spectra of Reichardt's dye in aqueous-DMSo mixes. Dye concentrations are from $2.9-3.8 * 10^{-4} \mathrm{M}$. Percent composition figures are volume 8 of water in DMSO.

should have only a minimal effect on solvent-solute interactions.

Data from three sets of measurements of Reichardt's dye in aqueous-DMSO mixes were averaged to obtain final values for the solvent-dependent wavelength of maximum absorption in each discrete mix of water and DMSO. These values are presented in Table III together with the calculated $\mathrm{E}_{\mathrm{T}}$ values in each mix.

Other researchers have studied the response of Reichardt's dye in many binary (2-component) solvent mixtures. Langhals ${ }^{58}$ collected data from 60 different binary solvent mixes and attempted to describe an equation that would apply to all of the mixtures and allow quantitative determination of 


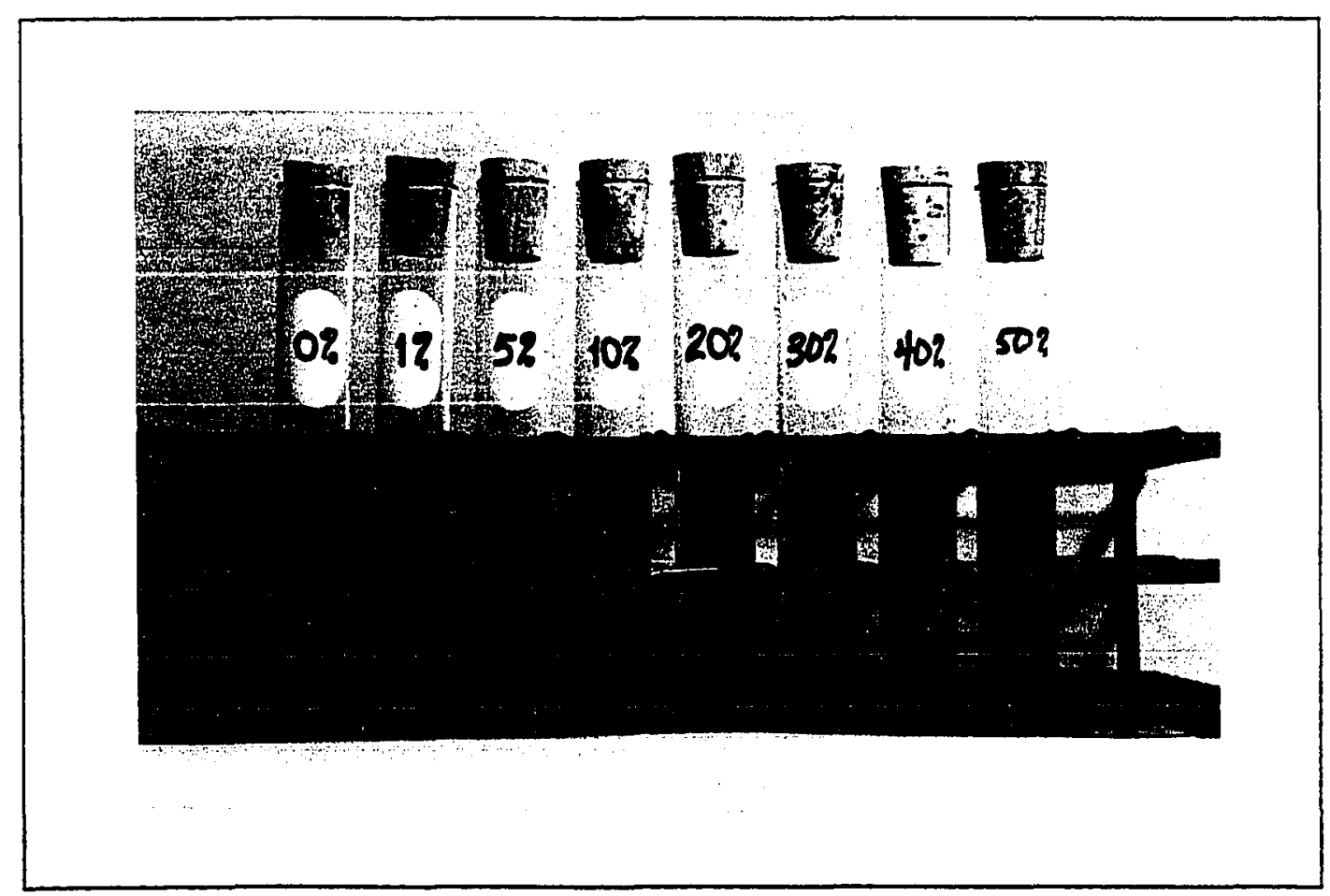

Figure 15. Photograph of solutions of Reichardt's dye in 08 to $50 \%$ water in DMSO.

the polarity of mixtures as a function of composition. The general type of equation is shown in Equation [18].

$$
E_{T}=a \cdot \ln \left(C_{p} / b+1\right)+E_{T}^{\circ}
$$

where $a$ and $b$ are adjustable parameters, $C_{p}$ is the molar concentration of the more polar component, and $\mathrm{E}_{\mathrm{T}}{ }^{\circ}$ is the value of $\mathrm{E}_{\mathrm{T}}$ in the pure, less polar component.

The above experimental data were fit to an equation of the type described by Langhals in order to obtain the final values of $\mathrm{E}_{\mathrm{T}}$ for correlation with porphyrin reduction potentials. Using a SIMPLEX routine ${ }^{65}$ written in T-BASIC, best fit 
TABLE III

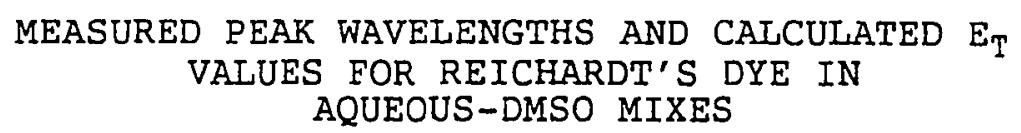

\begin{tabular}{|c|c|c|}
\hline Vol. \& Water & Wavelength & $E_{T}$ Values \\
\hline $0 \%$ & $631 \mathrm{~nm}$ & 45.3 \\
\hline 18 & $625 \mathrm{~nm}$ & 45.8 \\
\hline $5 \%$ & $607 \mathrm{~nm}$ & 47.1 \\
\hline $10 \%$ & $597 \mathrm{~nm}$ & 47.9 \\
\hline 158 & $585 \mathrm{~nm}$ & 48.9 \\
\hline $20 \%$ & $581 \mathrm{~nm}$ & 49.2 \\
\hline $25 \%$ & $564 \mathrm{~nm}$ & 50.7 \\
\hline $30 \%$ & $549 \mathrm{~nm}$ & 52.1 \\
\hline $40 \&$ & $531 \mathrm{~nm}$ & 53.9 \\
\hline $50 \%$ & $512 \mathrm{~nm}$ & 55.9 \\
\hline
\end{tabular}

values of $a$ and $b$ were determined from experimental data, and a set of model $E_{T}$ values were generated for concentrations of water between 0 and 50\%. Figure 16 is a plot of the experimental data and the best fit to the equation.

Reduction of TAPP in Aqueous-DMSO Mixes

The investigation into the solvent-dependency of the reduction of tetra(4-aminophenyl)porphyrin to its radical anion shows an unambiguous trend to less negative reduction potentials with added water. This trend is as predicted using the concepts outlined in the Introduction to this chapter. 
Because of solubility considerations, experiments could only be performed in DMSO mixtures up to 50 o DMSO: $\mathrm{H}_{2} \mathrm{O}$, which is the approximate limit of solubility of the porphyrin. Beer's Law studies of TAPP in $50 \%$ DMSO: $\mathrm{H}_{2} \mathrm{O}$ with and without added electrolyte (0.1 M TEAP) show no evidence of aggrega-

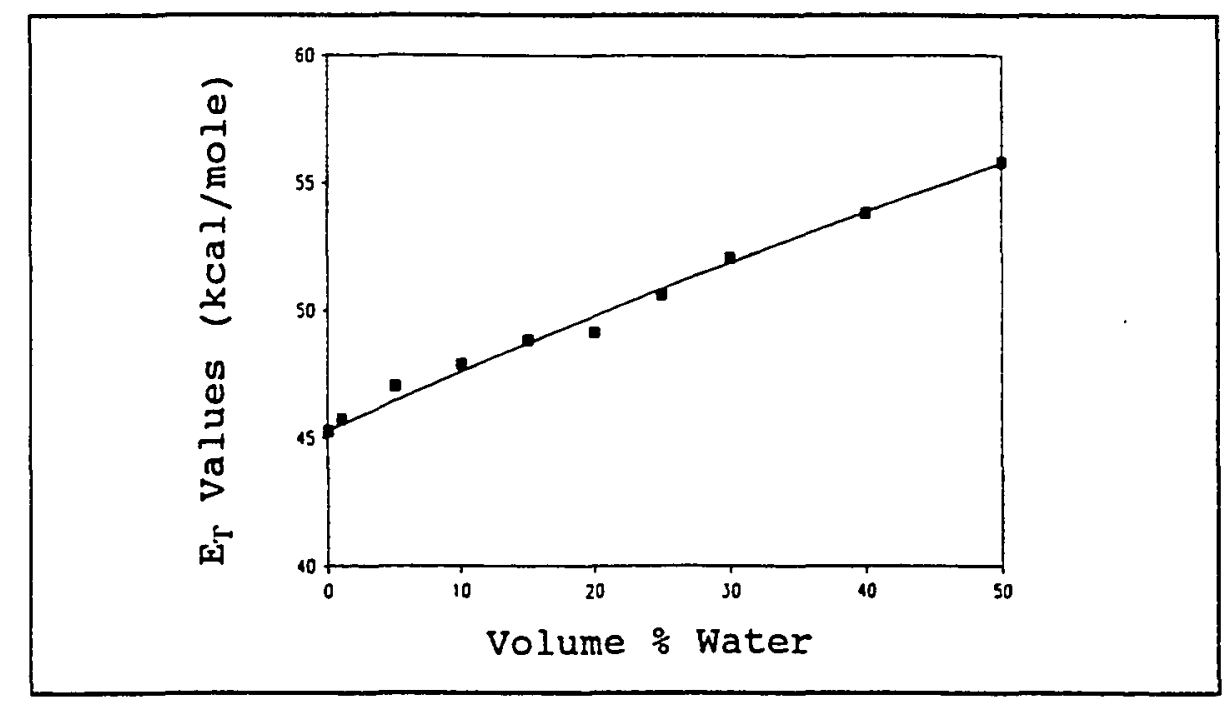

Fiqure 16. Experimental data for Reichardt's dye in aqueous-DMSO mixes. Solid line is the SIMPLEX fit to Equation [18].

tion. It is assumed that this case is an extreme example, and all lower concentrations of water will have less of a tendency to cause aggregation of porphyrin than 50\% DMSO: $\mathrm{H}_{2} \mathrm{O}$.

Spectra of the solutions resulting from electrochemical experiments do show another solvent effect: the peak wavelength of the Soret band shifts from $439 \mathrm{~nm}$ in pure DMSO to $431 \mathrm{~nm}$ in 508 DMSO:water. This example of negative solvatochromism has little implication for the solvent-dependency of the reduction of the porphyrin; it implies, however, that the ground state of the porphyrin is more dipolar than the excited state. 
Initial work in mixed solvents was referenced to the saturated calomel electrode ( $S C E$ ), which was later shown to have a significant solvent dependence of its own. This work showed some stabilization of the radical anion of the porphyrin in solutions with added water, as evidenced by a shift in reduction potential of $100 \mathrm{mV}$ to less negative values. A plot of these data vs. the previously determined $E_{T}$ values for each of the solvent mixes is shown in Figure 17.

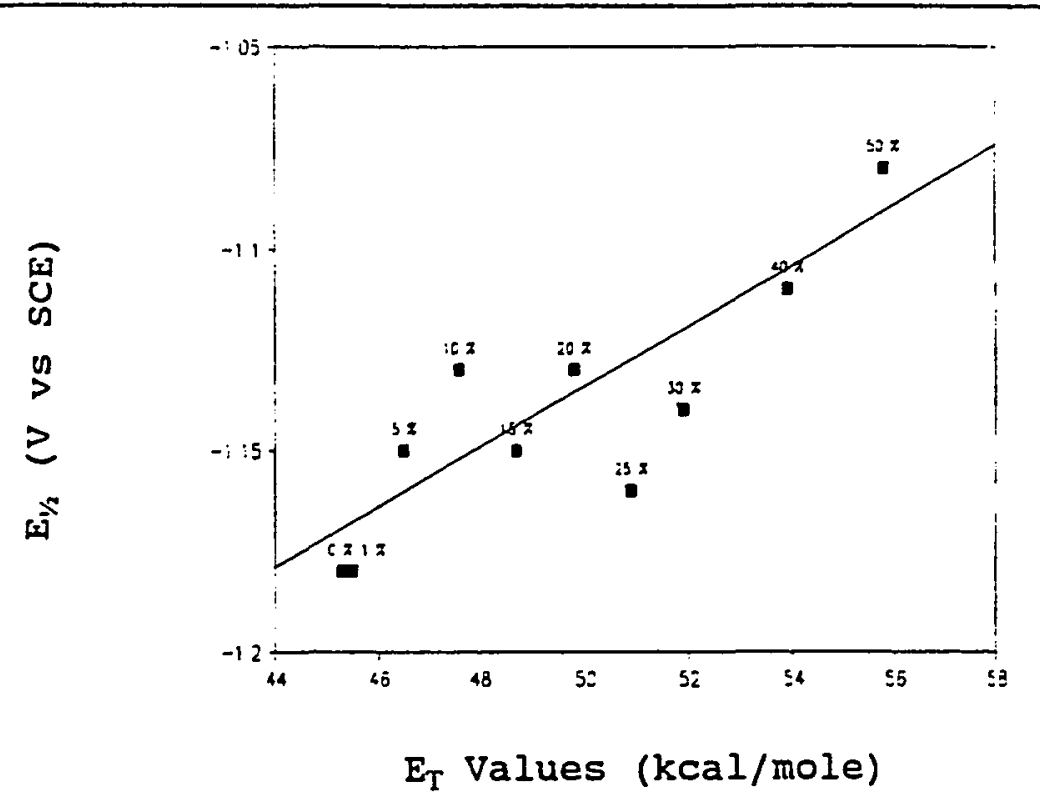

Figure 17. Plot of TAPP reduction potentials ( $V$ vs. SCE) vs, solvent $E_{T}$ values. $E_{T}$ values are experimentally determined for each solvent mix.

Later work was referenced to the ferrocene internal reference electrode, which has been proposed as one of a few solvent-independent redox couples. ${ }^{66}$ Measurements of the potential of oxidation of ferrocene $\left(\mathrm{FC}-\mathrm{Fc}^{+}\right.$) in DMSO yielded a potential of $+0.45 \mathrm{~V}$ vs SCE. This is to be compared to the 
value given by Kadish ${ }^{20}$ of $+0.48 \mathrm{~V}$ vs SCE. Additional measurements in 25 and 508 water in DMSO demonstrated a significant solvent-sensitivity for the saturated calomel reference electrode (assuming that the FC/FC $\div$ oxidation potential is indeed solvent-independent as proposed in the literature). Table IV shows the experimentally determined values of $E_{\frac{1}{2}}$ expressed relative to the ferrocene reference electrode.

TABLE IV

OXIDATION POTENTIAL OF SCE (VS. FC/FC ${ }^{+}$)

IN VARIOUS AQUEOUS-DMSO MIXES

\begin{tabular}{|c|c|}
\hline Volume 8 Water & $E_{\frac{1}{2}}, \operatorname{SCE}(n, s$. dev. $)$ \\
\hline 08 & $-0.45 \mathrm{~V}(2,0.02)$ \\
\hline 258 & $-0.38 \mathrm{~V}(2,0.02)$ \\
\hline 508 & $-0.31 \mathrm{~V}(2,0.01)$ \\
\hline
\end{tabular}

If the best fit line drawn through the 3 points listed above is used to calculate the expected values of $E_{\frac{1}{2}}$ for the SCE electrode vs. FC/FC ${ }^{+}$for all of the aqueous-DMSO mixes, the TAPP reduction potentials can be corrected so that they are referenced to the solvent-independent ferrocene reference system. Figure 18 shows a plot of the corrected $E_{\frac{1}{2}}$ values vs. the $E_{T}$ values of the solvent mixes in which they were measured. (Numerical values for Figures 17 and 18 , including the corrections used, are shown in Table V.) Using the SCE reference masked some of the effect of solvent on the TAPP reduction potentials since the changing calomel electrode 
liquid junction potentials offset $140 \mathrm{mV}$ of what is really a $240 \mathrm{mV}$ shift with added water.

The behavior shown in Figure 18 is in full agreement with predictions made on the basis of Kadish's experiments with metalloporphyrins. Kadish showed that porphyrin ring-centered reductions are affected by solvent in a manner that can be

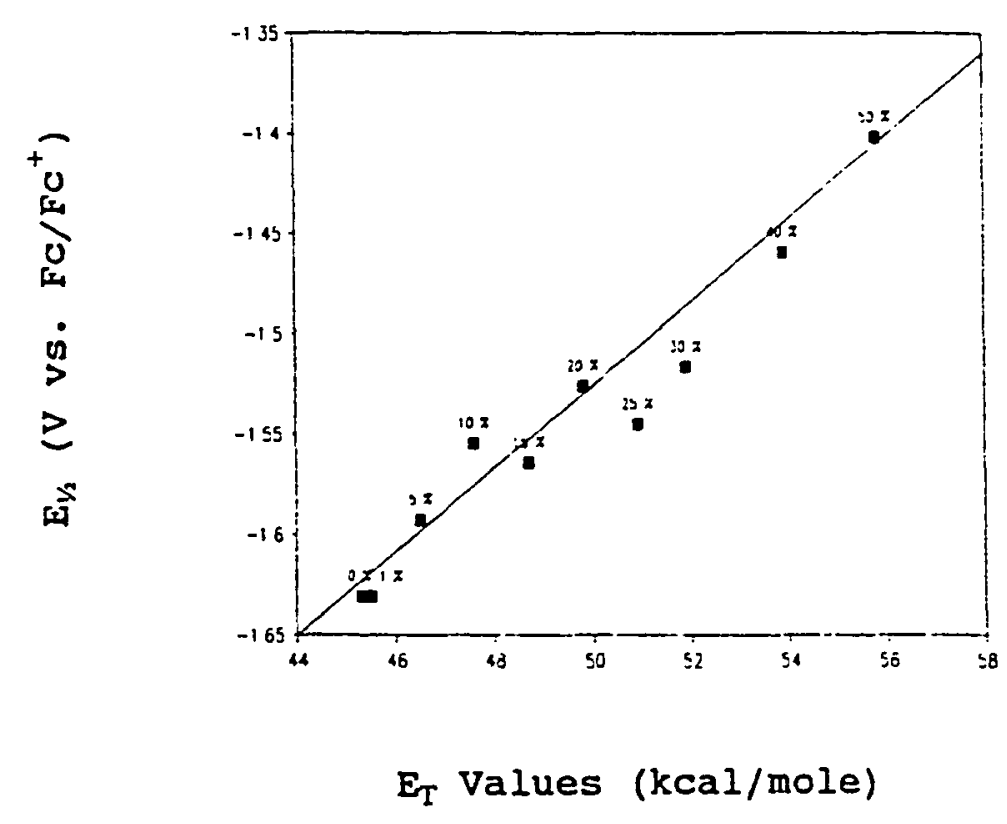

Figure 18. Plot of TAPP reduction potentials ( $\mathrm{V}$ vs. FC(FC $)$ vs. solvent $E_{T}$ values.

correlated with the Dimroth-Reichardt $E_{T}$ parameter. ${ }^{10}$ Such a result implies that within the range of solvents Kadish used there are no specific solvent-porphyrin interactions that would distort a correlation using a polarity and Lewis acidity indicator like Reichardt's dye.

By extension, the results shown here affirm that the electroreductions of porphyrins in DMSO can be used to 
TABLE V

REDUCTION POTENTIALS OF TAPP IN AQUEOUS-DMSO MIXES VS. SCE AND VS. FC/FC

\begin{tabular}{|c|c|c|c|c|}
\hline Water & Value & $(\mathrm{n}, \mathrm{s}$. dev. $)$ & $\mathrm{V}$ vs. Fc & $\begin{array}{c}E_{\frac{1}{2}}, \mathrm{~V} \text { vs. SCE } \\
\text { (std. dev.) }\end{array}$ \\
\hline 0 & 45.3 & $-1.18(8, .02)$ & -0.45 & $-1.63(0.03)$ \\
\hline 1 & 45.5 & $-1.18(1, \mathrm{NA})$ & -0.45 & $-1.63(0.03)$ \\
\hline 5 & 46.5 & $-1.15(2, .01)$ & -0.44 & $-1.59(0.02)$ \\
\hline 10 & 47.6 & $-1.13(2, .02)$ & -0.42 & $-1.55(0.03)$ \\
\hline 15 & 48.7 & $-1.15(1, N A)$ & -0.41 & $-1.56(0.03)$ \\
\hline 20 & 49.8 & $-1.13(3, .02)$ & -0.39 & $-1.52(0.03)$ \\
\hline 25 & 50.9 & $-1.16(2, .01)$ & -0.38 & $-1.54(0.02)$ \\
\hline 30 & 51.9 & $-1.14(2, .00)$ & -0.37 & $-1.51(0.02)$ \\
\hline 40 & 53.9 & $-1.11(2, .00)$ & -0.34 & $-1.45(0.02)$ \\
\hline 50 & 55.8 & $-1.08(2, .01)$ & -0.31 & $-1.39(0.02)$ \\
\hline
\end{tabular}

approximate the corresponding ease of reduction of the same porphyrin in aqueous solutions. Extrapolating from behavior in 50\% DMSO: $\mathrm{H}_{2} \mathrm{O}$ to that in pure water can be accomplished by extending the best-fit line shown in Figure 18 to an $E_{T}$ value of 63.1 (that for pure water).

If this is done, a further $130 \mathrm{mV}$ shift would occur for a total shift of $0.37 \mathrm{~V}$ relative to pure DMSO. If TAPP were soluble in water, one would expect to measure a reduction potential in water of $-1.26 \mathrm{~V}$ vs. $\mathrm{FC} / \mathrm{FC}^{+}$. An uncertainty 
value can be associated with that estimate by specifying a confidence limit. With a confidence limit of $95 \%$, the uncertainty in the estimate is $\pm 0.09 \mathrm{~V}$. 


\section{CHAPTER III \\ IONIZATION EFFECTS ON THE REDOX BEHAVIOR \\ OF SUBSTITUTED TETRAPHENYLPORPHYRINS}

\section{INTRODUCTION}

\section{Background}

The electron-donating or -withdrawing nature of a substituent moiety can be greatly altered by the state of ionization of that substituent.

For example, the amino group, $-\mathrm{NH}_{2}$, is one of the most electron-donating groups commonly encountered, with a Hammett substituent constant of -0.57 . This group is also relatively basic; aniline has $\mathrm{a} \mathrm{pK}_{\mathrm{b}}$ in water of 9.4 .67 When protonated, the amino (now ammonium) group becomes one of the most electron-withdrawing of substituents, and has a Hammett substituent constant of +0.57 (when the counterion is $\mathrm{Cl}^{-}$). This is illustrated using resonance structures in Figure 19.

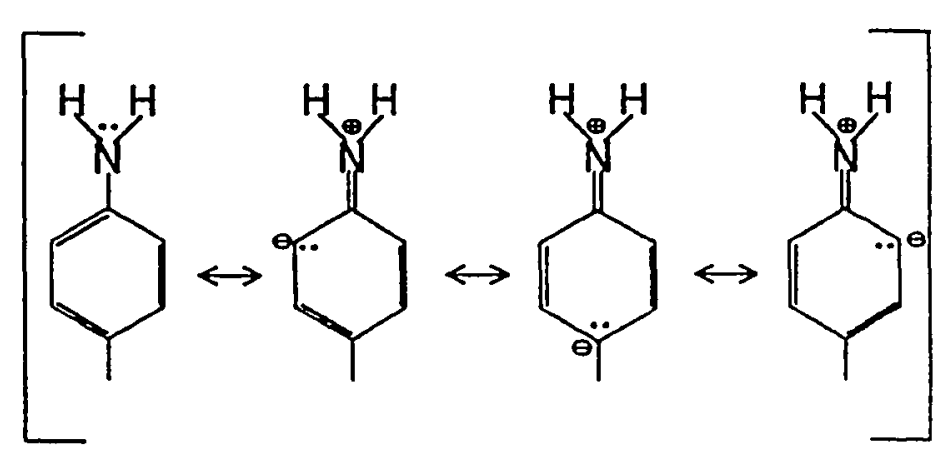

Figure 19. Resonance structures of an amino group on an aromatic ring. 
Other common substituent groups that can be acidic or basic under normal conditions are the hydroxy and carboxy groups. Neither of these exibits as large a swing in Hammett substituent constant when going from non-ionized to ionized forms as the amino group, but together they may offer an opportunity to observe the effect of ionization state on the redox behavior of porphyrins.

In the set of experiments to be described below, the state of ionization of the substituents at the para position on the four phenyl rings of a tetraphenylporphyrin is adjusted by the addition of a Brönsted acid, a proton donor. This proton donor could be acetic acid, sulfuric acid, or trifluoroacetic acid.

The effect of the added proton donor on the shape and number of voltammetric peaks is observed and correlated with observed spectroscopic changes. Several different models are available for use in interpreting the effects of such additions on the electrochemistry of organic compounds. These will be discussed in the following section.

\section{Ionization Effects on Electrochemistry}

There are several possible ways in which the addition of proton donors can affect the observed electrochemical behavior of porphyrins. The simplest of these is that the proton donor interacts primarily with bulk solution-phase porphyrin, changing its state of ionization. The ionized porphyrin would be expected to be either easier or harder to reduce, as predicted by the changing electron-donating nature of the four substituents attached on the phenyl rings. This bulk ioniza- 
tion mechanism is represented below in Equations [19]-[20], where $\mathrm{P}$ represents a neutral, free-base porphyrin.

$$
\begin{aligned}
& \mathrm{P}+\mathrm{H}^{+} \longrightarrow \mathrm{PH}^{+} \\
& \mathrm{PH}^{+}+\mathrm{e}^{-} \longrightarrow \mathrm{PH} \bullet
\end{aligned}
$$

In the case of TAPP, the electron-donating ability of the four amino- substituents makes this porphyrin harder to reduce than the unsubstituted TPP. In this simplest of approximations, protonating the four amino groups of TAPP should make those substituents electron-withdrawing, yielding a porphyrin that should be easier to reduce than TPP.

This can be quantified using the Hammett equation as shown in Equations [21]-[23].

$$
\begin{aligned}
\Delta E & =E^{\circ} \operatorname{TAPP} \text { (unprotonated) }-E^{\circ} \operatorname{TAPP} \text { (protonated) } \\
& =\left(E^{\circ} \mathrm{TPP}+4 \cdot \sigma_{x} \cdot \rho\right)-\left(E^{\circ} \mathrm{TPP}+4 \cdot \sigma_{y} \bullet \rho\right) \\
& =4 \cdot \rho \bullet\left(\sigma_{x}-\sigma_{y}\right)
\end{aligned}
$$

Calculating $\Delta \mathrm{E}$ for the amino vs. ammonium substituents, one finds that Hammett substituent constants lead one to expect a shift in reduction potential of $228 \mathrm{mV}$ from TAPP to $\mathrm{TAPP}^{+4}$.

An example of this type of behavior is the reduction of pyrimidine in acetonitrile. ${ }^{68}$ In nominally anhydrous acetonitrile, pyrimidine is reduced in a one-electron, diffusion-controlled process. Addition of acid to pyrimidine solutions in acetonitrile results in the appearance of a new wave at more 
positive potentials which the authors attribute to reduction of the $\mathrm{N}$-protonated species to produce a neutral free radical. But proton donors can participate in electrochemical reactions directly, in addition to simple acid-base effects on the bulk, dissolved species. Reduction of porphyrins forms the radical anion; further reduction forms the dianion.21-24 A sufficiently high concentration of proton donors can protonate the anion radical to form a neutral radical as shown in Equations [24]-[27], ${ }^{4}$ where $P$ represents a neutral free base porphyrin.

$$
\begin{aligned}
& \mathrm{P}+\mathrm{e}^{-} \quad \longrightarrow \mathrm{P}^{-\bullet} \\
& \mathrm{P}^{-\bullet}+\mathrm{H}^{+} \longrightarrow \mathrm{PH} \bullet \\
& \mathrm{PH} \cdot+\mathrm{e}^{-} \longrightarrow \mathrm{PH}^{-} \\
& \mathrm{PH}^{-}+\mathrm{H}^{+} \longrightarrow \mathrm{PH}_{2}
\end{aligned}
$$

In the course of investigating the reaction mechanism of the electroreduction of organic compounds, many researchers have conducted experiments in which they observe the effects of controlled additions of proton donors. These proton donors include alcohols or quinones, or may be just water. Indeed, the usual rationale for experiments in which proton donors are added to solutions of electrochemically active reagents is due to the ubiquitous presence of water in nominally pure organic solvents. One way to make certain that the observed behavior of electroreagents in organic solvents does not depend on the presence of water is to make controlled additions of water or 
other proton donors and extrapolate observed effects back to zero water content.

It has been shown that neutral radicals formed from protonation of aromatic radical anions should be reduced at a more positive potential than the parent compound. ${ }^{69}$ This means that both the parent compound and the neutral radical will be reduced simultaneously, usually involving more than one electron.

As an example of this type of behavior, pyridine, pyrazine, and pyridazine in acetonitrile in the presence of acid are reduced in overall two-electron processes that are postulated to follow an "ECE" mechanism. ${ }^{68}$ This notation refers to the type and order of reaction mechanism steps postulated to occur in a given reaction. "ECE" indicates that the mechanism of reaction is believed to involve an electrochemical electron transfer followed by a chemical reaction, which is in turn followed by another electrochemical electron transfer.

In this case, an initial one-electron reduction occurs, after which the radical anion generated abstracts a proton from an available proton source to form a neutral free radical. The neutral free radical is electroactive at the potential at which it is formed, and therefore is immediately reduced at the potential of its formation. ${ }^{68}$ The observed response is thus that of a single 2-electron wave shifted to more positive potentials than the original reduction to radical anion.

There are many other examples of such behavior in the literature. The electrochemical reductions of aromatic 
hydrocarbons such as anthracene or naphthalene, 70 or substituted oxazoles and oxadiazoles (5-membered heterocyclic compounds containing nitrogen and oxygen), ${ }^{71}$ or azo compounds such as azobenzene or benzo[c]cinnoline, 72 in the presence of proton donors can be modeled using an ECE reduction mechanism.

If the above mechanism occurs with the addition of proton donor to solutions of porphyrins, it would mean that, independent of the substituent on the porphyrin, addition of proton donor will always cause a new peak to grow in at potentials more positive than that of the neutral, parent porphyrin.

The contrast in the electrochemical behavior between pyrimidine and the related compounds pyridine, pyrazine, and pyridazine with respect to the effect of available proton donors points out how relatively minor structural differences can lead to different reaction mechanisms.

\section{Ionization Effects on Porphyrin Electrochemistry}

There has been little direct investigation into the effect of proton donors on the electrochemistry of porphyrins. peychal-Heiling and Wilson ${ }^{24}$ published early polarographic and voltammetric studies of porphyrins and their derivatives. In addition to their other types of experiments, they report the effect of controlled additions of water on the electrochemical behavior of tetraphenylporphyrins and porphyrin IX derivatives.

As an example of the response of a porphyrin IX derivative, deuteroporphyrin IX dimethyl ester in nominally aprotic DMF yields three reduction waves; the first two are reversible one-electron reactions and the third is an irreversible 
wave involving more than one electron. ${ }^{24 a}$ Similar results were obtained for the other porphyrin IX derivatives studied. The first two waves are unaffected by addition of water to the electrochemical solutions, but the third wave is increased in height and shifted to more positive potentials with addition of $0.5 \%(\mathrm{v} / \mathrm{v})$ water.

Through the use of thin-layer spectroelectrochemistry, the authors deduced the mechanism of reduction. The parent porphyrin is reduced in a reversible one-electron step to the radical anion. This is followed in the second wave by reduction of the radical anion to the dianion.

In the presence of protons, the first electrochemical reaction (reduction to radical anion) is followed by a chemical reaction: disproportionation of two radical anions to reform the parent porphyrin and with it the anion of the phlorin derivative of the parent. This phlorin derivative is then further reduced in the third wave to complete an ECE mechanism which is shown in Equations [28]-[30].

$$
\begin{aligned}
& \mathrm{P}+\mathrm{e}^{-} \longrightarrow \mathrm{P}^{-\cdot} \\
& 2 \mathrm{P}^{-\cdot}+\mathrm{H}^{+} \longrightarrow \mathrm{PH}^{-}+\mathrm{P} \\
& \mathrm{PH}^{-}+2 \mathrm{e}^{-}+\mathrm{H}^{+} \longrightarrow \mathrm{PH}_{2}^{-2}
\end{aligned}
$$

These results are to be compared with the equivalent studies performed by Peychal-Heiling and wilson on tetraphenylporpyrin (TPP). $24 \mathrm{~b}$ Reduction of TPP in DMF yields two reversible, one-electron waves which are the same as those observed in this thesis research in DMSO. These are followed by 
two irreversible, multi-electron transfers (which are not observable in DMSO).

The first two reductions are unaffected by addition of water up to $1.5 \%(\mathrm{v} / \mathrm{V})$. The fourth wave decreased in height and shifted to more positive potentials, which resulted in an increase in the third wave. Water is a weak acid in DMF, so the above results may not hold true if a strong acid is used, however, the results do suggest that an ECE mechanism is not appropriate for modelling the response of the first two tetraphenylporphyrin reductions to acid additions.

More recent work by Murray ${ }^{73}$ investigated the electrochemistry of tetraphenylporphyrin protonated prior to reduction. The center ring of a porphyrin can accommodate up to two additional protons to form the diprotonated species $\mathrm{H}_{2} \mathrm{TPP}^{+2}$. Only the diprotonated species has been detected; it is thought that the mono-protonated species is a less stable geometry which rapidly adds a second proton. ${ }^{74}$

Titration of benzonitrile solutions of TPP with perchloric acid used cyclic voltammetry as an indicator. Upon addition of $\mathrm{HClO}_{4}$, a reversible wave grows in at $-0.46 \mathrm{~V}$ (vs. SCE), while the wave that was formerly the first reduction of TPP shrinks proportionally. ${ }^{73}$ The transformation is complete after addition of 2 molar equivalents of acid, at which point the solution has changed color from purple-red to deep green. This is shown in Figure 20 .

Murray hypothesizes that the solution at this point contains primarily $\mathrm{H}_{2} \mathrm{TPP}^{+2}$, and that the wave at $-0.46 \mathrm{~V}$ represents the electrochemistry of this species. This new 


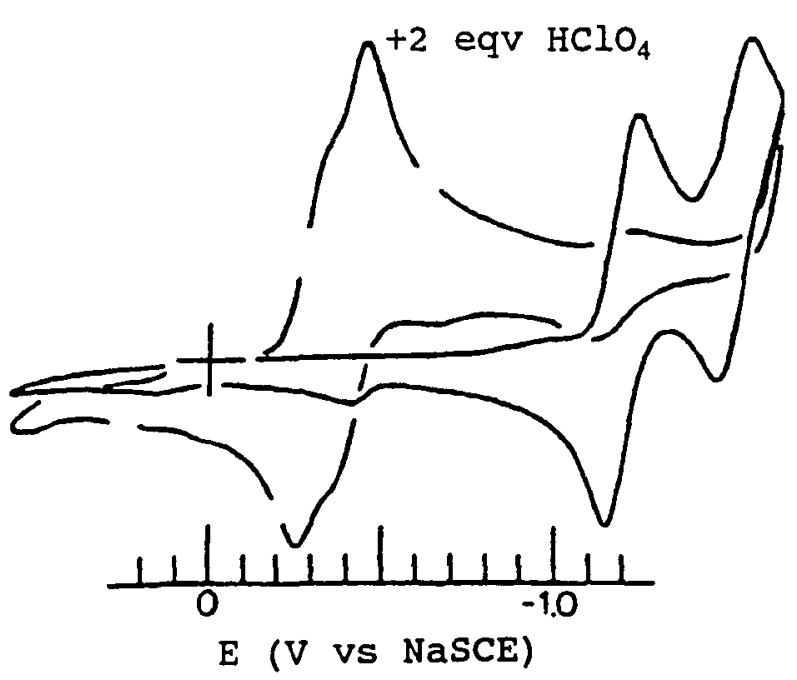

Figure 20. Voltammetry of TPP in benzonitrile. Solid line: no added açid; broken line: 2 equiv. perchloric acid added.

wave is more accurately described as a pair of overlapping waves. Murray postulates that the splitting of the reduction wave results from ion association effects rather than the monoprotonated $\mathrm{HTPP}^{+}$, since the reduction potential of $\mathrm{H}_{2} \mathrm{TPP}^{+2}$ is somewhat dependent on the anion present $\left(\mathrm{ClO}_{4}{ }^{-}\right.$in this case). With nitrate as the counterion, the wave appears at $-0.50 \mathrm{~V}$, and chloride yields a wave at $-0.61 \mathrm{~V}$.

\section{MATERIALS AND METHODS}

Materials

Copper tetraphenylporphyrins were synthesized by refluxing a DMF solution of the porphyrin and $\mathrm{Cu}$ (II) acetate with 3 drops of gl. acetic acid added. The product of this reaction was washed with water until the wash water ceased to be blue, and then oven-dried $\left(60^{\circ} \mathrm{C}\right.$ ) under vacuum ( 1 torr) for $24 \mathrm{hr}$. Other porphyrins are as described in chapter I. 
Aldrich spectroscopic grade DMSO was used in all experiments. Some experiments involving acidic porphyrins were conducted in DMSO saturated with LiOH (Aldrich Gold Label). Saturation was assured by allowing the DMSO to sit over LiOH for at least $24 \mathrm{hr}$.

Acidic DMSO solutions were prepared by adding acid to a volumetric flask and diluting with DMSO to just below the mark. After sufficient time for cooling of the solution, the flask was filled to the mark. Standardization of these solutions was accomplished by diluting the solution of acid in DMSO 1 to 10 in deionized water, adding 2 drops of $0.2 \%$ phenolphthalein, and titrating with a standard solution of sodium hydroxide (standardized using oven-dried kHP, potassium hydrogen phthalate).

Methods

Basic and neutral porphyrins (TAPP and TPP and their copper derivatives) were investigated in DMSO with added acid in the form of an acidic solution of DMSO. These experiments were otherwise conducted as per the description in Chapter I. The acid solution was added via 10 or $100 \mu l$ syringe after a voltammogram of the neutral porphyrin was recorded. A equilibration period of at least $5 \mathrm{~min}$. was allowed after each addition before taking a voltammogram for additional stirring and purging with nitrogen.

Acidic porphyrins (TCPP) were investigated in DMSO and DMSO saturated with LiOH. Acid was added via syringe as above. 
Simultaneous spectroscopic and voltammetric studies were performed as follows. After an aliquot of acid solution was added and a voltammogram of the resulting solution recorded, a $0.5 \mathrm{ml}$ aliquot of the porphyrin solution was removed and placed in a spectroscopic cell of $0.1 \mathrm{~cm}$ pathlength. A spectrum of the solution was recorded and the aliquot quantitatively returned to the electrochemical vessel.

\section{RESULTS AND DISCUSSION}

\section{Acid in DMSO}

Whenever acid is titrated into DMSO, an additional electrochemical reaction is observable. The reduction of hydrogen ion $\left(\mathrm{H}^{+}\right)$to $\mathrm{H}_{2}$ has a thermodynamic reduction potential of $0.00 \mathrm{~V}$ vs. the normal hydrogen electrode, or $-0.24 \mathrm{~V}$ vs. the standard calomel electrode (SCE). Because of kinetic barriers to this reaction, a more reducing potential than this is required to actually carry out this reaction; this is termed the reaction overpotential. In practice, this overpotential depends on the type and condition of the working electrode used as well as the nature of the solvent and electrolyte system.

At a platinum electrode in DMSO with tetraalkylammonium salts as the electrolyte, the $\mathrm{H}^{+} / \mathrm{H}_{2}$ reaction is observed at -1.6 to $-1.9 \mathrm{~V}$ vs. SCE. This is shown in Figure 21. Figure 21 happens to be a solution of ZnTHPP with a great excess of $38(\mathrm{v} / \mathrm{v}) \mathrm{H}_{2} \mathrm{SO}_{4}$ added. The wave due to reduction of $\mathrm{nnTHPP}$ can be made out at $\approx-1.0 \mathrm{~V}$, but that signal is overwhelmed by the irreversible reduction of hydrogen ion that has a peak at $-1.85 \mathrm{~V}$. 


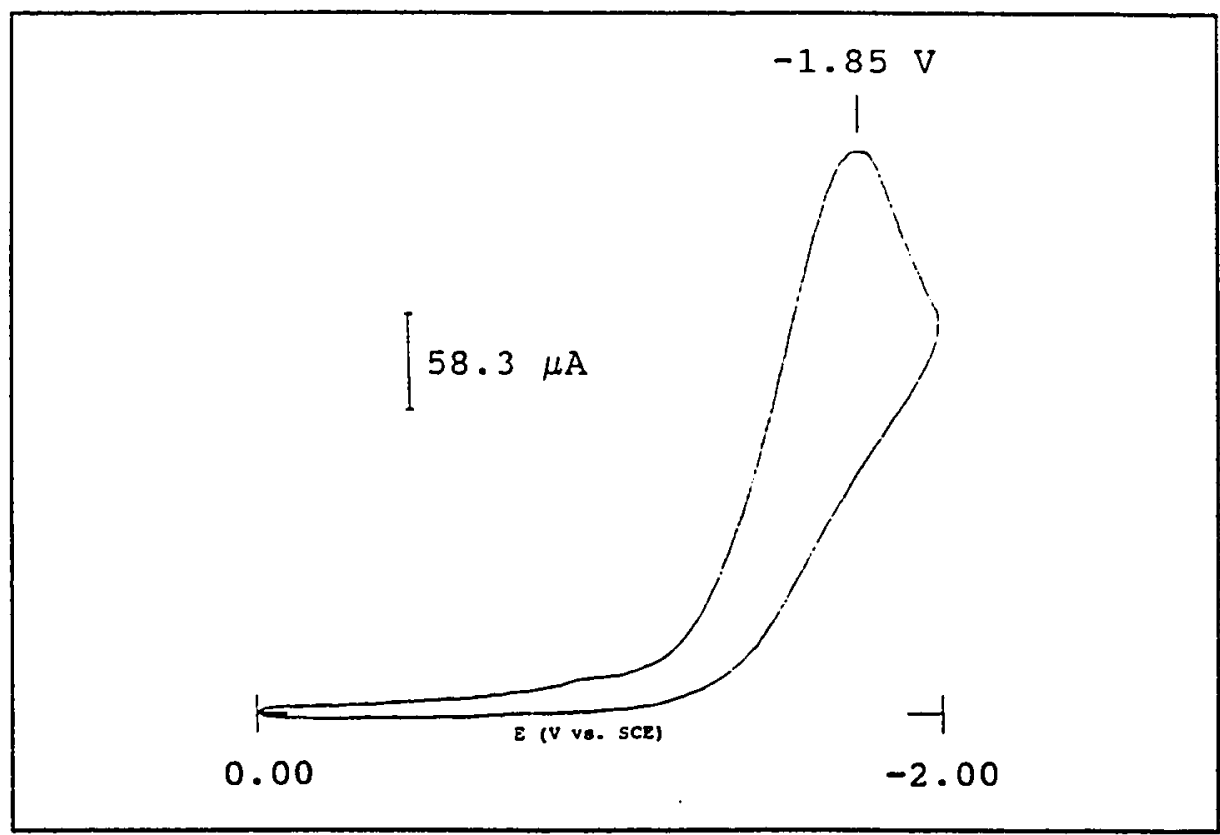

Fiqure 21. Reduction of hydrogen ion in DMSO.

The wave due to reduction of hydrogen ion is present in all voltammograms of acidified DMSO solutions, but occurs at potentials more negative than those of interest with regard to porphyrin electrochemistry. However, because the current due to reduction of hydrogen ion can be much larger in magnitude than that due to reduction of porphyrin, its effect can be seen in an upward trend in the current observed at the most negative potentials represented in voltammograms of acidic solutions of porphyrins.

\section{Acidic Porphyrin}

Addition of a solution of acid to TCPP solutions in DMSO would not be expected to result in variations in substituent electron-donating or -withdrawing ability due to protonation of the carboxy substituents. Those substituents are presumed to be protonated in neutral DMSO and, when protonated, are not 
very basic. Despite this, with the addition of 50 equivalents of trifluoroacetic acid to a solution of TCPP, the peak of the reduction wave of TCPP shifts from its original potential of $-1.01 \mathrm{~V}$ to $-0.90 \mathrm{~V}$. Simultaneously, a shoulder grows in on the reduction wave at $\approx-0.6 \mathrm{~V}$. This is shown in Figure 22 . (The above equivalents of acid value is reported as equivalents of acid per mole of porphyrin - it must be remembered that each mole of porphyrin has 4 moles of substituents.)

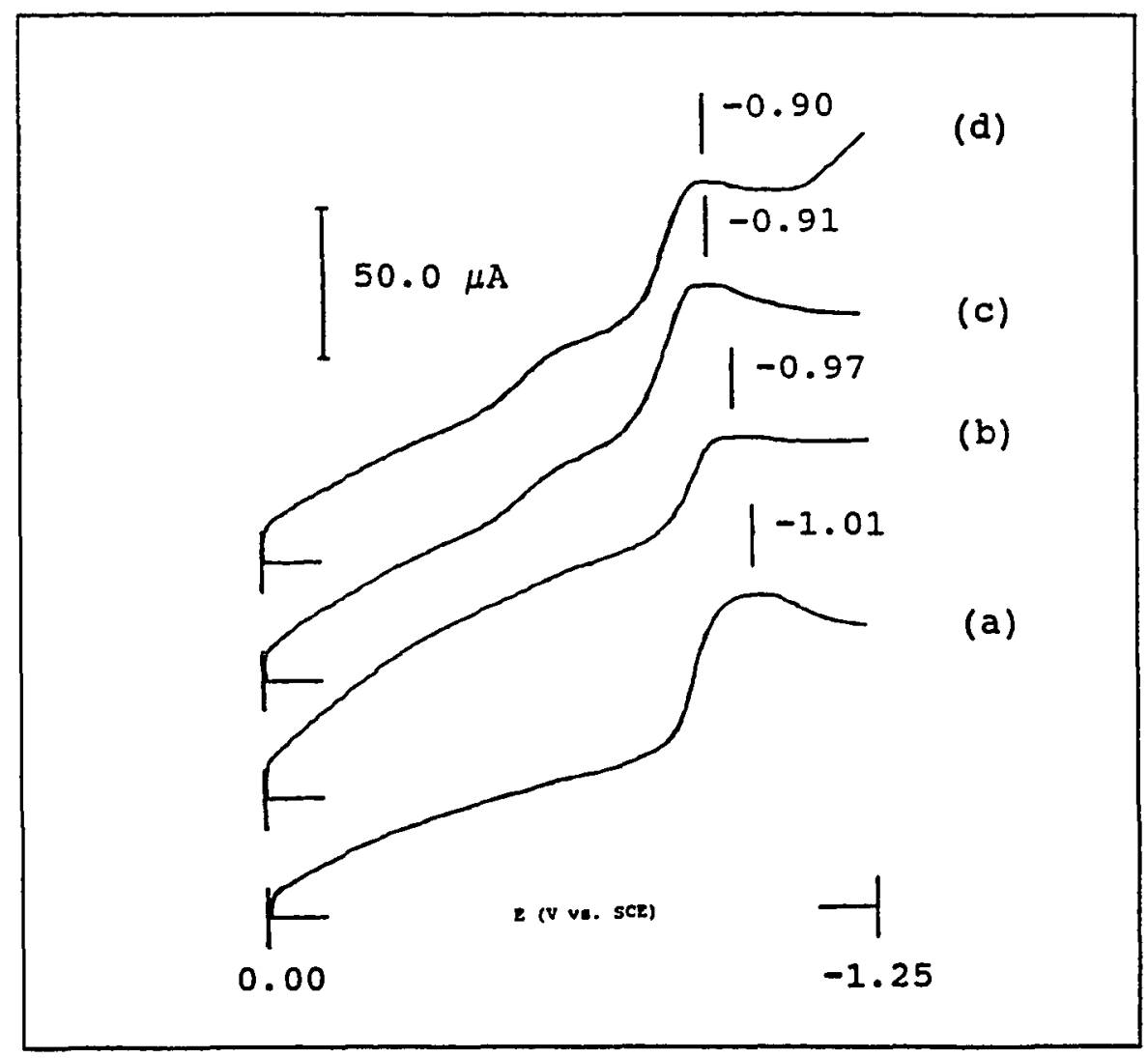

Fiqure 22. Effect of acid on TCPP voltammetry. Trifluoroacetic acid was used, $[\mathrm{TFA}]=1 * 10^{-6} \mathrm{eq} / \mu 1$, [TCPP $]=3 * 10^{-4} \mathrm{M}$. (a) no added acid; (b) total 20 $\mu I$ TFA added; (C) $40 \mu 1$; (d) $60 \mu \mathrm{l}$.

If the same experiment is conducted using DMSO that has been saturated with $\mathrm{LiOH}$, the peak of the original reduction 
of TCPP is at $-1.04 \mathrm{~V}$. With addition of 50 equivalents of trifluoroacetic acid, this peak again shifts to more positive potentials. The final value of the peak of the reduction wave is $-0.90 \mathrm{~V}$, the same as that observed after acidification beginning with neutral DMSO. This is shown in Figure 23.

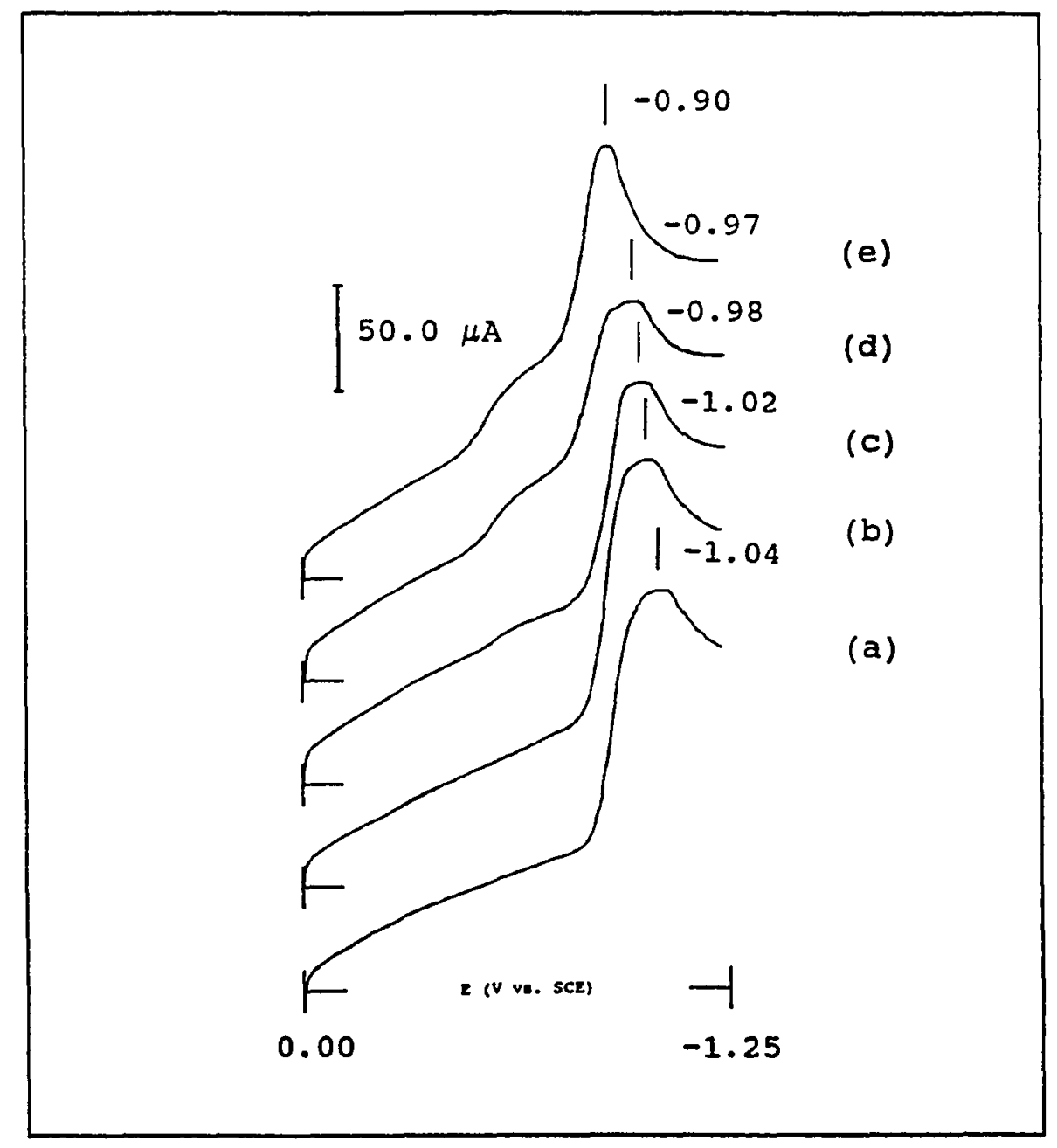

Figure 23. Effect of acid on TCPP voltammetry in basic DMSO. TFA used as acid, $[$ TFA $]=1 * 10^{-6} \mathrm{eq} / \mu 1$, $[$ TCPP $]=5 * 10^{-4}$. (a) no added acid; (b) $20 \mu l$ acid added; (c) $40 \mu \mathrm{l}$; (d) $60 \mu \mathrm{l}$; (e) $80 \mu \mathrm{l}$.

If the observed shift in peak potential of TCPP can be attributed to protonation of the substituent carboxy groups, 
this implies that that "neutral" TCPP will take up protons on the substituents prior to protonation of inner-ring nitrogens (which is shown by the growth of the shoulder at $-0.6 \mathrm{~V}$ ). This can be explained by either the singly-protonated carboxy groups acting as bases by accepting a second proton, or alternatively, by postulating that the "neutral" TCPP voltammogram actually represents the electrochemistry of the partially deprotonated species $T C P P^{-n}$, where $n=1$ to 3 .

In the latter explanation, bulk TCPP is partially ionized prior to the addition of trifluoroacetic acid, so that addition of acid returns the porphyrin to a predominantly neutral state which is reduced at $-0.90 \mathrm{~V}$. This explanation is plausible in that the solvent DMSO is a good base, and might be expected to assist dissociation of an acidic porphyrin such as TCPP. Performing the same experiment in DMSO with added base only exaggerates the effect: presumably the porphyrin in this case starts out completely deprotonated as $\mathrm{TCPP}^{-4}$, and with the addition of acid the porphyrin's state of ionization is pushed back through the state present in pure DMSO to the neutral state, which is again reduced at $-0.90 \mathrm{~V}$.

In Figure 10 of Chapter $I$, the value of $E_{\frac{1}{2}}$ that was used in plotting the point for TCPP $(\mathrm{X}=\mathrm{COOH})$ was that obtained in "neutral" DMSO. Whether in fact the species responsible for this reduction potential was partially ionized $\left(\mathrm{X}=\mathrm{COO}^{-}\right)$ TCPP, using a sigma value appropriate to that substituent ( $\sigma$ $=-0.05,4 \sigma=-0.20$ ) results in better agreement with the correlation presented in Figure 10. This conclusion is borne out by the agreement in Figure 10 of the starred points shown 
to the least squares best fit line for the first reduction reaction. These points are based on $E_{\frac{1}{2}}$ values derived from Figure 23 for fully ionized $\left(-\mathrm{COO}^{-*}\right)$ and fully protonated $\left(-\mathrm{COOH}^{*}\right)$ TCPP.

\section{Non-Ionizable Porphyrin}

In the category of non-ionizable porphyrins stands the parent porphyrin, TPP. With no acidic or basic substituents, one would expect that only the inner-ring nitrogens of the porphyrin could act as bases. It would therefore be predicted that with addition of acid no shift in potential should occur for the first reduction of TPP, although the experiments of Murray ${ }^{73}$ lead one to expect that with addition of acid a new wave will grow in at very easily reduced potentials due to formation of $\mathrm{H}_{2} \mathrm{TPP}^{+2}$.

In fact some shift of the original reduction wave of TPP is observed. With no added acid TPP is reduced in a wave with a peak of $-1.06 \mathrm{~V}$. After 7 equivalents of acid, the original peak has shifted to -1.02 and a new wave is growing in at $-0.65 \mathrm{~V}$. After 10 equivalents of acid, the original peak has shifted to -1.00 , and thereafter only the new peak at -0.65 is observed. This is shown in Figure 24.

Figure 25 shows the result of another experiment in which additional acid was added to push the equilibrium further over towards the $\mathrm{H}_{2} \mathrm{TPP}^{+2}$ form. The new wave growing in in this case has a peak at $-0.49 \mathrm{~V}$ with return oxidations at $-0.42 \mathrm{~V}$ and $-0.28 \mathrm{~V}$. Calculating an $\mathrm{E}_{\frac{1}{2}}$ using the former oxidation 


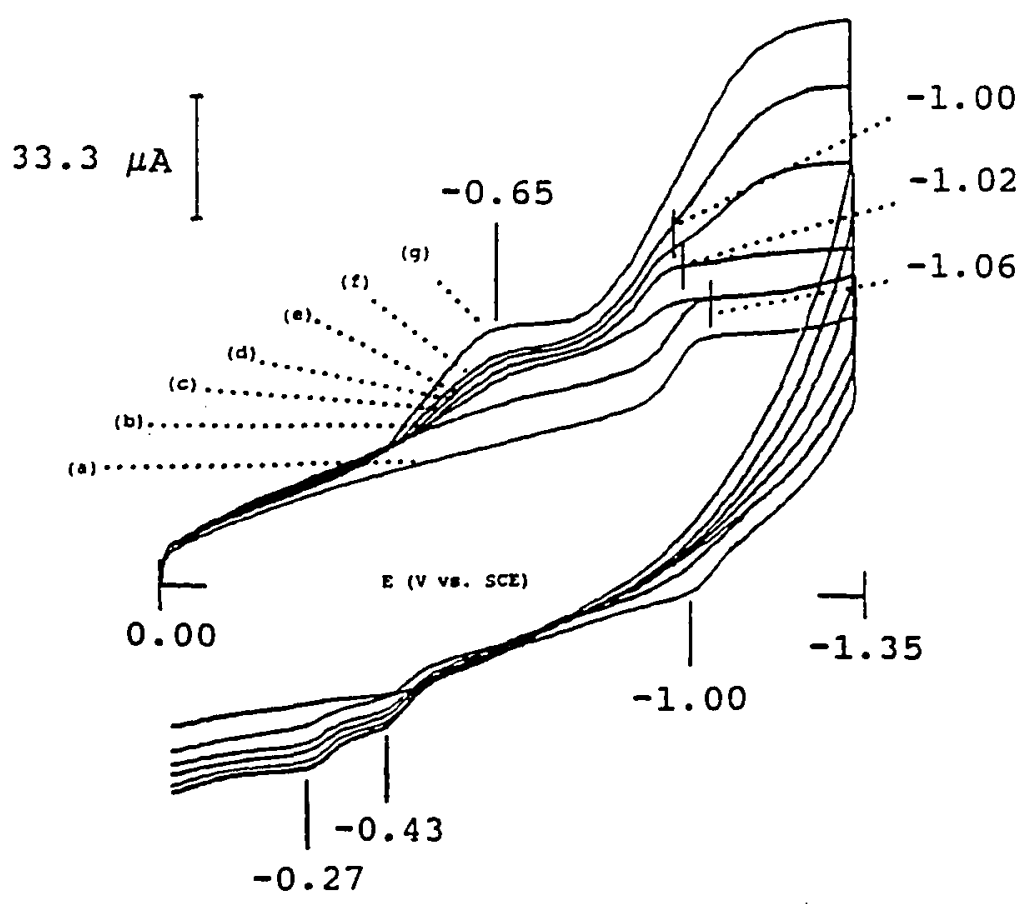

Fiqure 24. Effect of acid on TPP voltammetry. Sulfuric acid was used, $\left[\mathrm{H}_{2} \mathrm{SO}_{4}\right]=3.5 * 10^{-9} \mathrm{eq} / \mu \mathrm{l}$, [TPP] $=5 * 10^{-5}$. (a) no added acid; (b) $5 \mu \mathrm{l}$ acid added; (c) $10 \mu \mathrm{Ll}$ (d) $15 \mu \mathrm{l}$; (e) $25 \mu \mathrm{l}$; (f) $35 \mu \mathrm{l}$; (g) $45 \mu l$.

wave yields $E_{\frac{1}{2}}=-0.46 \mathrm{~V}$, which is very close to that reported by Murray. ${ }^{73}$

One way to test the hypothesis that $\mathrm{H}_{2} \mathrm{TPP}^{+2}$ is the species responsible for the growth of the new wave at $-0.45 \mathrm{~V}$ is to investigate the electrochemical behavior of the analogous metallated porphyrin. Inner-ring nitrogens of metalloderivatives should not act as bases to Bronsted acids since they are ligated to the metal. In this case, $\mathrm{Cu}$ (II)TPP was used in a similar experiment in which unstandardized $3 \%(\mathrm{v} / \mathrm{v})$ $\mathrm{H}_{2} \mathrm{SO}_{4}$ was added to a solution of CuTPP. The results are shown in Figure 26. 


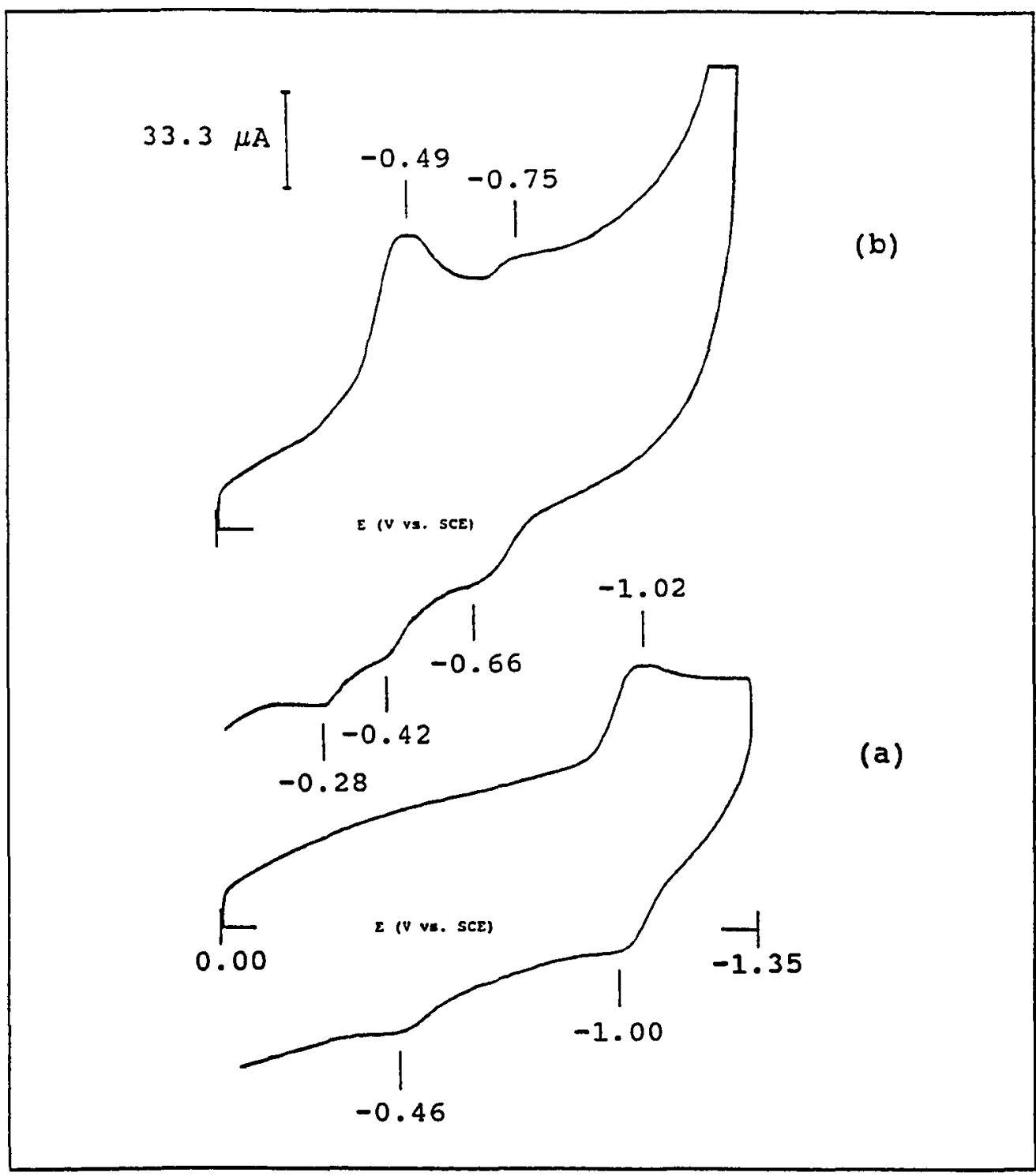

Figure 25. Comparison of voltammetry of neutral and acidified TPP. Unstandardized 38 (v/v) $\mathrm{H}_{2} \mathrm{SO}_{4}$ was used, $[\mathrm{TPP}]=1.5 * 10^{-4}$. (a) no added acid; (b) $55 \mu l$ acid added.

With no added acid the porphyrin solubility is low, giving rise to low Faradaic currents. An $E_{\frac{1}{2}}$ of $-1.16 \mathrm{~V}$ can nevertheless be determined from the voltammogram. Additions of acid resulted in the appearance of a new wave at $-0.63 \mathrm{~V}$. On first examination one concludes that this wave is evidence 


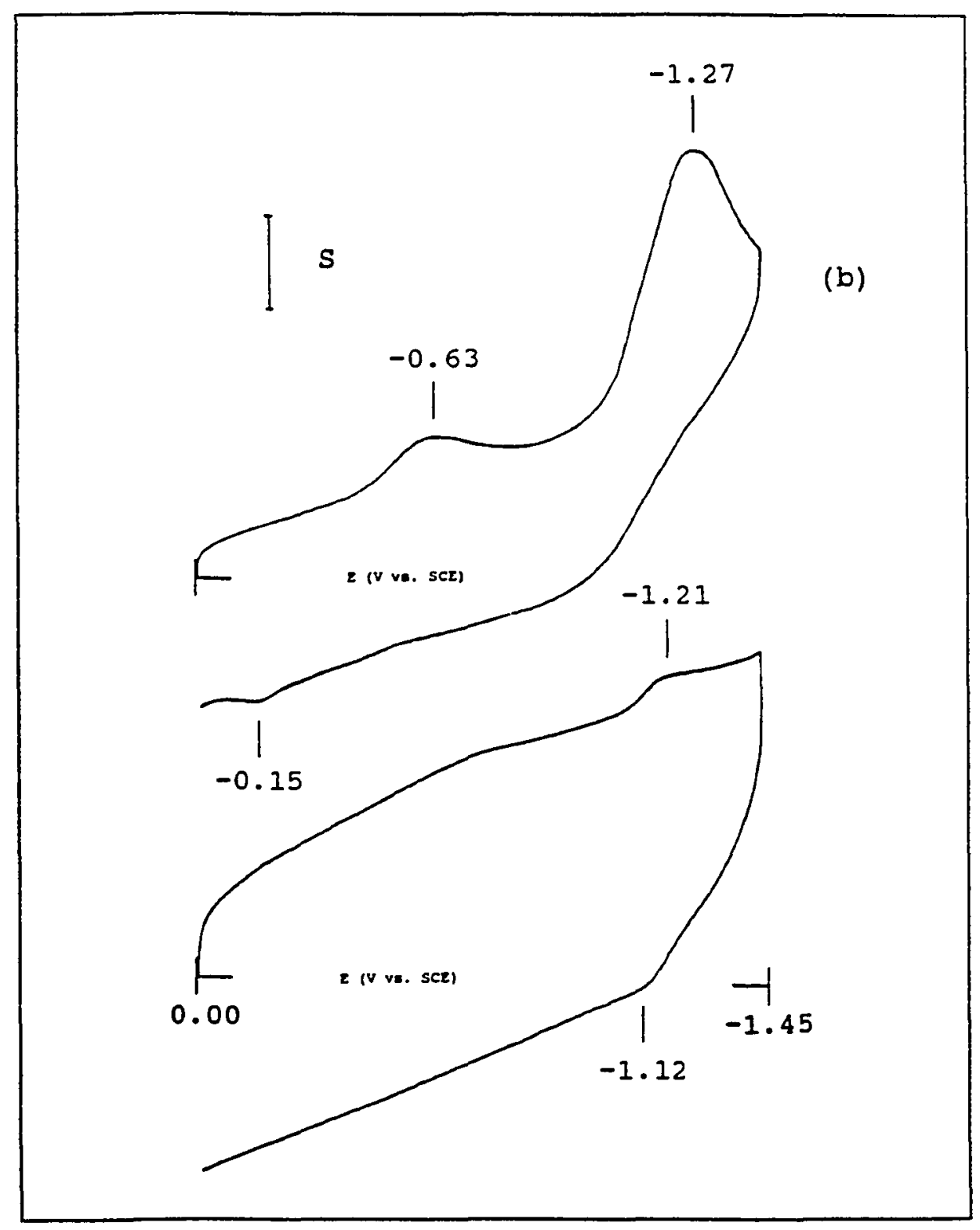

Figure 26. Effect of acid on CuTPP voltammetry. (a) $S=25 \mu \mathrm{A}$, no added acid; (b) $S=50 \mu \mathrm{A}, 10 \mu \mathrm{I}$ unstandardized $38(\mathrm{~V} / \mathrm{v}) \mathrm{H}_{2} \mathrm{SO}_{4}$ added. [CuTPP] unknown due to poor solubitity.

that an inner-ring-protonated porphyrin cannot be responsible for this wave (since CuTPP cannot have inner-ring-protonated nitrogens, yet has a wave at the approximately the same potential as the wave postulated to be due to such a species). 
Once present, the wave remained proportionally the same size relative to the wave resulting from reduction to the radical anion. This suggests an alternative explanation in which free base porphyrin exists as a contaminant in the copper derivative and is responsible for this wave. Since the CuTPP was not chromatographed or otherwise purified after synthesis, this is a reasonable hypothesis, and would explain why, having once appeared, the new wave does not grow at the expense of the original with additions of acid.

A curious phenomenon was observed with additions of acid: the peak current of the original reduction wave was increased many-fold, and its peak potential shifted to more negative values. The current rose to levels that are not consistent with the amount of porphyrin present in solution. With addition of $10 \mu \mathrm{l}$ of 38 acid, the peak current for the reduction of CuTPP had risen 22 fold. Further additions continued to increase the peak current until it was off-scale.

One explanation for this behavior is that the metal site in the porphyrin acts as a catalyst for the reduction of hydrogen ion, which is present in much higher concentrations in solution than the porphyrin. A catalytic mechanism is suggested in Equations [31]-[32], where $P$ represents a neutral porphyrin.

$$
\begin{aligned}
& \mathrm{P}+\mathrm{e}^{-} \longrightarrow \mathrm{P}^{-\cdot} \\
& 2 \mathrm{P}^{-\cdot}+2 \mathrm{H}^{+} \longrightarrow 2 \mathrm{P}+\mathrm{H}_{2}
\end{aligned}
$$

Since the thermodynamic potential for hydrogen reduction is at $-0.24 \mathrm{~V}$ (VS. SCE), the above represents a process that 
would lower the overpotential of the reaction and therefore itself exibit the magnitude of current usually seen in the hydrogen reduction peak. As with the hydrogen reduction wave, the new wave is also irreversible.

\section{Basic Porphyrin}

Porphyrins with basic substituents investigated in these experiments include TAPP and its metallo-derivative, CuTAPP. Addition of acid to solutions of TAPP derivatives is predicted to have a significant effect due to changes in the electrondonating ability of the substituents. As has been mentioned before, neutral amino substituents are among the most electron-donating of substituents, whereas addition of a proton to form the ammonium substituent creates one of the most electron-withdrawing of substituents.

Using a weak acid in experiments with TAPP results in the behavior shown in Figure 27. In this experiment, the acid solution added to the electrochemical solution was $508(\mathrm{v} / \mathrm{v})$ glacial acetic acid in DMSO. With no added acid TAPP has a reversible reduction with a peak at $-1.20 \mathrm{~V}$ and an $E_{\frac{1}{2}}$ of -1.16 V. An additional oxidation wave at $-0.65 \mathrm{~V}$ is also present. As acid solution is added, a shift in the peak of the reduction wave to more positive potentials is observed. The peak current of the anodic wave at $-1.12 \mathrm{~V}$ decreases while that of the anodic wave at $-0.65 \mathrm{~V}$ increases.

The quantity of acid solution necessary in order to see the above effects was quite large: by voltammogram (e) of Figure 27 , a total of $1.33 \mathrm{ml}$ of acid solution had been added, which would represent 10,000 equivalents per mole of porphyrin 


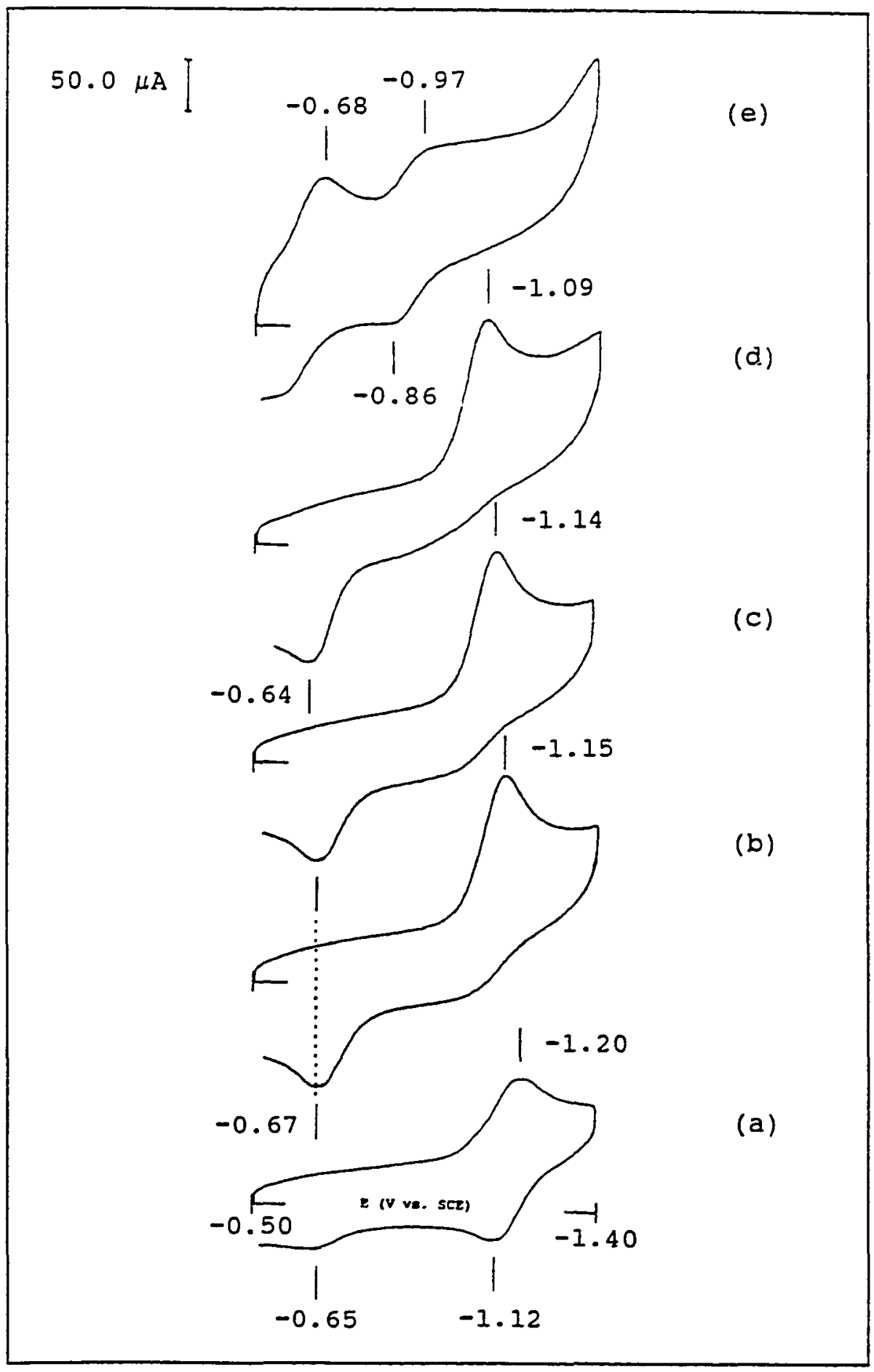

Figure 27. Effect of acetic acid on TAPP voltammetry. Unstandardized $50 \%(\mathrm{v} / \mathrm{v})$ gl. acetic acid used, [TAPP] $=9 * 10^{-5} \mathrm{M}$. (a) no added acid; (b) 4 $\mu l$ acid added; (c) $8 \mu l$; (d) $304 \mu l$; (e) $1328 \mu l$. 
if all of the acid was dissociated. However, the measurements of Kolthoff and Reddy ${ }^{75}$ on acid-base strength in DMSO yielded a $\mathrm{pK}_{\mathrm{a}}$ for acetic acid of 11.4 , which suggests that it would be expected for a great excess of acetic acid to be necessary in order to exert a comparable effect on an acid-base equilibrium as a much smaller quantity of strong acid (in contrast, Kolthoff and Reddy found sulfuric acid to be a strong acid in DMSO) .

Voltammogram (e) of Figure 27 shows that the original reduction wave of TAPP has been replaced with a broad, quasireversible $(\Delta E=109 \mathrm{mV})$ reduction with an $E_{\frac{1}{2}}$ of $-0.91 \mathrm{~V}$. It is not clear what species is responsible for this wave. There is a qualitative similarity between this voltammogram and the acidified TPP voltammogram shown in Figure 25 which may be significant. However, reduction potentials are different in the two cases: that of TPP is $-0.70 \mathrm{~V}(\Delta E=94 \mathrm{mV})$.

Different behavior is exhibited if a strong acid is added to the electrochemical solutions; both sulfuric and trifluoroacetic acid were investigated and found to elicit the same type of response. Figure 28 shows the effect of adding trifluoroacetic acid to TAPP solutions. As with the addition of the weak acid acetic acid, the anodic wave of the original first reduction shrinks in intensity at the expense of the second anodic wave (at $-0.67 \mathrm{~V}$ in the unacidified sample). However, other effects are not as in the case of weak acid additions .

The original first reduction wave of TAPP does not shift in potential as when acetic acid is added. Instead, a second wave at slightly more positive potentials grows at the expense 


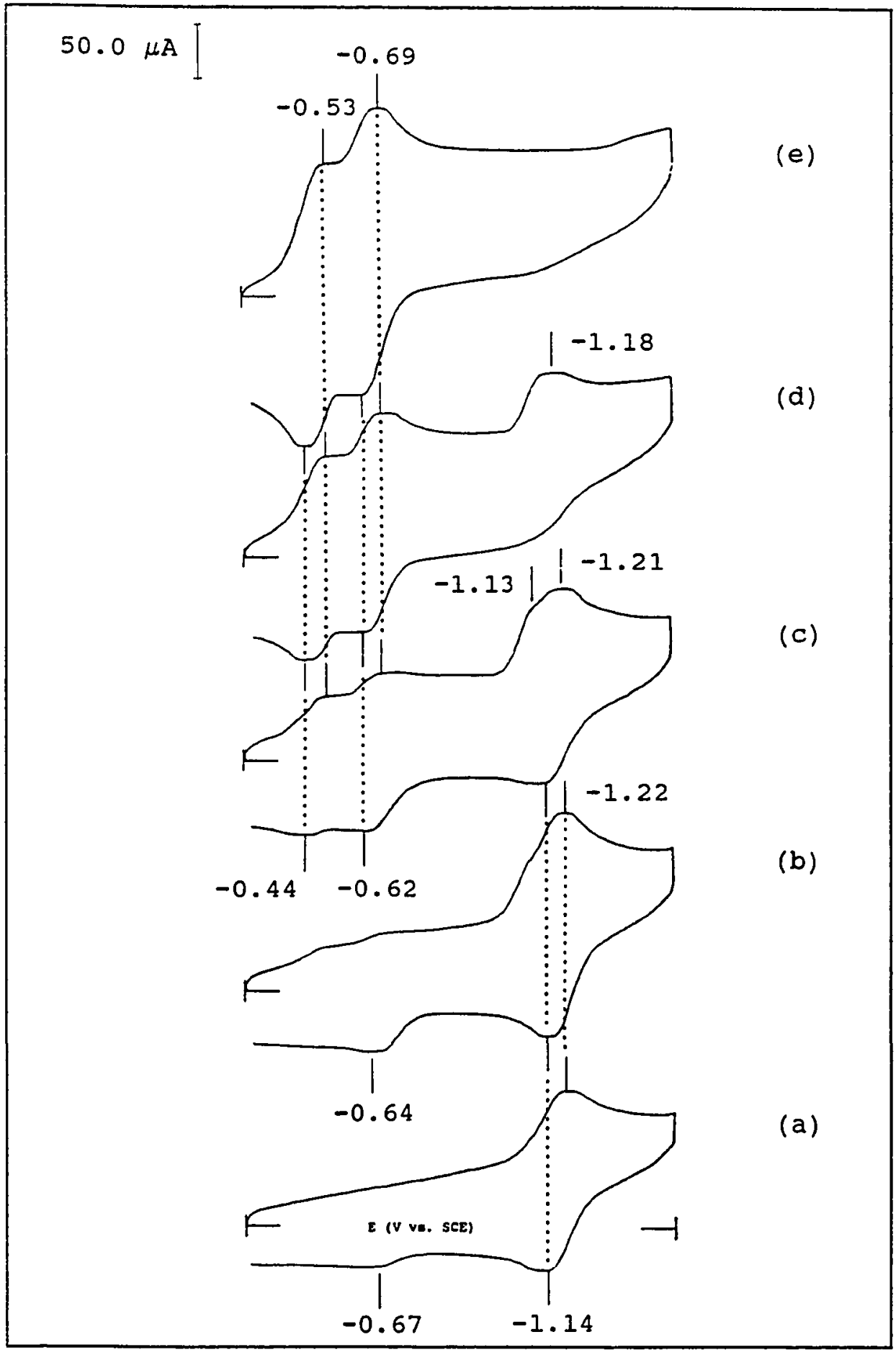

Fiqure 28. Effect of trifluoroacetic acid on TAPP voltammetry. [TFA] $=1 * 10^{-6}$ eq/ $\mu \mathrm{L},[$ TAPP $]=6 * 10^{-4}$ M. (a) no acid added; (b) $15 \mu \mathrm{l}$ acid added; (c) 35 $\mu \mathrm{I}$; (d) $65 \mu \mathrm{l}$; (e) $105 \mu \mathrm{l}$. 
of the original. Both of these waves are supplanted eventually by the growth of not one but two reduction waves at very easily reduced potentials. These differences are also observed with sulfuric acid as the proton donor.

A scan rate study on a solution with an intermediate amount of acid added (equivalent in concentration to (c) in Figure 28) was performed in order to see whether the two peaks represent species in an equilibrium, and if so, on what time scale the species are interconvertible. This is shown in Figure 29.

If the two adjacent waves of the original first reduction were caused by two species interconvertible on a short time scale, then slowing the scan rate should result in the more easily reduced wave gaining in intensity at the expense of the less easily reduced. In fact, this was not the case. Slowing from $100 \mathrm{mV} / \mathrm{sec}$ to a scan rate of $5 \mathrm{mV} / \mathrm{sec}$ resulted in better resolution of the adjacent waves, but their relative proportions remained the same. If the two species responsible for these waves are in equilibrium, then the equilibrium is slow on this time scale.

Investigations into the response of the metallated derivative CuTAPP Yielded similar behavior to that observed for CuTPP. Figure 30 shows the effect of additions of $3 \%$ sulfuric acid to a solution of CuTAPP, and Figure 31 shows a wider potential range of the same experiment with the original porphyrin solution and the final acidified solution. In this case also the copper derivative exhibits large increases in cathodic current with the addition of acid, which is attributed to catalysis of the $\mathrm{H}^{+} / \mathrm{H}_{2}$ reduction. No shift in peak 


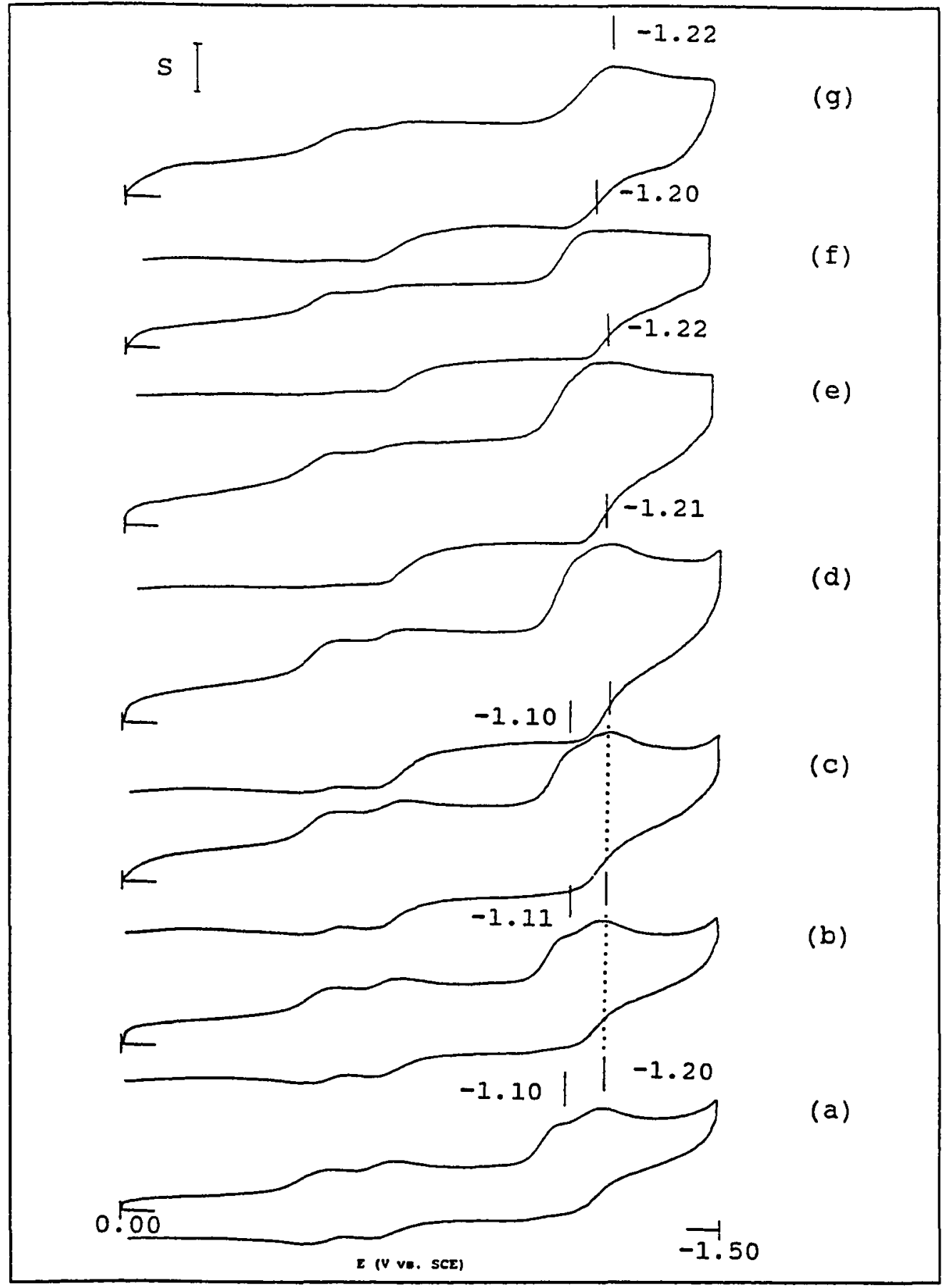

Figure 29. Scan rate study of the voltammetry of acidified TAPP. Scan rates and scales: (a) 5 $\mathrm{mV} / \mathrm{sec}, S=10 \mu \mathrm{A} ;$ (b) $10 \mathrm{mV} / \mathrm{sec}, S=12.5 \mu \mathrm{A}_{i}$ (c) $20 \mathrm{mV} / \mathrm{sec}, \mathrm{S}=14.3 \mu \mathrm{A} ;$ (d) $50 \mathrm{mV} / \mathrm{sec}, \mathrm{S}=20 \mu \mathrm{A}$; (e) $100 \mathrm{mV} / \mathrm{sec}, \mathrm{S}=33 \mu \mathrm{A}$; (f) $200 \mathrm{mV} / \mathrm{sec}, \mathrm{S}=67$ $\mu \mathrm{A} ;$ (g) $500 \mathrm{mV} / \mathrm{sec}, \mathrm{S}=100 \mu \mathrm{A}$. 


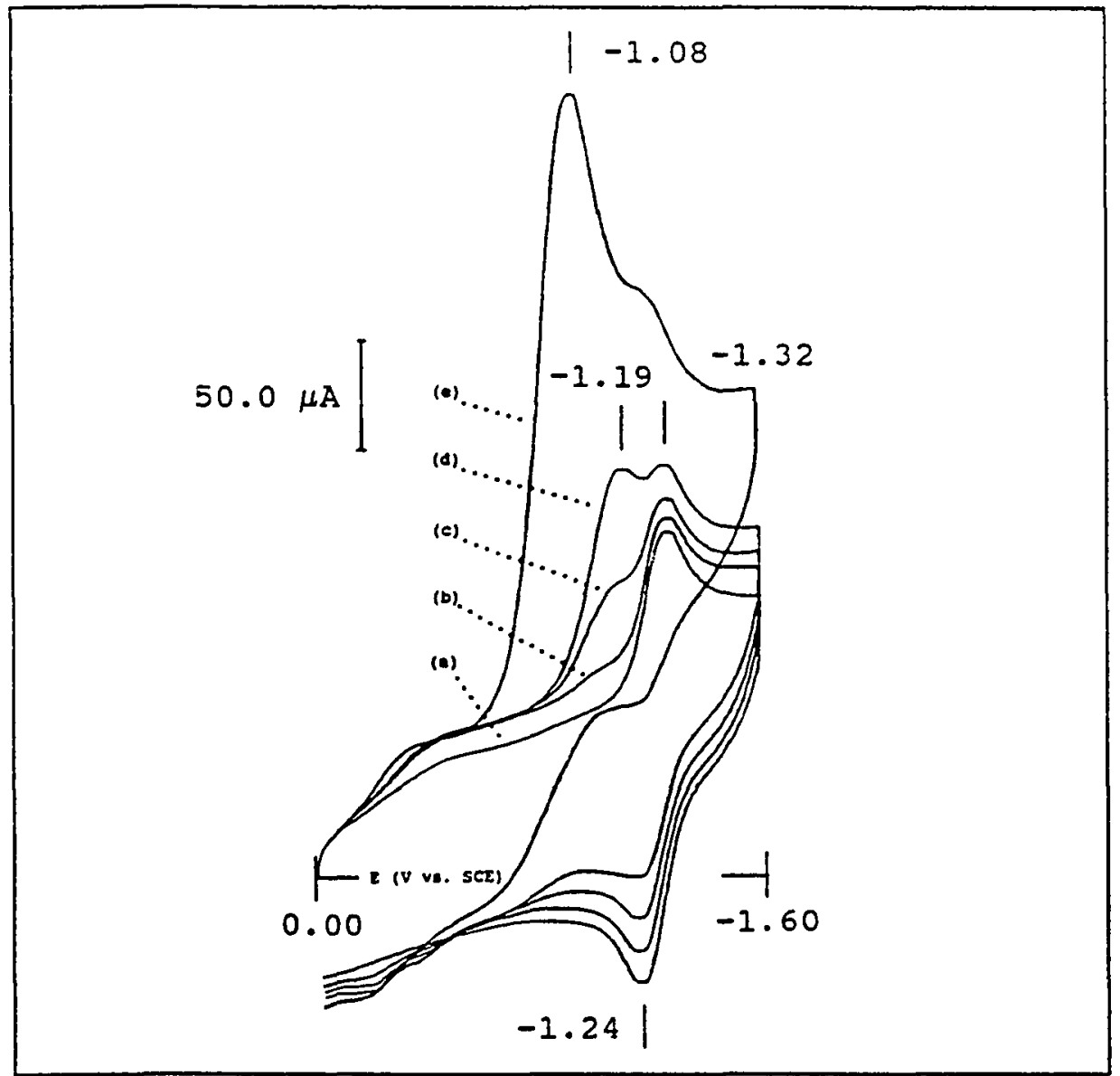

Fiqure 30. Effect of acid on CuTAPP voltammetry. Unstandardized $38(\mathrm{~V} / \mathrm{v}) \mathrm{H}_{2} \mathrm{SO}_{4}$ used, [CUTAPP] = $1 * 10^{-4}$. (a) no acid added; (b) $2 \mu l$ acid added; (c) $3 \mu l$; (d) $5 \mu l$; (e) $15 \mu l$.

potential with added acid was observed, instead a new wave grew in at potentials slightly more positive than the original. Simultaneously, the anodic portion of the original reduction wave decreased in intensity while intensity increased at another anodic wave $(-0.13 \mathrm{~V})$.

Most importantly, no new cathodic wave appeared at very easily reduced potentials. Since this wave was postulated to be due to the doubly-inner-ring-protonated porphyrin species which is prevented from forming from metalloporphyrins, these 


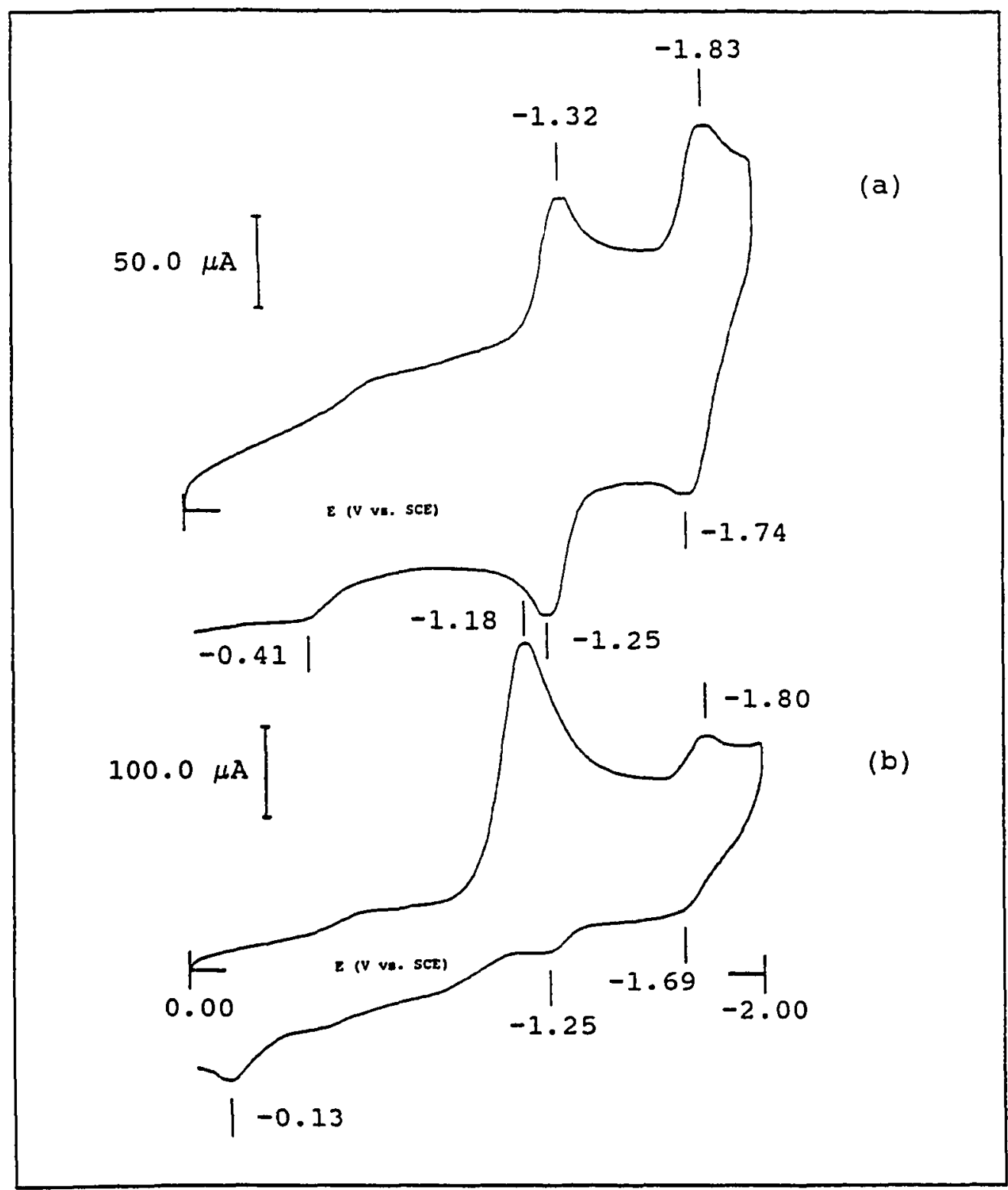

Figure 31. Large potential scale view of the effect of acid on CuTAPP voltammetry. (a) $s=50$ $\mu \mathrm{A}$, same as Figure $30(\mathrm{a}) ;(\mathrm{b}) \mathrm{S}=100 \mu \mathrm{A}$, same as Figure $30(e)$.

results are further evidence for this assignment of the species responsible for the new wave. 
Spectroscopic/Voltammetric Experiments

Experiments were performed in which UV/VIS spectra were taken of electrochemical solutions after every addition of acid in order to detect the presence of protonated porphyrin species. The change in molecular symmetry which results from protonation of the ring nitrogens of a porphyrin gives rise to distinct spectroscopic changes which can be monitored using visible spectroscopy. (As visual evidence of this, porphyrins change from deep purple-red in color in neutral solutions to bright green in acidic solution.)

As an example of this type of experiment, Figure 32 shows a spectrophotometric titration of $18(\mathrm{v} / \mathrm{v})$ sulfuric acid into a DMSO solution of TAPP. With added acid a shoulder appears

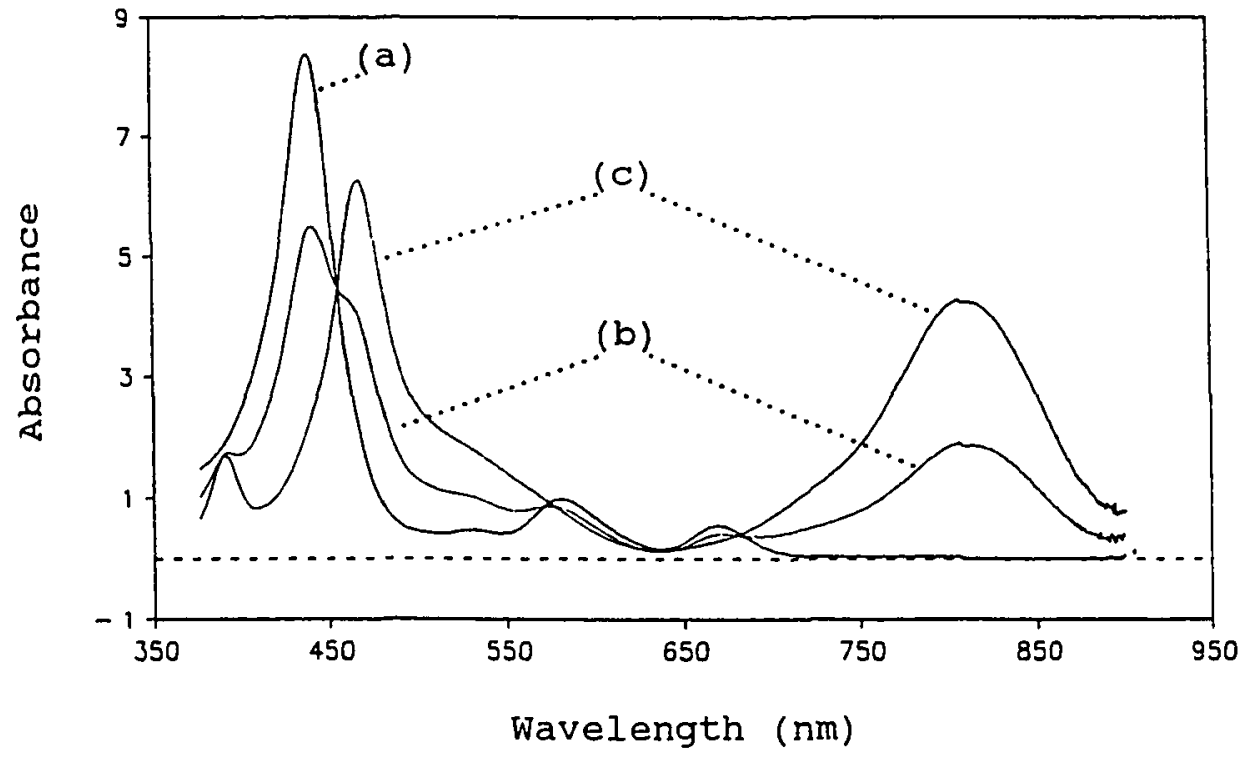

Fiqure 32. Changes in the visible spectrum of TAPP with added acid. (a): no added acid; (b) 3 eq. $\mathrm{H}_{2} \mathrm{SO}_{4}$ added; (c) 10 eq. $\mathrm{H}_{2} \mathrm{SO}_{4}$ added. 
on the red side of the Soret peak of the porphyrin, the Qbands decrease in intensity, and a new peak grows in at 810 nm. The presence of a distinct isosbectic point implies the existence of two and only two species in this titration. Spectroscopic data for neutral and acidified TAPP are given in Table VI.

TABLE VI

SPECTROSCOPIC DATA FOR TAPP IN NEUTRAI AND ACIDIFIED DMSO

\begin{tabular}{|c|c|c|c|}
\hline \multicolumn{2}{|c|}{ NEUTRAL TAPP } & \multicolumn{2}{c|}{ ACIDIFIED TAPP } \\
\hline$\lambda_{\max }$ & $\epsilon$ & $\lambda_{\max }$ & $\epsilon$ \\
\hline $439 \mathrm{~nm}$ & $1.7 * 10^{5}$ & $391 \mathrm{~nm}$ & $3.4 * 10^{4}$ \\
\hline $528 \mathrm{~nm}$ & $9.0 * 10^{3}$ & $467 \mathrm{~nm}$ & $1.2 * 10^{5}$ \\
\hline $581 \mathrm{~nm}$ & $2.0 * 10^{4}$ & $810 \mathrm{~nm}$ & $8.4 * 10^{4}$ \\
\hline $668 \mathrm{~nm}$ & $1.1 * 10^{4}$ & & \\
\cline { 1 - 4 } & & &
\end{tabular}

When an experiment with concurrent voltammetry and spectroscopy was performed on TAPP with added $18(\mathrm{v} / \mathrm{v})$ sulfuric acid, it was observed that the first solution in which the new voltammetric wave at $\approx-0.6 \mathrm{~V}$ appears is also the first solution in which the new absorption peaks at 467 and $810 \mathrm{~nm}$ can be observed. This is good evidence for assignment of the species responsible for both as $\mathrm{H}_{2} \mathrm{TAPP}^{+2}$.

A similar experiment was performed using the unsubstituted TPP. The puzzling result was that no spectral changes were observed despite observed changes in the voltammetry identical to those already related. One mitigating circum- 
stance was the presence of undissolved porphyrin in the spectroscopic solutions. It is possible that the aliquots of acid added were interacting with the solid phase porphyrin in such a way as to offset any changes in absorption spectra. 


\section{CHAPTER IV}

\section{CONCLUSIONS}

\section{CORRELATIONS OF THE REDOX POTENTIALS OF TETRAPHENYLPORPHYRINS}

The results of Chapter I confirm that linear free energy relationships using the unmodified Hammett substituent constants are useful in correlating the effect of substituent on the electrochemical properties of tetraphenylporphyrins.

This is not an original conclusion as such; other researchers such as Kadish ${ }^{30}$ have independently verified that the electrochemical behavior of tetraphenylporphyrins can be modelled with LFERs. The contribution of this work has been to demonstrate that the behavior of specific porphyrins necessary to the preparation of asymmetric polyporphyrin membranes fit the established models.

One conclusion, based on the linear free energy correlations made in Chapter $I$, is that choices made on the basis of the predictions of the Hammett equation as to which reactive monomeric porphyrins to use in interfacial polymerization experiments ${ }^{1}$ were correct to the extent possible. A further implication is that other such choices could also be made on predictions of the Hammett equation with the expectation of reasonable accuracy. It should be noted, however, that any such prediction based on properties of monomeric porphyrin is 
not intended to cover the full range of interactions present in a polymeric membrane.

Other conclusions can be drawn from the irregularities observed in the Hammett plots of the $E_{\frac{1}{2}}$ of first reduction and of first oxidation of the tetraphenylporphyrins. First, it was noted previously that the order of reduction for the carboxyphenylporphyrin (TCPP) and its toluamide (TTCPP) was reversed from that predicted on the basis of the Hammett substituent constants for those substituents.

Later, in Chapter III, it was shown that experiments into the electrochemical behavior of monomeric TCPP in DMSO were in all likelihood performed on partially ionized TCPP due to the combination of acidic porphyrin and basic solvent. If the value of $E_{\frac{1}{2}}$ for the first reduction of TCPP is replaced with the value corresponding to that of predominantly neutral TCPP, the original discrepancy between the predictions of the Hammett substituent constants and the observed results is eliminated.

It is reasonable to conclude from these results that predictions made using Hammett substituent constants are valid for use in correlating the effect of the carboxy substituent on tetraphenylporphyrin redox properties.

A second irregularity was observed in the Hammett plot of the $E_{\frac{1}{2}}$ of porphyrin oxidation. In this case, two regions of different slopes were discovered, implying a change in oxidation mechanism across the two regions. It was concluded that the site of oxidation for the amino- and hydroxyderivatives was the substituted phenyl ring instead of the porphyrin macrocycle. 
This conclusion was based on literature data indicating that both TAPP and THPP could be oxidatively electropolymerized in the same manner, a process that involved oxidation and subsequent linking of the aminophenyl or hydroxyphenyl moieties. This process is resonance stabilized as shown in Figure 33 using the example of TAPP oxidation.

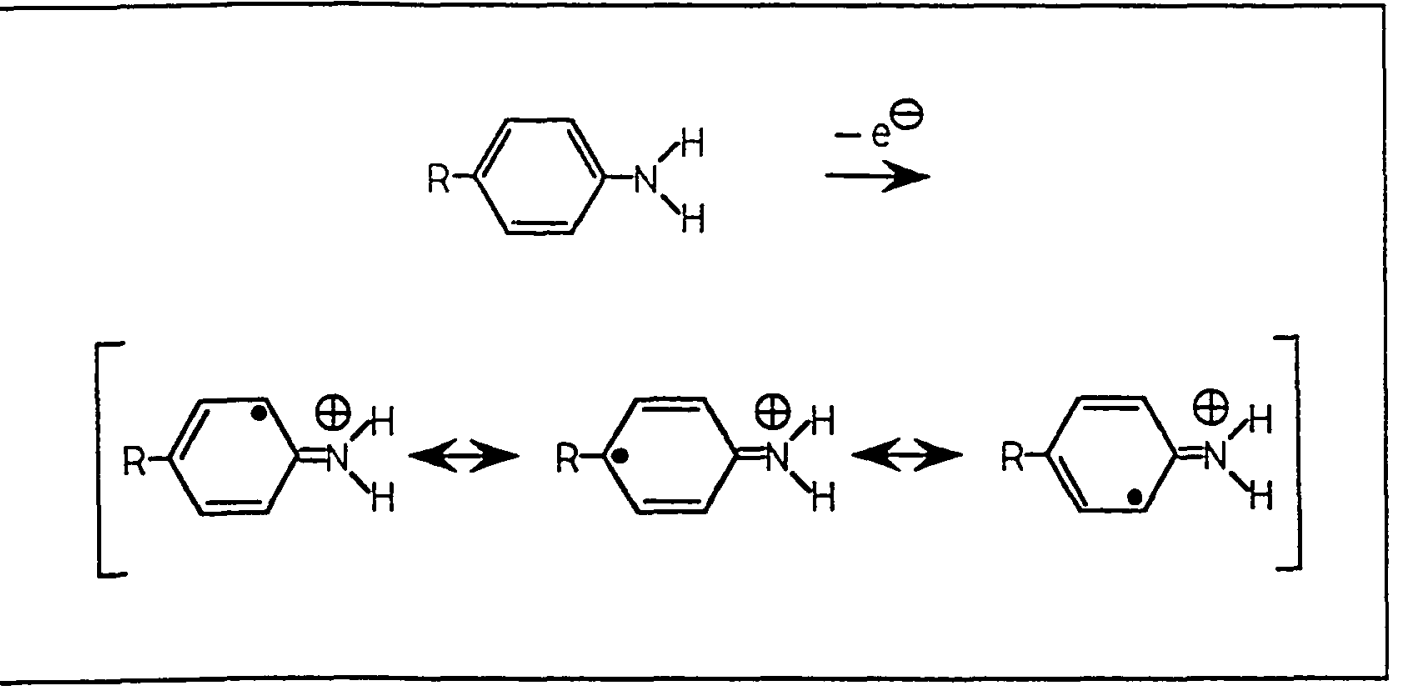

Figure 33. Oxidation of aminophenyl moiety showing resonance stabilization. $R$ refers to a meso-substituted porphyrin.

The process shown in Figure 33 involves direct substituent attachment to the oxidized $\pi$-electron system. In such a process, it is expected that substituents would exert a larger influence on the equilibrium of the reaction, here reflected in the $E_{\frac{1}{2}}$ of the oxidation. In keeping with this idea, the slope of the region encompassing TAPP and THPP is indeed larger than that corresponding to oxidation of the porphyrin macrocycle of the other porphyrins. This slope is comparable, however, to the slope obtained for the oxidation of substitut- 
ed biphenyls, whose mechanism should be analogous to the mechanism proposed here for the oxidation of TAPP and THPP. 37

If this irregularity in oxidation potential is reflected in the properties of polyporphyrin membranes that incorporate either TAPP or THPP, it would only serve to enhance the predicted gradient in electrochemical potential energy. However, because the membrane is intended to transport electrons (or energy) excited through absorption of a photon into the macrocyclic $\pi$-ring chromophore of the porphyrin, it is unclear whether the unexpected electrochemical oxidation mechanism of TAPP and THPP will have any practical significance.

\section{SOLVENT EFFECTS ON TAPP REDUCTION}

The data presented in Chapter II confirm literature data ${ }^{7}$ that the Dimroth-Reichardt $E_{T}$ parameter is useful in correlating the effect of solvent variations on the electrochemical behavior of tetraphenylporphyrins. In contrast to previous studies, this work investigates continuous alterations in solvent polarity using various mixes of water and DMSO as the electrochemical solvent. All other work of an electrochemical nature was limited to discrete increments of solvent polarity through their use of various pure solvents.

The specific solvent effect investigated in this research was that resulting from additions of water to solutions of TAPP in DMSO. The influence of water on the electrochemical properties already investigated in DMSO was of importance to related polyporphyrin membrane studies in that the proposed membranes are intended for use in aqueous solutions. A method 
of extrapolation from the known behavior of porphyrins in DMSO (in which porphyrins are readily soluble) to the expected behavior in water solutions (practically inaccessible due to the low solubility of porphyrins in water) was deemed necessary.

The positive correlation $(r=0.97)$ shown in Figure 18 constitutes such a method of extrapolation. A shift in $E_{\frac{1}{2}}$ of reduction of $240 \mathrm{mV}$ is observed when changing the solvent from pure DMSO to $508(\mathrm{v} / \mathrm{v})$ water in DMSO. A valid correlation in this case assumes no variability in the nature of interactions between solvent and porphyrin when changing from $50 \&(\mathrm{v} / \mathrm{v})$ water in DMSO to pure water.

It is also concluded that the correlation observed is a trend in the direction predicted from solvent polarity considerations. The electroreaction investigated in these experiments is the reduction of a neutral organic species to its corresponding radical anion product. There is a greater range of interactions possible for the radical anion, which is negatively charged, than is possible for the neutral reactant. Because of that, and because the addition of water to solutions of DMSO constitutes an increase in solvent polarity, it is predicted that additions of water should facilitate the reduction process. The observed result confirms this prediction; additions of water make the reduction of TAPP easier, as seen by a shift to less negative reduction potentials. 


\section{IONIZATION EFFECTS ON THE REDOX BEHAVIOR \\ OF TETRAPHENYLPORPHYRINS}

The effect of added acid on the electrochemical behavior of tetraphenylporphyrins with ionizable substituents was investigated in the experiments described in Chapter III. One general conclusion that can be drawn from these data is that all of the porphyrins so investigated can act as bases toward Brönsted acids due to the presence of nitrogens with lone-pair electrons in the macrocycle itself. The observed result of this protonation is the appearance of a wave representing a very easily reduced porphyrin in the range of -0.5 to $-0.7 \mathrm{~V}$ vs. SCE.

The presence of this species, designated $\mathrm{H}_{2} \mathrm{TPP}^{+2}$, and its electrochemistry have already been observed and reported in the literature ${ }^{73}$ and were merely confirmed here. There are no significant implications of the electrochemistry of $\mathrm{H}_{2} \mathrm{TPP}^{+2}$ for the functioning of an asymmetric polyporphyrin membrane, as it is unlikely that both sides of such a membrane would be immersed in such acidic solutions.

Should such a situation arise, however, it is possible that the asymmetry of the membrane would significantly degrade. Polar effects arising from variations in para-phenyl substituents on the porphyrin periphery may have little effect of the oxidation or reduction potentials of a porphyrin already bearing one or two positive charges on the macrocycle itself. If so, when both sides of a polyporphyrin membrane are contacted by solutions acidic enough to form $\mathrm{H}_{2} \mathrm{TPP}^{+2}$ species, the formerly asymmetric sides may then be similar 
enough to significantly degrade any previously existing gradient in electrochemical potential energy.

Another conclusion can be drawn from the results of experiments on the effect of added acid to solutions of copper derivatives of the various tetraphenylporphyrins. With addition of acid, increases in peak current for the reduction of such porphyrins are observed that cannot be accounted for given the amount of porphyrin present in solution. It was therefore proposed that such increases in current were due to an electrocatalytic effect of the ligated copper. Specifically, the conclusion was reached that the presence of copper tetraphenylporphyrins is capable of catalyzing the reduction of hydrogen ion, $\mathrm{H}^{+}$, to hydrogen gas, $\mathrm{H}_{2}$.

This reduction process would occur in the range of $\approx-1.6$ to $-1.8 \mathrm{~V}$ vs SCE in the absence of copper porphyrins. The porphyrins themselves are reduced in the range of $\approx-1.2$ to $-1.3 \mathrm{~V}$, and can apparently pass on the electrons they have accepted in that reduction to hydrogen ions present in the acidified solutions, thus lowering the overpotential of the $\mathrm{H}^{+} / \mathrm{H}_{2}$ reaction.

At present, all artificial photosynthesis schemes proposed utilize a separate catalytic step, usually involving metallic platinum, ${ }^{11}$ to couple the energy of reduced porphyrin to the hydrogen ion (or water) reduction step in the formation of hydrogen gas. This discovery has implications for such schemes in that there exists the apparent potential for direct photosynthetic activity on the part of the porphyrins themselves. 
Conclusions regarding the effects of added acid on the mechanism of reduction can be drawn from consideration of the specific effects of such additions on the electrochemistry of each porphyrin. The original hypothesis related to Chapter III was that the primary effect of additions of acid would be to vary the state of ionization of the porphyrin substituents and in so doing alter the reduction potential of the porphyrin in a manner consistent with that predicted by the resulting changes in Hammett substituent constants. The large question to be answered is thus whether this hypothesis is confirmed in part or in whole by the observed results, and whether other mechanistic effects must be considered in addition to that mentioned above.

The effect of additions of acid on the electrochemical behavior of the acidic porphyrin TCPP is consistent with the original hypothesis described above. It is concluded that in this case, TCPP apparently equilibrates in pure DMSO to a partially ionized state through deprotonation of the acidic carboxy substituents by the basic solvent DMSO. The observed effect of additions of acid is consistent with the premise that added proton donor protonates the already ionized carboxy substituents, returning the porphyrin to a predominantly neutral state. This is shown experimentally in a shift of reduction potential to more easily reduced potentials, which is as predicted from examination of the relative electrondonating character (as reflected in the values of the Hammett substituent constant) of the ionized and neutral carboxy substituents. 
Further additions of acid do not result in further shifts in the peak of the original first reduction, but instead go towards protonating the nitrogens of the porphyrin macrocycle, giving rise to a peak representing the electrochemistry of the species $\mathrm{H}_{2} \mathrm{TCPP}^{+2}$.

Interpretation of the results of experiments on TAPP are less conclusive. The two types of experiments, additions of weak and of strong acids, result in shifts toward more easily reduced potentials, or the appearance of a new peak at more easily reduced potentials, respectively. Both effects are in the direction predicted by comparison of the Hammett substituent constants of the amino and ammonium substituents. However, it is not immediately apparent why there seems to be different effects (a shift versus the appearance of a new peak) when using a weak acid (acetic acid) or a strong acid (trifluoroacetic or sulfuric acid).

One possible explanation can be found in considering the relative numbers of equivalents of acid added in the two types of experiments. In the case of acetic acid, small increments of acid (an average of 0.09 equivalents per addition) were added, whereas when trifluoroacetic acid was used, much larger additions were used (an average of 1.6 equivalents per addition). What is postulated, then, is that the two types of experiments represent extreme cases of the same phenomenon. If it were possible to add strong acid in small enough aliquots (a practical impossibility), behavior equivalent to that seen with addition of weak acid might be observed.

On the basis of these data alone the conclusion could be drawn that the hypothesis has been confirmed which states that 
the added acid is serving only to protonate bulk-phase porphyrin. For both TAPP and TCPP, the observed results are consistent with the effect predicted from variations in the electron-donating or -withdrawing ability of ionizable paraphenyl substituents. This conclusion is muddied by the results seen for addition of acid to TPP.

With no ionizable substituents, TPP should exhibit only the effect attributed to formation of the $\mathrm{H}_{2} \mathrm{TPP}^{+2}$ species. This means that no shift in peak potential or appearance of new peaks should be observed with the exception, with addition of sufficient acid, of the protonation of the two nitrogens of the porphyrin macrocycle. In fact, Figure 22 demonstrates a measurable shift in the peak potential of the original first reduction of TPP with added acid.

This experimental result forces reconsideration of the possibility of some contribution to the observed effect of acid on tetraphenylporphyrins by what has been described as an "ECE" mechanism. If this mechanism of electroreduction has any effect, it would also be to shift the former peak of the reduction wave to more easily reduced potentials, such as has been observed for TPP.

Acid-base equilibria are fast on the time scale employed in cyclic voltammetry. The experimental method described in Chapter III allows at least 5 minutes of stirring and purging after addition of an aliquot of acid before any voltammogram is recorded. For this reason it is implausible that the effect of adding acid to electrochemical solutions of tetraphenylporphyrins is solely that possible through an ECE mechanism (that is, protonation of the radical anion produced 
in electroreduction followed by immediate reduction of the neutral radical so formed). Through the evidence obtained through addition of acid to solutions of TPP, however, some contribution to the overall effect of acid from an ECE mechanism cannot be ruled out.

It is therefore concluded that the original hypothesis discussed above holds true: predictions made on the basis of Hammett substituent constants can be expected to be correct at least in the direction of the expected effect of varying the state of ionization of substituents, if not in the magnitude of that effect.

The implication of these data for the performance of a polyporphyrin membrane immersed in aqueous solutions of varying $\mathrm{pH}$ is that the surface porphyrins whose behavior is modelled in ionization effect research can be expected to follow the trend in electrochemical potential energy predicted on the basis of variations in the electron-donating ability of the substituents on that porphyrin. 


\section{REFERENCES}

(1) Wamser, C.C.; Bard, R.R.; Senthilathipan, V.; Anderson, V.C.; Yates, J.A.; Lonsdale, H.K.; Rayfield, G.W.; Friesen, D.T.; Lorenz, D.A.; Stangle, G.C.; van Eikeren, P.; Ransdell, R.A.; Golbeck, J.H.; Baer, D.; Babcock, W.C.; Sandberg, J.J.; Clarke, S.E. J. Am. Chem. Soc. $1989,111,8485$.

(2) (a) Hammett, I.P. Chem. Rev. 1935, 17, 125. (b) Burkhardt, Nature $1935,136,684$. (c) Burkhardt, Ford, Singleton $J$. Chem. Soc. 1936, 17. (d) Burkhardt, Evans, Warhurst, J. Chem. Soc. 1936, 25. (e) Hammett, L.P. J. Am. Chem. Soc. $1937,59,96$. (f) Hammett, L.P. Trans. Faraday Soc. 1938, 34,156 .

(3) Hammett, L.P. Physical Organic Chemistry; McGraw-Hill: N.Y., 1940, p 185 .

(4) Ibid, p 194

(5) Shorter, J. Correlation Analysis In Organic Chemistry; Clarendon Press: Oxford, 1973; Chp. 3.

(6) (a) Ritchie, C. D.; Sager, W.F. Prog. Phys. Org. Chem. $1964,2,323$. (b) Jaffe, H.H. Chem. Rev. 1953, 53, 191. (c) McDaniel, D.H.; Brown, H.C. J. Org. Chem. 1958, 23, 420. (d) Shorter, J. Correlation Analysis in Organic Chemistry; Clarendon Press: Oxford, 1973; Chp. 1. (e) Exner, 0. A Critical Compilation of Substituent Constants In Correlation Analysis in Chemistry; Shorter, J., Eds.; Plenum Press: N.Y., 1978 .

(7) Kadish, K.M. The Electrochemistry of Metalloporphyrins in Non-aqueous Media In Progress in Inorganic Chemistry; Lippard, S.J., Ed.; Wiley: New York, 1986; Vol. 34, p 435 .

(8) (a) Silvers, S.J.; Tulinsky, A. J. Am. Chem. Soc. 1967, 94, 4763. (b) Fleischer, E.B. ACC. Chem. Res. 1970, 3, 105 .

(9) Walker, F.A.; Barry, J.A.; Balke, V.L.; McDermott, G.A.; Wu, M.Z.; Linde, P.F. In Electrochemical and Spectrochemical Studies of Biological Redox Components; Kadish, K.M., Ed.; Advances in Chemistry Series 201; American Chemical Society: Washington, D.C., 1982; Vol. 201, p 377 .

(10) Kadish, K.M.; Cornillon, J.-L.; Yao, C.-L.; Malinski, T.; Gritzner, G. J. Electroanal. Chem. Interfac. Electrochem. $1987,235(1-2), 189$. 
(11) (a) Fendler, J.H. J. Phys. Chem. 1985, 89, 2730. (b) Balzani, V.; Moggi, L.; Scandola, F. In Supramolecular Photochemistry; Balzani, V., Ed.; NATO ASI Series, Series C; D. Reidel: Dordrecht, Holland, 1987; Vol. 214, p 1.

(12) (a) Gubelmann, M.; Harriman, A.; Lehn, J.-M.; Sessler, J.I. J. Chem. Soc., Chem. Comm. 1988, 2, 77. (b) Wasielewski, M.R.; Niemczyk, M.P. J. Am. Chem. Soc. 1984, 106, 5043. (C) Wasielewski, M.R.; Niemczyk, M.P.; Svec, W.A.; Pewitt, E.B. J. Am. Chem. Soc. 1985, 107, 1080. (d) Gust, D.; Moore, T.A.; Moore, A.L.; Barrett, D.; Harding, I.O.; Makings, L.R.; Liddell, P.A.; De Schryver, F.C.; Van der Auweraer, M.; Bensasson, R.V.; Rougee, M. J. Am. Chem. Soc. 1988, 110, 321. (e) Wasielewski, M.R.; Johnson, D.G.; Svec, W.A. ; Kersey, K.M.; Minsek, D.W. J. Am. Chem. Soc. 1988, 110, 7219. (f) Schmidt, J.A.; McIntosh, A.R.; Weedon, A.C.; Bolton, J.R.; Connolly, J.S.; Hurley, J.K.; Wasielewski, M.R. J. Ann. Chem. Soc. $1988,110,1733$.

(13) Gust, D.; Moore, T.A. In Supramolecular Photochemistry; Balzani, V., Ed.; NATO ASI Series, Series C; D. Reidel: Dordrecht, Holland, 1987; Vol. 214, p 267.

(14) (a) Schmehl, R.H.; Shaw, G.L.; Whitten, D.G. Chem. Phys. Lett. 1978, 58(4), 549. (b) Chandrasekaran, K.; Giannotti, C.; Monserrat, K.; Otruba, J.P.; Whitten, D.G. J. Am. Chem. Soc. 1982, 104(23), 6200. (c) Collins-Gold, L.C.; Barber, D.C.; Hagen, W.J.; Gibson, S.L.; Hilf, R.; Whitten, D.G. Photochem. Photobiol. 1988, 48(2), 165. (d) Baral, S.; Fendler, J.H. J..Am. Chem. Soc. 1989, 111, 1604. (e) Infelta, P.P.; Grätzel, M.; Fendler, J.H. J. Am. Chem. Soc. 1980, 102(5), 1479. (f) Hurst, J.K.; Thompson, D.H.P.; Connolly, J.S. J. Am. Chem. SoC. 1987, 109,507 .

(15) Mau, A.W.-H.; Huang, C.-B.; Kakuta, N.; Bard, A.J.; Campion, A.; Fox, M.A.; White, J.M.; Webber, S.E. J. Am. Chem. Soc. 1984, 106, 6537.

(16) (a) Sobczynski, A.; Bard, A.J.; Campion, A.; Fox, M.A.; Mallouk, T.E.; Webber, S.E.; White, J.M. J. Phys. Chem. 1989, 93, 401. (b) Honda, K.; Kuwano, A.; Chiba, K.; Ishikawa, A. ; Miyama, H. Chem. Lett. (Tokyo) 1988, 2, 195. (c) Yildiz, A.; Sobczynski, A.; Bard, A.J.; Campion, A.; Fox, M.A.; Mallouk, T.E.; Webber, S.E.; White, J.M. Langmuir 1989, 5, 148.

(17) Vlachopoulos, N.; Liska, P.; Augustynski, J.; Grätzel, M. J. Am. Chem. Soc. 1988, 110, 1216 . 
(18) (a) Enkelmann, V.; Wegner, G. Makromol. Chem. 1972, 157, 303. (b) Enkelmann, V.; Wegner, G. Amer. Chem. Soc., Polym. Prep. 1975, 16(1), 409. (c) Cadotte, J.E.; Peterson, R.J. In Synthetic Membranes; Turbak, A., Ed.; ACS Symposium Series 153; American Chemical Society: Washington, D.C. , 1981; Vol. 1. (d) Cadotte, J.E.; King, R.S.; Majerle, R.J.; Peterson, R.J. In Interfacial Synthesis; Carraher, C.E. Jr.; Preston, J., Eds.; Marcel Dekker: N.Y., 1982; Vol. 3, p 47.

(19) Falk, J.E. Porphyrins and Metalloporphyrins; Elsevier: Amsterdam, 1964.

(20) Clark, W.H. Oxidation-Reduction Potentials of Organic Systems; Williams and Wilkens: Baltimore, 1960.

(21) Fuhrhop, J.-H.; Kadish, K.M.; Davis., D.G. J. Am. Chem. Soc. 1973, 95, 5140 .

(22) Felton, R.H.; Linschitz, H. J. Am. Chem. Soc. 1966, 88, 1113 .

(23) Clack, D.W.; Hush, N.S. J. Am. Chem. Soc. 1965, 87, 4238.

(24) (a) Peychal-Heiling, G.; Wilson, G.S. Anal. Chem. 1971, 43, 545. (b) Peychal-Heiling, G.; Wilson, G.S. Anal. Chein. 1971, 43, 550 .

(25) Manassen, J.; Ẅolberg A. J. Ani. Chem. Soc. 1970, 92, 2982 .

(26) Fajer, J.; Borg, D.C.; Forman, A.; Dolphin, D.; Felton, R.H. J. Am. Chem. Soc. 1970, 92, 3451 .

(27) Dolphin, D.; Felton, R.H. ACC. Chem. Res. 1974, 7, 26.

(28) Stanienda, A.; Biebl, G. Z. Phys. Chem. (Frankfurt am Main) 1967, 52, 524.

(29) Dolphin, D.; Felton, R.H.; Borg, D.C.; Fajer, J. J. Am. Chem. Soc. 1970, 92, 743 .

(30) (a) Kadish, K.M.; Morrison, M.M. Inorg. Chem. 1976, 15, 980. (b) Kadish, K.M.; Morrison, M.M. Bioelectrochem. Bioenerg. 1977, 3, 480. (c) Kadish, K.M.; Morrison, M.M. Bioinorg. Chem. 1977, 7,107. (d) Kadish, K.M.; Morrison, M.M. J. Am. Chem. SoC. 1976, 98, 3326. (e) Malinski, T.; Chang, D.; Bottomley, L.A.; Kadish, K.M. Inorg. Chem. 1982, 21, 4248. (f) Walker, F.A.; Beroiz, D.; Kadish, K.M. J. Am. Chem. Soc. 1976, 98, 3484 . 
(31) (a) Callot, H.J.; Giraudeau, A.; Gross, M. J. Chem. Soc., Perkin Trans. 2 1975, 12, 1321. (b) Giraudeau, A.; Callot, H.J.; Gross, M. Inorg. Chem. 1979, 18, 201. (c) Giraudeau, A.; Callot, H.J.; Jordan, J.; Ezahr, I.; Gross, M. J. Am. Chem. Soc. 1976, 101, 3857. (d) Giraudeau, A. ; Ezahr, I.; Gross, M.; Callot, M.; Jordan, J. Bioelectrochem. Bioenerg. 1976, 3, 519.

(32) Momenteau, M.; Mispelter, J.; Loock, B.; Bisagne, E. J. Chem. Soc., Perkin Trans. I, 1983, 1, 189.

(33) Lindsay, J.S.; Schreiberman, I.C. ; Hsu, H.C.; Kearney, P.C.; Marguerettaz, A.M. J. Org. Chem. 1987, 52, 827.

(34) Adler, A.D.; Longo, F.R.; Finarelli, J.D.; Goldmacher, J.; Assour, J.; Korsakoff, I. J. Org. Chem. 1967, 32, 476 .

(35) Hawkridge, F.M.; Kuwana, T. Anal. Chem. 1973, 45, 1021.

(36) Bettelheim, A.; White, B.A.; Raybuck, S.A.; Murray, R.W. Inorg. Chem. 1987, 26, 1009.

(37) Hertl, P.; Rieker, A.; Speiser, B. J, Electroanal. Chem. $1986,200,147$.

(38) I.und, H. In Organic Electrochemistry; Baizer, M.M; Lund, H., Eds.; Marcel Dekker: N.Y., 1983; Chp. 5, p 192.

(39) Reichardt, C. Solvents and Solvent Effects in Crganic Chemistry; VCH Verlagges.: Weinheim, FRG, 1988.

(40) Kosower, E.M. An Introduction to Physical Organic Chemistry; Wiley and Sons: N.Y, 1968, p 293.

(41) (a) Meyer, K.H. Ber. Dtsch. Chem. Ges. 1914, 47, 826. (b) Meyer, K.H. Ber. Dtsch. Chem. Ges. 1920, 53, 1410. (c) Meyer, K.H. Ber. Dtsch. Chem. Ges. 1921, 54, 579.

(42) (a) Gutmann, V.; Wychera, E. Inorg. Nucl. Chem. Lett. 1966, 2, 257. (b) Gutmann, V. Coordination Chem. Rev. 1967, 2, 239. (c) Gutmann, V. Coordination Chemistry in Non-Aqueous Solvents; Springer: Wien, N.Y., 1968. (d) Gutmann, V.; Scherhaufer, A. Monatsh. Chem. 1968, 99, 335. (e) Gutmann, V. Chimia 1969, 23, 285. (f) Gutmann, V. Chemische Funktionslehre; Springer: Wein, N.Y.' 1971 . (g) Gutmann, V. Electrochemica Acta 1976, 21, 661. (h) Gutmann, Coordination Chem. Rev. 1976, 18, 225. (i) Gutmann, V. The Donor-Acceptor Approach to Molecular Interactions; Plenum: N.Y., 1978.

(43) (a) Mayer, U.; Gutmann, V. Structure and Bonding 1972, 12, 113. (b) Schmid, R. J. Solution Chem. 1983, 12, 135.

(44) (a) Sabatino, A.; La Manna, G.; Paoloni, L. J. Phys. Chem. 1980, 84, 2641. (b) Hiraoka, K. Bull Chem. Soc. Jpn. 1986, 59, 2571 . 
(45) (a) Elégant, L.; Fratini, G. i Gal, J.-F.; Maria, P.-C. Journ. Calorim. Anal. Therm. 1980, 11, 1. (b) Maria, P.C., Gal, J.-F. J. Phys. Chem. 1985, 89, 1296. (c) Maria, P.-C.; Gal, J.-F.; de Franceschi, J.; Fargin, E. J. Am. Chem. Soc. 1987, 109, 483.

(46) Kelly, K.M.; Bent, D.V.; Hermann, H.; Schulte-Frohlinde, D. ; Koerner von Gustorf, E. J. Organomet. Chem. 1974, 69, 269 .

(47) (a) Leo, A.; Hansch, C.; Elkins, D. Chem. Rev. 1971, 71, 525. (b) Hansch, C. Recent Advances in Biological QSAR In Correlation Analysis in Organic Chemistry - Recent Advances; Chapman, N.B. , Shorter, J., Eds.; Wiley-Interscience: New York, 1979. (c) Hansch, C.; Leo, A. Substituent Constants for Correlation Analyses in Chemistry and Biology; Wiley-Interscience: New York, 1979.(d) Leo, A. J. Chem. Soc., Perkins Trans. II 1983, 6, 825.

(48) (a) Grunwald, E.; Winstein, S. J. Am. Chem. Soc. 1948, 70, 846. (b) Winstein, S.; Grunwald, E.; Jones, H.W. J. Am. Chem. Soc. 1951, 73, 2700. (c) Fainberg, A.H.; Winstein, S. J. Am. Chem. Soc. 1956, 78, 2770. (d) Fainberg, A.H.; Winstein, S. J. Am. Chem. Soc. 1957, 79, 1597, 1602, 1608. (e) Winstein, S.; Fainberg, A.H.; Grunwald; E. J. Am. Chem. Soc. 1957, 79, 4146, 5937. (f) Smith, S.G.; Fainberg, A.H.; Winstejn, S. J. Am, Chem. SoC. $1961,83,618$.

(49) (a) Bentley, T.W.; Schadt, F.L.; Schleyer, P.V.R. J. Ann. Chem. Soc. 1972, 94, 992. (b) Bentley, T.W.; Schadt, F.L.; Schleyer, P.V.R J. Am. Chem. Soc. 1976, 98, 7667 . (c) Bentley, T.W.; Bowen, C.T.; Morten, D.W.; Schleyer, P.V.R. J. Am. Chem. Soc. 1981, 103, 5466.

(50) ref. (39), Chp. 7, p 359.

(51) IR: (a) Allerhand, A.; Schleyer, P.v.R. J. Am. Chem. Soc. 1963, 85, 371. (b) Allerhand, A.; Schleyer, P.v.R. J. Am. Chem. Soc. 1964, 86, 5709. (c) Kagiya, T.; Sumida, Y.; Inoue, T. Bull. Chem. Soc. Jpn. 1968, 41, 767. (d) Burden, A.G.; Collier, G.; Shorter, J. J. Chem. Soc. Perkins Trans. II 1976, 14, 1627. (e) Nicolet, P.; Iaurence, C.; Lucon, M. J. Chem. Soc., Perkins Trans. II 1987, 4, 483. Fluorescence: (f) Dong, D.C.; Winnik, M.A.; Photochem. Photobiol. 1982, 35, 17. (g) Dong, D.C.; Winnik, M.A. Can. J. Chem. 1984, 62, 2560. ESR: (h) Knauer, B.R.; Napier, J.J. J. Am. Chem. Soc. 1976, 98, 4395. (i) Kolling, 0. Anal. Chem. 1977, 49, 591. (j) Kolling, 0. Anal. Chem. 1983, 55, 143. (k) Reddoch, A.H.; Konishi, S. J. Chem. Phys. 1979, 70, 2121. (1) Symons, M.C.R.; Pena-Nufnez, A.S. J. Chem. Soc., Faraday Trans. I 1985, 81, 2421. NMR: (m) Brownlee, R.T.C.; Dayal, S.K.; Lyle, J.L.; Taft, R.W. J. Am. Chem. Soc. 1972, 94, 7208 . (see also ref. (56)) 
(52) (a) Gough, T.E.; Irish, D.E.; Lantzke, I.R. Spectroscopic Measurements (Electron Absorption, Infrared, Raman, ESR and NMR spectroscopy) In Physical Chemistry of Organic Solvent Systems; Covington, A.K.; Dickinson, Eds ; Plenum Press: N.Y., 1973; Chp. 4, p 405. (b) Jauquet, M.; Laszlo, $\mathrm{P}$. Influence of Solvents on Spectroscopy In Solutions and Solubilities; Dack, M.R.J., Ed. In Techniques of Chemistry; Weissberger, A., Ed.; Wiley-Interscience: N.Y., 1975; Vol. VIII, Part I, p 195. (C) Rao, C.N.R.; Singh, S.; Senthilnathan, V.P. Chem. Soc. Rev. 1976, 5, 297 .

(53) Brooker, L.G.S.; Keyer, G.H.; Heseltine, D.W. J. Am. Chem. Soc. 1951, 73, 5350 .

(54) (a) Kosower, E.M. J. Am. Chem. Soc. 1958, 80, 3253. (b) kosower, E.M. J. Chim. Phys. 1964, 61, 230. (c) Kosower, E.M. : Mohammed, M. J.Am. Chem. Soc. 1968, 90, 3271. (d) Kosower, E.M. An Introduction to Physical Organic Chemistry; Wiley: N.Y., 1968, p 296. (e) Kosower, E.M.; Mohammed, M. J. Am. Chem. Soc. 1971, 93, 2713.

(55) (a) Mayer, U.; Gutmann, v. Monatsh. Chem. 1975, 106, 1235. (b) Mayer, U.; Gutmann, V. Monatsh. Chem. 1977, $108,489,757$. (c) Gutmann, V. Electrochimica Acta 1976, 21, 661. (d) Gutmann, V. CHEMTECH 1977, 7, 255. (e) Parker, A.J.; Mayer, U.; Schmid, R.; Gutmann, V. J. Org. Chem. 1978, 43, 1843. (f) Schmid, R. J. Solution Chem. 1983, 12, 135. (g) Mayer, U. NMR Spectroscopic Studies on Solute-Solvent and Solute-Solute Interactions In Ions and Molecules in Solution; Tanaka, N.; Ohtaki, H.; Tamamushi, R., Eds.; Elsevier: Amsterdam, 1983, p 219.

(56) (a) Dimroth, K.; Reichardt, C.; Siepmann, T.; Bohlmann, F. Liebigs Ann. Chem. 1963, 661, 1. (b) Dimroth, K., Reichardt, C., Schweig, A. Leibigs Ann. Chem. 1963, 669, 95. (c) Dimroth, K.; Reichardt, C. Fortschr. Chem. Forsch. 1968, 11, 1. (d) Dimroth, K.; Reichardt, C. Liebigs Ann. Chem. 1969, 727, 93. (e) Reichardt, C. Liebigs Ann. Chem. 1971, 752, 64. (f) Maksimovic, Z.B.; Reichardt, C.; Spiric, A. Z. Anal. Chem. 1974, 270, 100.

(57) (a) Reichardt, C.; Harbusch-Görnert, E. Liebigs Ann. Chem. 1983, 721. (b) Laurence, C.; Nicolet, P.; Reichardt, C. Bull. Soc. Chim. Fr. 1987, 125. (c) Laurence, C.; Nicolet, P.; Lucon, M.; Reichardt, C. Bull. Soc. Chim. Fr. 1987, 1001 .

(58) Langhals, H. Angew. Chem. Intl. Eng. Ed. 1982, 21, 724. (from: Langhals, H. Angew. Chem. 1982, 94, 739.)

(59) Krygowski, T.M.; Wrona, P.K.; Zielkowska, U. Tetrahedron $1985,41(20), 4519$. 
(60) (a) Reichardt, C.; Harbusch, E.; Müller, R. Pyridinium-Nphenoxide Betaine Dyes as Solvent Polarity Indicators. Some New Findings In Advances in Solution Chemistry; Bertini, I.; Lunazzi, L.; Dei, A., Eds.; Plenum Press: N.Y., 1981, p 275. (b) Tamura, K.; Ogo, Y.; Imoto, T. Chem. Lett. (Toyko) 1973, 625. (c) Jouanne, J.v.; Palmer, D.A.; Kelm, H. Bul1. Chem. Soc. Jpn. 1978, 51, 463. (d) Dähne, S.; Radeglia, R. Tetrahedron 1971, 27, 3673. (e) Hollmann, G.; Vogtle, F. Chem. Ber. 1984, 117, 1355. (f) Braun, R.; Sauer, J. Chem. Ber. 1986, 119, 1269. (g) Langhals, H. Tetrahedron 1987, 43, 1771.

(61) Cotton, T.M.; Heald, R.I. J. Phys. Chem. 1987, 91, 3891.

(62) Marcus, R.A. J. Chem. Phys. 1965, 43, 679.

(63) (a) Gritzner, G.; Rechberger, P.; Gutmann, V. J. Electroanal. Chem. 1980, 114, 129. (b) Gritzner, G. J. Electroanal. Chem. 1983, 144, 259. (C) Gritzner, G. J. Phys. Chem. 1986, 90, 5478 .

(64) (a) Kadish, K.M.; Morrison, M.M.; Constant, L.A.; Dickens, L.; Davis, D.G. J. Am. Chem. Soc. 1976, 98 (26), 8387. (b) Kadish, K.M.; Bottomley, L.A.; Kelly, S.; Schaeper, D.; Shiue, L.R. Bioelectrochem. Bioenerg. 1981, 8, 213. (C) Bottomley, L.A.; Kadish, K.M. Inorg. Chem. 1981, 20, 1348. (d) Kelly, S.L.; Kadish, K.M. Inorg. Chem. 1982, 21, 3614, 3623, 3631. (e) Bottomley, L.A.; Olson, L.; Kadish, K.M. Redox Tuning of Iron Porphyrins In Electrochemical and Spectrochemical Studies of Biological Redox Components; Kadish, K.M., Ed.; Advances In Chemistry Series; American Chemical Society: Washington, D.C., 1982; Vol. 201, p 279.

(65) (a) Deming, S.N.; Parker, L.R.,Jr. CRC Critical Reviews in Analytical Chemistry 1978, 7, 187. (b) Leggett, D.J. J. Chem. Educ. 1983, 60(9), 707. (c) Caceci, M.S.; Cacheris, W.P. Byte 1984, May, 340.

(66) (a) Gritzner, G.; Kuta, J. Pure Appl. Chem. 1982, 54, 1527. (b) Gritzner, G.; Kuta, J. Pure Appl. Chem. 1984, 56,461 .

(67) Streitwieser, A.; Heathcock, C.H. Introduction to Organic Chemistry, Second Edition; Macmillan Publishing: N.Y., $1981, \mathrm{p} 737$.

(68) O'Reilly, J.E.; Elving, P.J. J. Am. Chem. Soc. 1972, 94, 7941 .

(69) (a) Nicholson, R.S.; Shain, I. Anal. Chem. 1964, 36, 706. (b) Nicholson, R.S.; Shain, I. Anal. Chem. 1965, 37, 179. 
(70) (a) Wawzonek, S ; Wearring, D. J. Am. Chem. Soc. 1959, 81, 2067. (b) Velthorst, N.H.; Hoijtink J. Am. Chem. Soc. $1965,87,4529$. (c) Santhanam, R.S.V.; Bard, A.J. J. Am. Chem. Soc. 1966, 88, 2669. (d) Jezorek, J.R.; Mark, H.B., Jr. J. Phys. Chem. 1970, 74, 1627 .

(71) (a) Greig, W.N.; Rogers, J.W. J. Electrochem. Soc. 1970, 117, 1141. (b) Smith, G.I.; Rogers, J.W. J. Electrochem. Soc. 1971, 118, 1089. (c) Smith, G.L.; Cook, L.D.; Rogers, J.W. J. Electrochem. Soc. 1972, 119, 1332.

(72) (a) Cheng, S.; Hawley, M.D. J. Org. Chem. 1985, 50, 3388. (b) Mugnier, Y.; Laviron, E. J. Org. Chem. 1988, 53, 5781 .

(73) Rocklin, R.D.; Murray, R.W. J. Electroanal. Chem. 1979, $100,271$.

(74) (a) Aronoff, S. J. Phys. Chem. 1958, 62, 428. (b) Stone, A.; Fleischer, E.B. J. Am. Chem. SoC. 1968, 90, 2735. (c) Abraham, R.J.; Hawkes, G.E.; Smith, K. Tetrahedron Lett. $1974,1,71$.

(75) Koltho.f, I.M.; Reddy, T.B. Inorganic Chemistry 1962, 1, 189 . 